\title{
Methanol as a fuel for internal combustion engines
}

Progress in Energy and Combustion Science Vol. 70, pp43-88, January 2019

Sebastian Verhelst, James WG Turner, Louis Sileghem and Jeroen Vancoillie

(paper as accepted by Elsevier, before editing)

doi: https://doi.org/10.1016/j.pecs.2018.10.001 


\section{Contents}

\begin{tabular}{lll}
\hline & Introduction & 6
\end{tabular}

1.1 Methanol versus ethanol . . . . . . . . . . . . . . . . . . 8

1.2 Historical use of methanol as an engine fuel . . . . . . . . . . . . 9

1.3 Existing infrastructure/production capacity . . . . . . . . . . . . 13

1.4 Renewable production of methanol . . . . . . . . . . . . . . . . 14

1.5 Health and safety . . . . . . . . . . . . . . . . 17

1.6 Methods of using methanol as an engine fuel . . . . . . . . . . . 19

1.6.1 Binary alcohol blends . . . . . . . . . . . . . . 20

1.6 .2 Ternary blends . . . . . . . . . . . . . . . . . 21

\begin{tabular}{|lll}
2 & Fundamentals & $\mathbf{2 3}$
\end{tabular}

$2.1 \quad$ Physical and chemical properties of methanol relevant to engines 23

2.2 Reaction kinetics and emission formation mechanisms . . . . . . 28

2.3 Laminar burning velocities . . . . . . . . . . . . . . . . . 30

2.4 Turbulent burning velocities . . . . . . . . . . . . . . . . . . . . . . . . . . . . 32

2.5 Ignition delay . . . . . . . . . . . . . . . . . . . . . . 33

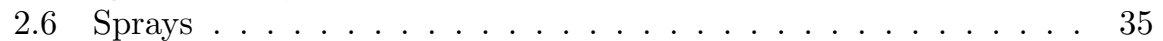

2.7 Properties of methanol-water blends . . . . . . . . . . . . . . . . 36

2.8 Properties of methanol-gasoline blends . . . . . . . . . . . . . . . 37

2.8 .1 Volume versus mole concentration . . . . . . . . . . . . . 37

$2.8 .2 \quad$ Vapour pressure . . . . . . . . . . . . . . . . . . 38

$2.8 .3 \quad$ Distillation curve . . . . . . . . . . . . . . . . . . . 38

2.8 .4 RON/MON . . . . . . . . . . . . . . . . . . . . . . . . . 39

2.8 .5 Density . . . . . . . . . . . . . . . . . . . . . . . . 40

2.8.6 Water tolerance of methanol-gasoline blends . . . . . . . . 40

2.8.7 Burning velocities . . . . . . . . . . . . . . . . . 41

2.8.8 Autoignition delay time . . . . . . . . . . . . . . . . . . . 42

2.9 Properties of ternary blends . . . . . . . . . . . . . . . . . . . . . . . . . . . . . .

2.9.1 Volumetric relations . . . . . . . . . . . . . . . . 43

2.9 .2 Ternary blend properties . . . . . . . . . . . . . . . . 44

3 Methanol engine and vehicle design features 45

3.1 Introduction . . . . . . . . . . . . . . . 45

3.2 Material compatibility . . . . . . . . . . . . . . 46

3.3 Cold start . . . . . . . . . . . . . . . . . . . . . . . 47

3.4 Ignition and fueling systems . . . . . . . . . . . . . . . . . . . 49

3.5 Engine cylinder head and peripherals . . . . . . . . . . . . . . . . 49

3.6 Vehicle adaptations . . . . . . . . . . . . . . . . . 50

4 Spark ignition engine experiments $\quad 51$

4.1 Mid to high level blends and pure methanol . . . . . . . . . . . . 51

4.1.1 Dedicated methanol engines . . . . . . . . . . . . . 51

4.1 .2 Flexible fuel vehicles . . . . . . . . . . . . . . . . . . . . 53

4.2 GEM blends . . . . . . . . . . . . . . . . . . . . 55 
4.3 Methanol-water blends . . . . . . . . . . . . . . . . . . . 55

4.4 Octane on demand . . . . . . . . . . . . . . . . . 56

5 Using methanol in compression ignition engines 59

5.1 CI concepts . . . . . . . . . . . . . . . 59

5.2 CI engine results . . . . . . . . . . . . . . . . . . . . . . . . . . . . . . . 61

5.2 .1 Fumigation . . . . . . . . . . . . . . . . . . 61

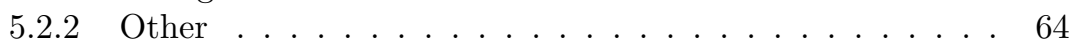

5.3 Methanol as a fuel for shipping . . . . . . . . . . . . . . . 66

\begin{tabular}{|lll}
6 & Fuel reforming using engine waste heat & 67
\end{tabular}

\begin{tabular}{lll}
\hline 7 & Simulation studies & $\mathbf{7 1}$
\end{tabular}

7.1 Quasi-dimensional models . . . . . . . . . . . . . 71

7.1.1 Modelling regular combustion of pure methanol . . . . . . 72

7.1.2 Modelling regular combustion of alcohol blends . . . . . . 73

7.1.3 Knock modelling of pure alcohols . . . . . . . . . . . . 75

7.1.4 Knock modelling of alcohol-gasoline blends . . . . . . . . 75

7.1.5 In-cylinder heat transfer sub-model . . . . . . . . . . . . . 76

7.1 .6 Fuel reforming . . . . . . . . . . . . . . . . . . 77

7.2 Multidimensional models . . . . . . . . . . . . . . . . . . 78

8 Conclusions, outlook and recommendations $\quad 79$ 


\title{
Methanol as a fuel for internal combustion engines
}

\author{
Sebastian Verhelst ${ }^{\mathrm{a}, \mathrm{b}, *}$, James WG Turner ${ }^{\mathrm{c}}$, Louis Sileghem ${ }^{\mathrm{b}}$, Jeroen \\ Vancoillie $^{\mathrm{b}}$ \\ ${ }^{a}$ Department of Energy Sciences, Lund University \\ ${ }^{b}$ Department of Flow, Heat and Combustion Mechanics, Ghent University \\ ${ }^{c}$ Department of Mechanical Engineering, University of Bath
}

\begin{abstract}
Transportation of people and goods largely relies on the use of fossil hydrocarbons, contributing to global warming and problems with local air quality. There are a number of alternatives to fossil fuels that can avoid a net carbon emission and can also decrease pollutant emissions. However, many have significant difficulty in competing with fossil fuels due to either limited availability, limited energy density, high cost, or a combination of these.

Methanol $\left(\mathrm{CH}_{3} \mathrm{OH}\right)$ is one of these alternatives, which was demonstrated in large fleet trials during the 1980s and 1990s, and is currently again being introduced in various places and applications. It can be produced from fossil fuels, but also from biomass and from renewable energy sources in carbon capture and utilization schemes. It can be used in pure form or as a blend component, in internal combustion engines (ICEs) or in direct methanol fuel cells (DMFCs). These features added to the fact it is a liquid fuel, making it an efficient way of storing and distributing energy, make it stand out as one of the most attractive scalable alternatives.

This review focuses on the use of methanol as a pure fuel or blend component for ICEs. First, we introduce methanol historically, briefly introduce the various methods for its production, and summarize health and safety of using methanol as a fuel. Then, we focus on its use as a fuel for ICEs. The current data on the physical and chemical properties relevant for ICEs are reviewed, highlighting the differences with fuels such as ethanol and gasoline. These are then related to the research reported on the behaviour of methanol and methanol blends in spark ignition and compression ignition engines. Many of the properties of methanol that are significantly different from those of for example gasoline (such as its high heat of vaporization) lead to advantages as well as challenges. Both are extensively discussed.

Methanol's performance, in terms of power output, peak and part load efficiency, and emissions formation is summarized, for so-called flex-fuel engines
\end{abstract}

*Corresponding author. Tel.: +32(0)92643306; Fax: +32(0)92643590

Email addresses: sebastian.verhelst@ugent.be,sebastian.verhelst@energy.lth.se (Sebastian Verhelst), j.turner@bath.ac.uk (James WG Turner), louis.sileghem@ugent.be (Louis Sileghem), vancoillie.jeroen@gmail.com (Jeroen Vancoillie) 
as well as for dedicated engines. We also briefly touch upon engine hardware changes and material compatibility. Methanol fuel reforming using engine waste heat is discussed, as a potential route towards further increases in efficiency and decreases in emissions. Next to the experimental work, research efforts into modelling the behaviour of methanol as a fuel are also reviewed, including mixture formation, normal and abnormal combustion. Methanol's properties such as high latent heat, fast burning velocity, high knock-resistance and no carbonto-carbon bonds are shown to leverage engine technology developments such as increased compression ratios, downsizing and dilution; enabling much increased engine efficiencies.

Finally, we point out the current gaps in knowledge to indicate which areas future research should be directed at.

Keywords: methanol, renewable, internal combustion engine, fuel blends, combustion, emissions

\section{Nomenclature}

\section{Abbreviations}

ADI anti-detonant injection

AFR air/fuel ratio

API American Petroleum Institute

ASTM American Society for Testing and Materials

BMEP brake mean effective pressure

BTDC before top dead center

BTE brake thermal efficiency

CA crank angle

CAFE Corporate Average Fuel Economy

CARB California Air Resources Board

CCM chemistry coordinate mapping

CFD computational fluid dynamics

CFR cooperative fuel research

CI compression ignition

$\mathrm{CN} \quad$ cetane number

$\mathrm{CO}$ carbon monoxide

$\mathrm{CO}_{2} \quad$ carbon dioxide

$\mathrm{COV}$ coefficient of variation

DF dual fuel

DI direct injection

DISI direct injection spark ignition

DOE Department of Energy

ECA Emission Control Area

ECU engine control unit

EGR exhaust gas recirculation

EPA Environmental Protection Agency 


$\begin{array}{ll}\text { EXX } & \text { XX\% by volume ethanol in bulk gasoline } \\ \text { FFV } & \text { flexible fuel vehicle } \\ \text { FID } & \text { flame ionization detector } \\ \text { FTIR } & \text { Fourier transform infrared } \\ \text { FTP } & \text { federal test procedure } \\ \text { GDI } & \text { gasoline direct injection } \\ \text { GEM } & \text { gasoline-ethanol-methanol } \\ \text { HC } & \text { hydrocarbon } \\ \text { HCCI } & \text { homogeneous charge compression ignition } \\ \text { HCHO } & \text { formaldehyde } \\ \text { HFO } & \text { heavy fuel oil } \\ \text { ICE } & \text { internal combustion engine } \\ \text { IMEP } & \text { indicated mean effective pressure } \\ \text { IMO } & \text { International Maritime Organization } \\ \text { IQT } & \text { ignition quality tester } \\ \text { KLSA } & \text { knock-limited spark advance } \\ \text { LBV } & \text { laminar burning velocity } \\ \text { LCA } & \text { life cycle analysis } \\ \text { LFL } & \text { lower flammability limit } \\ \text { LHV } & \text { lower heating value } \\ \text { LNG } & \text { liquefied natural gas } \\ \text { LNT } & \text { lean NOx trap } \\ \text { MBT } & \text { minimum spark advance for best torque } \\ \text { MON } & \text { motor octane number } \\ \text { MTBE } & \text { methyl tertiary butyl ether } \\ \text { MXX } & \text { XX\% by volume methanol in bulk gasoline } \\ \text { NO } & \text { nitric oxide } \\ \text { NOx } & \text { oxides of nitrogen } \\ \text { OEM } & \text { original equipment manufacturer } \\ \text { ON } & \text { octane number } \\ \text { OOD } & \text { octane on demand } \\ \text { PFI } & \text { port fuel injection } \\ \text { PM } & \text { particulate matter } \\ \text { PN } & \text { particle number } \\ \text { PPC } & \text { partially premixed combustion } \\ \text { PRF } & \text { primary reference fuel } \\ \text { PTG } & \text { power to gas } \\ \text { rms } & \text { root mean square } \\ \text { RON } & \text { research octane number } \\ \text { RPM } & \text { revolutions per minute } \\ \text { RVP } & \text { Reid Vapour Pressure } \\ \text { SI } & \text { spark ignition } \\ \text { SOI } & \text { start of injection } \\ \text { STP } & \text { standard temperature and pressure }(300 ~ K, 1 \text { atm }) \\ \text { TDC } & \text { top dead center } \\ \text { TWC } & \text { three-way catalyst } \\ & \end{array}$




$\begin{array}{ll}\text { UHC } & \text { unburned hydrocarbons } \\ \text { WOT } & \text { wide open throttle }\end{array}$

Symbols

Le Lewis number

M molar mass

p pressure

$\mathrm{t}$ time

$\mathrm{T}$ temperature

$\mathrm{u} \quad$ burning velocity

u' rms turbulent velocity

$\mathrm{V} \quad$ volume

Greek symbols

$\alpha \quad$ temperature exponent

$\gamma \quad$ residual gas fraction

$\lambda \quad$ air to fuel equivalence ratio

$\rho$ density

$\phi \quad$ fuel to air equivalence ratio

\begin{tabular}{ll}
\multicolumn{2}{l}{ Subscripts } \\
$\mathrm{E}$ & ethanol \\
$\mathrm{G}$ & gasoline \\
$\mathrm{l}$ & laminar \\
$\mathrm{M}$ & methanol \\
$\mathrm{n}$ & normal \\
$\mathrm{t}$ & turbulent
\end{tabular}

\section{Introduction}

Methanol, $\mathrm{CH}_{3} \mathrm{OH}$, is a simple oxygenated hydrocarbon that is among the top five of most widely traded chemicals in the world [1, traditionally used to produce adhesives, paints, LCD screens, silicones, pharmaceuticals, and also used on large scale by the wood and automotive industry. Since a couple of years, it is increasingly being used for energy applications, with some 20 million tons of methanol being produced yearly as fuel or fuel blend component, a number that is increasing every year [2].

Scalability is one of the main reasons for investigating methanol as a transport fuel. Its ease of synthesis and broad range of source feedstocks makes it a strong candidate for a sustainable fuel with the potential to significantly reduce the fossil carbon footprint of transportation. The increased efficiency with 
which it can be synthesized in relation to ethanol or synthetic hydrocarbons (see Sections 1.1 and 1.4), coupled with the improved brake thermal efficiency it produces in combustion systems (see Sections 4 and 5), means that there is a double, compounded effect on improving primary energy utilization. Additionally, while it does produce hydrocarbon emissions at a similar level to gasoline (albeit of different species), its combustion characteristics and single-carbonmolecule nature mean that its emissions of oxides of nitrogen and particulate matter are significantly lower than for complex hydrocarbon fuels. Hence, it has potential advantages from energy security, sustainability and air quality viewpoints, all with no real upper limit on scale. This latter point is the case when production techniques using renewable energy and direct air capture of $\mathrm{CO}_{2}$ are considered as a means of providing inputs to a closed carbon cycle (see Section 1.4.

Methanol has many desirable attributes which make it an excellent sparkignition engine fuel. These include (see Tables 1 and 2):

- High heat of vaporization ('latent heat')

- Low stoichiometric air-fuel ratio (AFR)

- High specific energy ratio (i.e., energy per unit of fuel-air mixture)

- High flame speed

- High molar expansion ratio

- Low combustion temperature

- High hydrogen-to-carbon ratio

- Being liquid at standard temperature and pressure (STP)

All of these will be discussed further, but two important characteristics are that first, it can be extremely clean burning; as mentioned later, methanol has been used as a fuel for air quality reasons. Having a single carbon atom it cannot easily form the carbonaceous particulate matter common from long-chain hydrocarbons (a characteristic it shares with methane). Second, methanol is the simplest carbonaceous molecule that is liquid at STP. This makes it easy to store and transport with minimal losses on the vehicle and in the fuel infrastructure. Methanol is liquid at STP because of the hydrogen bonding phenomenon arising from its $\mathrm{OH}$ characteristic group, as explained in more detail in Section 2.1.

Also advantageous is that methanol is not a mixture of compounds of which the properties can change depending on the source, as is the case with gasoline, diesel, kerosene etc. Methanol consists of just one molecule and as such it is easier to simulate/optimize the process for.

Before subsequent sections discuss methanol's combustion properties and performance as engine fuel, the following subsections provide background on:

- The various uses of methanol as an engine fuel, from the beginning of the 20th century up to today (Section 1.2) 
- Current production of methanol (Section 1.3)

- Production of renewable (carbon-neutral) methanol (Section 1.4)

- Health and safety (Section 1.5)

- The different ways in which methanol can be used as engine fuel (Section 1.6 )

After these background sections, we delve into:

- The properties of methanol relevant to its use as an engine fuel: physical and chemical properties, reaction kinetics, burning velocities, properties of blends containing methanol etc. (Section 2).

- The required hardware changes in order for engines and vehicles to run on mid to high level methanol blends, or pure methanol (Section 3).

- Experimentally obtained results from spark ignition engines running on methanol and methanol blends (Section 4).

- The use of methanol in compression ignition engines, looking at various concepts and the results obtained with them (Section 5).

- Using waste engine heat to reform methanol into a hydrogen-rich gas to benefit efficiency and emissions (Section 6).

- Numerically obtained results and computational capabilities for methanolfuelled operation (Section 7).

After which we wrap-up and point to areas that would benefit from further research or demonstration (Section 8).

First however, we briefly discuss the use of methanol, $\mathrm{CH}_{3} \mathrm{OH}$, versus that of ethanol, $\mathrm{C}_{2} \mathrm{H}_{5} \mathrm{OH}$.

\subsection{Methanol versus ethanol}

Methanol and ethanol are both simple molecules 1 . Methanol shares many attributes with ethanol, particularly in combustion systems. These are driven by their similar octane numbers, very high heats of vaporization and low stoichiometric air-fuel ratios (although the latter two differ by more than the former). As a consequence of this plus the fact that (due to its increasing popularity and use as a biofuel) there is often more recent data on the performance of ethanol in engines, in this paper we use ethanol as an analogue for methanol where we consider it robust to do so, in order to estimate the effects of methanol. This is further supported by the fact that the similarity of the two molecules means that they also lend themselves to being blended together with gasoline and there

\footnotetext{
${ }^{1}$ Methanol and ethanol are the simplest alcohols and are usually referred to as the 'light' alcohols. They are also known as methyl alcohol and ethyl alcohol, respectively.
} 
are blending rules which essentially mean that drop-in fuels can be created ${ }^{2}$ (see Section 1.6.2.

While its similarity to ethanol is useful when attempting to predict how methanol will perform in combustion systems, there is a difference which may prove very useful in terms of greenhouse gas mitigation. Methanol is conventionally made from fossil sources (usually either by steam reformation or from coal, which in itself has a significant fossil $\mathrm{CO}_{2}$ impact) but since it can be made from anything containing carbon by thermochemical means, it is possible that - unlike ethanol - it could be manufactured from biogenic feedstocks. Since chemical processes are generally significantly more rapid than biological ones, this has the potential to increase production rates [3, 4. Also, the difficulties surrounding bioethanol production from non-food crops - such as lignocellulosic processes - are bypassed with this approach, and with this the feedstock limitations in terms of type and quantity. As a consequence methanol production is potentially more easily scalable and could also be incorporated with bioethanol plants in order to increase the overall energy yield from the feedstock entering the process [5].

\subsection{Historical use of methanol as an engine fuel}

From the early days of the spark ignition engine, means to extend what is now referred to as the octane rating of fuels was sought, and the early development of octane enhancers such as aniline compounds and ultimately tetraethyl lead (TEL) was begun. Boyd discusses early concerns that oil would run out in the 1920s and the consequent efforts to increase engine efficiency to reduce consumption via improved knock resistance of refined fuels in this regard [6]. Interestingly, he states that "butyl alcohol [butanol] did not knock in any of the engines they had then", referring to engines available in the 1920s; demonstrating that the attractiveness of alcohols as knock-resistant fuels was apparent very early on.

As is already known since the search for a scale for a fuel's autoignition resistance [7, 8], isomerization is an important parameter. Isomerization of longchain alkanes has the potential to hold octane numbers $(\mathrm{ONs})$ in the region of 100. However, the same is true of simple molecules. Figure 1 shows the values of research octane number $(\mathrm{RON})$ taken from several sources for saturated molecules versus the number of carbon atoms contained. Immediately apparent in the figure is that, with normal alkane molecules, as the chain lengthens so the knock resistance drops markedly. Conversely, if the molecule can be heavily isomerized then the RON stays high - broadly constant at around 100. Note that the simple alcohols methanol and ethanol are also very highly knock resistant in their own right, which can be attributed to the absence of NTC behaviour as explained in Section 2.5. As the normal carbon backbone of the alcohol

\footnotetext{
${ }^{2}$ Drop-in blends for gasoline, however, are limited to low concentrations of alcohols. Higher concentrations require engine modifications such as for E85 use. This will be explained in detail in later sections.
} 
lengthens so the knock resistance drops, and this can be recovered in the same way as for the other families by isomerization. Nevertheless the inherently high ON of alcohol molecules is apparent, and it is worth noting that they are the only family shown with carbon numbers lower than four which are liquid at standard temperature and pressure (STP), a factor which makes them sensible fuels.

The performance-enhancing attributes of both ethanol and methanol were realized early on in motor racing. Blends containing methanol and benzene were often used in Grand Prix cars, especially as supercharging was developed as a tool to extract maximum performance from a given engine swept volume (and charge cooling was not widely used). Among others Alfa Romeo and Bugatti used such mixtures in their pre-war Grand Prix cars 9. While the presence of methanol caused a reduction in volumetric energy content (see Section 2), with fuel introduction before the supercharger its high latent heat cooled the charge as it was compressed, while its high octane number supported that of the benzene proportion (whose density helped to offset the deleterious effect of methanol in terms of volumetric energy content).

Aviation also represented an arena where methanol was used for its benefits in terms of ON and latent heat, but only on take-off and to an extent when maximum power was required. Energy density is an overriding consideration for aircraft propulsion, so straight hydrocarbon fuels were mostly used in highlyboosted aircraft engines. However, at take-off maximum performance is required at sea level, and supplementary mixtures of methanol and water were used as a knock suppressant, injected with the main fuel into the compressor entry. This meant that minimal amounts of the 'anti-detonant injection' (ADI) fluid had to be carried, minimizing its effect on aircraft mass. The volume ratio between water and methanol in ADI was usually 50:50. As well as supplying some chemical availability, the methanol also helped to stop the water freezing at altitude.

In many ways this approach foreshadowed the so-called octane on demand (OOD) approach, where beyond the knock limit of the main fuel an octane booster is introduced [10, 11, 12, 13, 14, 15, 16]. This is not a new concept, the potential for both methanol or ethanol as octane boosters to a lower-quality main fuel having been understood very early on [17. Both have often been used for this function, but the approach requires dual fuel systems, and therefore (together with the requirement to blend the octane booster in with load) increases complexity and cost aboard the vehicle. This subject will be returned to in Section 4.4

The simplicity of a single fuel approach is arguably one of the reasons why the current model of IC engine and hydrocarbon fuel has become dominant in transport. However, flex-fuel approaches - where a single fuel system is retained, but the control system can optimize for any proportion of two fuels which can be mixed in any ratio in the fuel tank [18 - are almost as cheap to apply as proved by the US vehicle manufacturer's response to the Corporate Average Fuel Economy (CAFE) regulations put in place to increase the efficiency of their products. Here many vehicles capable of operating on any mixture of 
gasoline and $\mathrm{E} 85^{3}$ in the fuel tank were sold to customers at no increase in list price over the gasoline-only equivalent. This was done because the fiscal benefit of selling the cars in terms of CAFE credits outweighed the cost of producing them. Flex-fuel operation with E85 was seen as advantageous since the US could make first-generation ethanol in large quantities (i.e. from corn). The vehicle technology was already developed as well, since the methanol equivalent of E85 - M85 - had already been proven to be practical in the California methanol fuel trial in the 1980s and 1990s; in reality, gasoline-ethanol flex-fuel capability was developed and fully proven first for methanol.

The California methanol fuel trial was driven primarily by air quality considerations, methanol causing significantly lower unburned hydrocarbon (UHC) and oxides of nitrogen $\left(\mathrm{NO}_{\mathrm{X}}\right)$ emissions than typical gasolines in use at the time. During it, 15,000 M85-gasoline flex-fuel vehicles, ranging from light-duty to buses and trucks, were sold and operated by Californians of all background no specific training in their use was required [19, 20, 21]. On a technical level it was completely successful, and furthermore, the toxicity of methanol (see Section 1.5 was not found to be an issue at all. Its eventual failure was related to air quality, but only insofar as in order to achieve a similar level of such quality with gasoline the California Air Resources Board (CARB) mandated the use of reformulated gasoline 4 and the methanol previously being used as fuel in the trial was diverted to make MTBE, a completely different molecule.

Ironically there then followed ground water contamination issues since MTBE forms very long plumes when it leaks from tanks (as happened with the old infrastructure in place) and, since it was made from methanol, it gave the alcohol a completely undeserved bad name solely by association. Methanol (and ethanol) are actually simply biodegradable and do not cause any environmental issues as opposed to MTBE [23. Note that MTBE is still widely used as an octaneboosting gasoline additive in Europe [1, where fuel infrastructure is modern, and with no issues. It is furthermore ironic that the technology developed for the California M85 trial was simply modified for its analogue with ethanol, and forms the basis of all flex-fuel vehicles today [20. In itself this illustrates how simple and robust the provision of alcohol/gasoline flex-fuelling is.

Ethanol flex-fuelling has had a long history in Brazil, and arguably even more (but still affordable) sophisticated vehicle technology has been evolved there to cater for the wide variety of blends offered. For the Brazilian market OEMs also developed technologies not generally seen elsewhere: for example, starting systems which use gasoline before switching over to ethanol once the engine is warm enough; this technology has also been adopted in parts of China

\footnotetext{
${ }^{3}$ E85 is notionally $85 \%$ ethanol and $15 \%$ gasoline by volume, although the proportions (and formulation) of the gasoline is often varied for reasons of cold startability etc. Conventionally, 'EXX' refers to XX\% by volume ethanol in bulk gasoline; the analogue situation for methanol is to use 'MXX'.

${ }^{4}$ Note that the EPA reported testing of a number of vehicles on different fuels and found that emissions when running on M85 had a lower ozone forming potential than reformulated gasoline 22]
} 
for the analogue case of M100 fuelled cars.

China's take up of a methanol transport economy has been driven by various factors, not least being the stipulation that in order to gain valuable coal mining permits companies have to provide a use for that coal; this has led to the construction of mega methanol plants since methanol is easily made from gasified coal 24. In turn, and related to China's reliance on imported oil, methanol has been promoted in various provinces, particularly those rich in coal. This has led to the establishment of various regional and national methanol fuel standards. So much low cost methanol is available that adulteration of gasoline with the alcohol is common. These factors have led to the development of methanolgasoline flex-fuel vehicles. Pure M100 vehicles are also available, and research is under way to understand how future legislation should evolve with regards to the exhaust emissions from such vehicles [25].

While in general Western OEMs show little enthusiasm for methanol as a transport fue ${ }^{5}$, the sheer magnitude of the Chinese market and the fact that many have partnerships with Chinese companies in order to access it means that methanol fueling for light-duty is well understood by global OEMs. While methanol from coal is very poor in terms of well-to-tank $\mathrm{CO}_{2}$ emissions (over four times worse at $124.7 \mathrm{~g} \mathrm{CO}_{2}$-e/MJ versus $28.6 \mathrm{~g} \mathrm{CO}_{2}$-e/MJ for natural gas [11]), it is argued that the driving of the technology for methanol usage by the Chinese economy will reduce demand-side barriers to decarbonizing the fleet via the fuel as the technology to reduce the carbon intensity of the methanol supplied develops.

Thus it can be seen that the light alcohols ethanol and methanol have been used and understood as transport fuels for almost as long as the motor vehicle has been around, and that the vehicle technology to employ them is well understood. Worldwide use of ethanol at up to $85 \%$ blend rate was shown to be straightforward, and at low blend rates it is becoming increasingly common. The technically successful fleet trial in California showed that there were no real barriers to the introduction of methanol at high blend rates. Its use in China, for different reasons, has shown the same thing. On a vehicle level there are therefore no real technical reasons why these fuels should not be adopted more widely.

The interest in methanol as a fuel is currently picking up also in regions outside of China. The strongest drive currently seems to be in the marine sector, as discussed in Section 5.3. It is also increasingly being used as a blend component, added to gasoline together with ethanol. This is being demonstrated in Israel [26], Australia [27] and in the Junior World Rally Championship which holds races across Europe [28.

Moreover, the light alcohols and methanol in particular can improve vehicle performance and efficiency markedly over conventional gasoline formulations.

\footnotetext{
${ }^{5}$ Likely due to a reluctance to undertake extra calibration effort and a division of labour at a time when hybridization and the development of battery electric vehicles is being encouraged by governments as a means of ensuring compliance with tailpipe $\mathrm{CO}_{2}$ legislation.
} 
This subject will be discussed throughout this paper.

\subsection{Existing infrastructure/production capacity}

One of the advantages of methanol is that there is already fairly large scale production capacity and infrastructure in place. Methanol is one of the most widely used chemicals, as stated above, with 70 million metric tons produced in 2015 and a global production capacity of about 110 million metric tons [29] (note global gasoline production in 2012 was roughly one billion metric tons). One of its uses is to support the petrochemical industry: it can be used to make many other chemicals via the methanol-to-olefins process and from these higher plastics etc. 30, 24.

As a consequence of this it is one of the most widely shipped chemicals around the globe, and due to the fact that it is also a fuel its shipment in large volume is driving the development of marine engines to use it, which is discussed in Section 5.3. Regional coal mining permits have driven the construction of very large methanol production capacity in China; there is already enough installed capacity to provide half of China's road transport fuel needs 24]. US methanol capacity more than doubled in 2015, with prices coming down as cheap natural gas from shale rock became increasingly available, resulting in the US displacing China as the world's low cost methanol producer [1. To put things in perspective, a large oil refinery typically processes about 500,000 barrels of crude oil per day. A large methanol production facility today produces about 20,000 barrels of methanol per day.

Bozzano and Manenti have recently reviewed the production of methanol 31, explaining how current production comprises three basic steps. The first is the production of synthesis gas (syngas), a mixture of $\mathrm{CO}, \mathrm{H}_{2}$ and $\mathrm{CO}_{2}$. The most common syngas production is by reforming of natural gas, but it can also be obtained from other carbon-based materials, be they fossil or renewable. The second step is the conversion of the syngas to methanol. Bozzano and Manenti review the different processes currently used on an industrial scale, and those in development aimed at lowering the temperature and pressure requirement for the synthesis reaction. They expect innovation in reactor technology, and heat removal and recovery, to further improve the overall process's energy efficiency, which they state is currently of the order of $75 \%$. The final step is distillation. As mentioned above, methanol is a polar molecule, as is water. Consequently methanol is infinitely miscible with water and can also absorb water from the atmosphere. Most of the production processes for methanol result in a crude methanol containing residual gases and a significant amount of water. Thus, distillation becomes an inevitable step to obtain high grade methanol. The dehydration step accounts for an important part of the overall cost of production, both in terms of capital and operating costs. Therefore it would be interesting, from an economic point of view, to use hydrous, or 'raw' methanol and reduce or avoid the dehydration process. A second incentive to investigate hydrous methanol is the potential of increasing the engine efficiency by means of the cooling effect of water. E.g. for hydrous ethanol (up to $7 \mathrm{wt} \%$ water content), several publications [32, 33, 34. pointed out that it can be used as an efficient 
fuel. The properties of methanol-water blends are discussed in Section 2.7 with the effect on engine operation elaborated in Section 4.3 . Implications on storage when methanol is intended to be blended into gasoline are discussed in Section 2.8.6.

Importantly, methanol forms no azeotrope with water. This is unique among the alcohols, which means that the extra process energy required to dry them beyond an azeotrope is absent. Conversely ethanol forms a minimum boiling azeotrope at a composition of $95.6 \%$ of ethanol and $4.4 \%$ of water; distillation under pressure or a vacuum, or the use of chemical sieves are required to dry the ethanol fully and these processes are costly and increase its carbon footprint. For a quantification of the distillation cost, various parameters such as water content of the crude methanol must be taken into account. The water content itself highly depends on the production process. When, for example, methanol is formed with renewable hydrogen and atmospheric $\mathrm{CO}_{2}$ (see Section 1.4), the reaction is theoretically:

$$
\mathrm{CO}_{2}+3 \mathrm{H}_{2} \rightarrow \mathrm{CH}_{3} \mathrm{OH}+\mathrm{H}_{2} \mathrm{O}
$$

I.e. per mole of methanol, there is a mole of water. Note that current methanol production is directed primarily at supplying neat methanol to the chemical industry and therefore crude methanol is not available on the market today.

\subsection{Renewable production of methanol}

The light alcohols make excellent spark-ignition fuels, but one of the reasons that ethanol became so popular as a potential replacement was that it is capable of being manufactured renewably. As discussed earlier, Brazil originally led the way on this. Such bioethanol, made from food stuffs, is termed 'first generation', and issues of 'food versus fuel' quickly became prevalent on its introduction in other markets. Additionally, there were issues of indirect land use change (ILUC) and conversion of land to agriculture to manufacture biofuels causing release of naturally-sequestered $\mathrm{CO}_{2}$.

Consequently, first generation bioethanol only really works as a mass transportation fuel in Brazil, where a combination of relatively low population density, climate and the ensuing efficiency of sugar cane production make it a very desirable energy carrier. In contrast bioethanol from corn in the US is more energy intensive and on a life-cycle basis its return on energy investment is significantly lower [35]. In Europe the land area for ethanol production sufficient to provide all the required energy for transport cannot be found [36]. As a consequence of all of these issues, much emphasis has been put on second and third generation ethanol. Here lignin and cellulose - the waste, inedible parts of the crop - are broken down before fermentation. This holds out the hope that much greater yields of ethanol can be achieved without disruption in the food chain. The US has enacted legislation mandating the use of such lignocellulosic ethanol in gasoline to ever greater degrees, with a target of a total of 36 billion US gallons of ethanol from all sources being produced indigenously for use in the US fuel pool by 2022 [37. Whether this can be achieved is open to question. 
Methanol was traditionally made from wood, hence one of its common names, 'wood alcohol' (ethanol has similarly historically been termed 'corn alcohol'). However, being the simplest alcohol and readily synthesized from any carbonaceous stock, methanol can be made by gasifying waste and using thermochemical (rather than biological) processes. In this respect the energetic yield is higher, interference with the food chain can be avoided, and the process is faster. Historically it was also made by BioMCN in The Netherlands using glycerin, itself a byproduct of the esterification of biodiesel, as a feedstock. Since methanol itself is used to esterify biodiesel in the first place, this permitted a gradual reduction in the fossil footprint of the methanol produced by this process. Others have proposed and studied combined ethanol/methanol production plants, the energetic yield of which would be high and the carbon footprint low [5]. Bergins et al. [38] describe existing industrial sources of hydrogen and carbon dioxide and how to use these for methanol synthesis.

Although the production of methanol from biomass and waste has definite potential, scaling up sustainable methanol production to meet transportation demands needs a production method that goes beyond these feedstocks. Sustainable fuels can also be produced using electricity from renewables and atoms harvested from the atmosphere. It is contended that fuels that can be synthesized using electricity should perhaps be termed 'electrofuels' since they represent a means to store energy gathered and transmissible using this medium [39. As mentioned, methanol can be made from anything carbonaceous, via chemical processes which synthesize the molecule from carbon, oxygen and hydrogen atoms. Methanol is thus the simplest liquid electrofuel and an excellent hydrogen carrier. In fact, as Fig. 2 shows, per unit volume, methanol contains $40 \%$ more hydrogen than liquid hydrogen $\left(\mathrm{LH}_{2}\right)$, without the issues of required energy input for storage, which are severe for molecular hydrogen as discussed by the US Department of Energy (DoE) 40. Since liquid hydrogen has about twice the density as 700 bar hydrogen, these observations also apply to that alternative storage method.

In fact, Gardiner's data shows that the magnitude of the energy input required to make hydrogen storable by the methods proposed is of the order of that which it takes to synthesize methanol on a per-unit-energy basis (expressed as a fraction of the lower heating value, about $21 \%$ for $\mathrm{LH}_{2}$ and $10 \%$ for 700 bar $\mathrm{H}_{2}$ ). The DoE document also states that for 700 bar storage on board a vehicle the gas will have to be delivered at 880 bar and precooled to $-40^{\circ} \mathrm{C}$ because of the heating it undergoes in the refilling process. Methanol is therefore an attractive alternative hydrogen storage medium in the form of its chemical liquefaction.

The above logic applies to any suitable and synthesizable hydrocarbon, which is the rationale behind so-called power-to-gas (PTG), proposed by Specht and co-workers and supported by Audi [41. Here, renewable hydrogen is fixed to waste $\mathrm{CO}_{2}$ - in the case of the Audi process this is taken from a biogas plant to form methane, and this is put into the gas grid. Because of the magnitude of the gas storage and distribution network for many countries this provides a means of storing renewable energy which can help to alleviate the "wrong- 
time renewables' problem. For example Specht et al. state that in Germany the storage represented by the gas grid could supply the average output during 2000 hours, whereas the electricity grid could only do so for 0.6 hour. For automotive use natural gas is removed from the grid and put into cars with a typical storage pressure of 200 bar and replenished by renewable methane synthesized at the plant.

As Fig. 3 shows, methane compressed to 200 bar has essentially the same energy storage capacity in an automotive storage system (i.e. when the mass or volume of the storage medium is also taken into account for automotive applications) as hydrogen compressed to 700 bar; liquid hydrogen is worse than 700 bar hydrogen in terms of its net volumetric energy. The challenges of manufacturing a liquid hydrogen storage tank were discussed by Amaseder and Krainz 42, the problem of liquid hydrogen for transport is one that is arguably best served by scale, which is why, for instance, liquid hydrogen can be practically used in space transportation. Bossel and co-workers discuss the challenges of molecular hydrogen as an energy vector for road transport in some detail, including the number of extra fuel tankers that would be required were the current model for fuel distribution to be continued for hydrogen, and the implications for upstream energy if these tankers were fueled by hydrogen themselves (as would have to be the case for a zero-carbon realization of the molecular hydrogen economy) [43, 44,

Ethanol is included in Fig. 2 because of its renewable nature, and also isooctane because, if higher hydrocarbon electrofuels could be synthesized from renewable carbon and hydrogen, then the data shows that they have similar hydrogen mass storage capability to methane (as might be expected since they are both fully saturated hydrocarbons). It is interesting that such hydrocarbons have similar hydrogen mass concentrations to water. Ammonia has also been included in Fig. 2 because historically it too has been proposed as an electrofuel, due to the ease with which its other major constituent, nitrogen, can be extracted from the atmosphere 45]; such an approach was proposed during the 1960s by the US military, with the supplied energy to have come from a mobile Compact Military Reactor in the theatre of operation.

Of the fuels shown in Figs. 2 and 3, methanol is the simplest molecule that is liquid at standard temperature and pressure (STP). If sufficient waste $\mathrm{CO}_{2}$ can be obtained then using it to convert hydrogen to an electrofuel provides a means to break the biomass limit suffered by ethanol, butanol and biodiesel for example. Using air-extracted $\mathrm{CO}_{2}$ represents an effectively limitless source of carbon that can be used for this process, as proposed by Steinberg and Olah among others as the "methanol economy" 46, 47, 48, 30, 23, 49.

Thus, methanol is also being advanced as one of the most interesting energy carriers in "PtX" schemes, power-to-x, with $\mathrm{x}$ denoting a fuel. These schemes support the development of renewable energy production by allowing large scale energy storage and buffering, producing a storable energy carrier when there is excess renewable energy so this can later be used at times when there is insufficient power from renewables. Renewable methanol production is starting, with the Carbon Recycling International plant in Iceland being the best known 
example. Being the simplest electrofuel that is liquid at STP results in methanol being the cheapest liquid electrofuel that can be produced [50].

The high value of energy and the ease with which liquids can be transported makes the concept attractive, especially since the main inputs to the process - renewable energy and the two feedstocks $\mathrm{CO}_{2}$ and hydrogen - are effectively limitless, or at least are not subject to price control by humans. Once a plant is built then theoretically only maintenance costs have to be offset against the high value of the fuel it would continuously manufacture. It should be noted that this also represents a way to provide carbon-neutral chemical feedstocks to the petrochemical industry via the methanol-to-olefins (MTO) process for instance, and that should such methanol be used the whole process can be made carbon-negative since the resulting plastics and paints, made ultimately from $\mathrm{CO}_{2}$ originally extracted from the atmosphere, effectively sequestrate the carbon they contain.

Regardless of whether mass electrification of light-duty transportation is successful in the long term, electrofuels may be needed to decarbonize some or all of the remaining forms of transport that cannot be served by the adoption of batteries. Aviation, shipping and long-distance haulage of goods represent significant challenges for decarbonization, with varying levels of imperative associated with energy density, quantity of energy to be stored and speed of refueling. Plainly at present these requirements are met by liquid fuels so decarbonization of these would facilitate a decarbonized endgame without fundamental changes being necessary to the machinery already in place. France et al. 51 discuss recent methods to create higher hydrocarbons from $\mathrm{CO}_{2}$ and hydrogen either with or without methanol as part of the direct pathway.

Clearly methanol has the potential to play an important role in future transport systems as an intermediate hydrogen carrier for renewable energy distribution and storage, but many workers have investigated its use as a blend component as its own right. Later sections in this paper will discuss this approach.

\subsection{Health and safety}

Despite of their interesting beneficial properties the use of light alcohols as fuels has met with resistance due to toxicological and fire safety concerns. This is particularly the case for methanol. Pearson and Turner [49] and Bromberg et al. 52 reviewed the safety aspects of methanol and ethanol and concluded that although both alcohols are dangerous and toxic agents, this is true for all fuels being considered as gasoline and diesel substitutes. In many respects alcohols can actually be regarded safer than gasoline, which was also a conclusion reached for methanol in studies by Machiele for the US Environmental Protection Agency [53, 54].

The major issue alcohols - and especially methanol - have to face is toxicity both in terms of ingestion, skin or eye contact or inhalation. Although it is readily metabolized in small amounts by the human body, on account of it being found naturally in fruit and vegetables and therefore not rejected by the body as an alien substance, methanol toxicity arises as a result of overloading the digestive system. When this occurs, the concentration of the toxic intermediary 
products formaldehyde and formic acid becomes too high, and this is what causes damage:

$$
\underset{(\text { methanol) }}{\mathrm{CH}_{3} \mathrm{OH}} \rightarrow \underset{\text { (formaldehyde) }}{\mathrm{HCHO}} \rightarrow \underset{\text { (formic acid) }}{\mathrm{HCOOH}} \rightarrow \mathrm{CO}_{2}+\mathrm{H}_{2} \mathrm{O}
$$

Reported fatal doses when untreated are between 1 and $2 \mathrm{ml}$ per $\mathrm{kg}$ body weight. This would correspond to $60-240 \mathrm{ml}$ for a typical range of body weights [53. Note that Gable reported that a fatal dose for ethanol is only about twice as much as for methanol (350-577 $\mathrm{ml}$ for ethanol, depending on body mass and metabolism, and $115-470 \mathrm{ml}$ for methanol) [55]. Gasoline is similarly toxic although the toxicity of gasoline results from different reasons. Symptoms of acute methanol poisoning from direct ingestion include dizziness, nausea, respiratory problems, coma and finally death. However, the process takes between 10 and 48 hours after ingestion and the cure is well understood, consisting of intravenous administration of ethanol, which the body preferentially metabolizes while the methanol is ejected. Accidental ingestion of methanol or ethanol can be avoided by appropriate design of fuel dispensing systems and by making the fuel completely unpalatable to human taste through additives such as denatonium benzoate (marketed as 'Bitrex' [56]). Skin or eye contact with methanol, as well as inhalation of methanol vapours are generally of much lower concern, as long as it does not persist for hours. The results of animal tests to determine the toxicity of various fuels by inhalation, oral and dermal contact have shown that the toxicity of alcohol fuels is comparable, and in many cases better than that of common gasoline or diesel [52].

With regard to fire safety, methanol shows clear advantages over gasoline. It is not readily ignitable below $10^{\circ} \mathrm{C}$, and Machiele reports that it has a similar flammability index to diesel [54. When compared to gasoline, it has a lower volatility, vapour density and heat release rate in a pool fire, the latter being about $11 \%$ that of gasoline. It also requires a greater concentration to form a combustible mixture in air (cfr. Table 3). A significant hazard is that methanol flames are practically invisible in sunlight, but this can be addressed through additives or the use of methanol-gasoline blends, although Machiele shows that blending $15 \%$ gasoline into methanol halves the difference in the flammability index of the two. This, of course, underlines the primary safety difficulty of gasoline. An advantage of methanol, however, is that thanks to its miscibility, pure methanol fires can be extinguished with water. The inherent fire safety factors of methanol were the primary reasons why neat methanol was the fuel of choice for Indianapolis-style racing in the US for decades until it was replaced by E85. Note that, as discussed in more detail in Section 2.1, the minimum ignition energy of methanol is lower than gasoline.

Methanol has gained a negative reputation when it comes to groundwater contamination through its association with MTBE, which is made from it. Thus, the connection is not a valid one. MTBE is often used as an octane enhancer for gasoline, and is known to form long plumes if it gets into the soil, as has happened with leaking fuel storage tanks. It also has a very strong 
taste, and for this reason its use is banned in the US. In reality, unlike MTBE, methanol and ethanol do not form long plumes and are biodegradable on a very short timescale (a few days) and their spills mostly self-clean [52. This rapid biodegradation property also makes the light alcohols attractive as marine fuels, since any spill quickly disperses due to their infinite solubility in water, and then biodegrades simply; this contrasts sharply with the consequences of a hydrocarbon fuel spillage in the marine environment.

As a consequence of the above, widespread methanol usage would be expected to lead to a reduction in deaths, fires and property loss in the region of $90-95 \%$ versus gasoline [54, 23]. Finally, it should be noted that during the Californian M85 trial, which lasted for several years and involved 15,000 vehicles being used by the general public without special training in the refuelling or use of gasoline/methanol flex-fuel vehicles, not a single issue of toxicity was reported [19]. This is clear empirical proof that methanol fuels can be deployed safely in the market.

\subsection{Methods of using methanol as an engine fuel}

There are several ways to use methanol as an engine fuel:

- In SI engines: Principally methanol is considered an SI engine fuel, due to its high autoignition resistance and also high heat of vaporization (see Section 2.1. Methanol can be used as a pure fuel or as a blend component. The modifications necessary for SI operation are not too significant, see Section 3. The fact that it condenses at low temperatures can also mean that changes to operational parameters need to be performed, but nevertheless significant numbers of gasoline/alcohol flex-fuel engines have been built and operated around the world. Results obtained on SI engines operated on pure methanol or methanol blends are reported in Section 4

- In CI engines: Alcohols have also been used in diesel applications but require more significant modifications from the norm in that application, again a corollary of their high autoignition resistance. Dual-fuelling has also been adopted, recently in large ship engines such as the Stena Germanica, where the methanol is introduced separately to the diesel which is then used as a source of ignition. This obviously requires some significant modification to the fuelling system, but fortunately this is largely common with LNG conversions of such engines. Port-fuel injection of the methanol is a possibility in these dual-fuel engines, too, and is being investigated particularly as a means of providing improved emissions in water craft. The use of methanol in CI engines is discussed in detail in Section 5.

- In SI engines, as a separate fuel stream: As mentioned, it is possible to use an octane-on-demand approach where alcohols are used as an octane booster and introduced separately to gasoline, and only when the knock avoidance afforded by their high octane numbers and charge cooling effect is required. Thus increased compression ratio or engine downsizing can be provided, and with them an improvement in vehicle energy consumption. 
Ideally the overall alcohol consumption is lower than if they were blended in a monofuel approach, but there is clearly increased complication on an engine and vehicle level due to having to provided two fuel systems and a concomitantly more sophisticated engine management system. With improved gasoline consumption the 'gearing effect' of the available alcohol is higher. This approach is elaborated in Section 4.4 .

The following two sections will explain the background for why using binary and ternary blends containing methanol offer attractive possibilities.

\subsubsection{Binary alcohol blends}

The blending of alcohols into automotive fuels has been undertaken for many years, particularly in Brazil, and arguably the first significant use of methanol as a blend component was during the Californian methanol fuel trial, both of which have been discussed above. Since the Californian M85 trial there has been a steady increase in the amount of ethanol blended into US gasoline, driven by energy security concerns. During recent years the Corporate Average Fuel Economy (CAFE) regulations raised on vehicle OEMs in the US has driven the sale of E85/gasoline flex-fuel cars, since essentially the fuel consumption associated with the ethanol in the fuel is ignored as far as the reportable fuel consumption is concerned. In fact the M85 and E85 situations in the US are linked because the technology for the former was easily transplanted to the latter, as discussed by Nichols [20], who also stated that the original Ford M85 development vehicles could operate on any mixture of gasoline, ethanol and methanol in their fuel tanks; this will be returned to later.

The nominally $15 \%$ by volume gasoline in these blends serves to denature the alcohol to prevent ingestion, to provide a more ignitable mixture (which is particularly important at low temperatures) and also to provide a more visible flame should a vehicle fire occur.

The OEM use of flex-fuel vehicle (FFV) technology to meet the CAFE regulations also serves to highlight how cheap it is to apply in a real marketplace. Contrary to the electric vehicle market at present, it works in a marketplace

operating without government subsidy and as it is effectively 'hidden' from the public it has a disproportionately large number of early-adopting consumers. Many E85/gasoline vehicles were sold without the purchasers being told of this capability; this demonstrates that the technology was, at point of sale, effectively a zero-cost one, since such purchasers believed they were buying gasoline-only vehicles at that price point.

Alcohol blending can take the form of low-, mid- and high-level blends, for which there is no formal definition, but which Turner et al. considered to be up to $15 \%$ by volume (low), $15-30 \%$ (mid) and over $30 \%$ by volume (high) [57. Israel recently adopted an M15 standard [58. Low ethanol blends are common in the US and Europe now, typically at 10\%, with the US Environmental Protection Agency (EPA) investigating an increase to $15 \%$ for air quality reasons with waivers for more modern vehicles. Up to this level of concentration the changes in the gasoline distillation curve that ethanol causes can be mitigated by changes 
to the bulk hydrocarbon components. However, the vehicle OEMs will have to make increased calibration efforts to make their products effectively flex-fuel to accept fuels whose oxygenate concentration could vary significantly from zero to proportions of $15 \%$ and higher; the swing in stoichiometric air-fuel ratio obviously becomes greater the more ethanol is blended in (nominally reducing from 14.7 for gasoline to 13.8 for E15).

Accordingly, there are considerations being given to increasing the octane number of the fuel as the ethanol concentration is increased. The traditional approach taken by fuel suppliers to date has been to decontent the hydrocarbon component in the fuel by using ethanol's octane enhancing attributes to facilitate the removal of high-octane components from the bulk hydrocarbon fuel, as would be expected in the interest of greater financial return. However, as Anderson et al. have shown, significant increases in octane can be expected with relatively low volumes of ethanol addition and this can be satisfactorily estimated when the components are considered as molar fractions [59], see Section 2.8.4.

Above say $15 \%$ ethanol by volume it becomes increasingly difficult to match a traditional gasoline distillation curve since the alcohol has a tendency to increase the vapour pressure due to the fact that a gasoline-alcohol mixture does not follow Raoult's Law (see Section 2.8.3). Even at $15 \%$ waivers are being considered as mentioned above. Nevertheless the fact that E85 vehicles could be manufactured shows that the technology exists to overcome this issue. This may be important since the optimal level of alcohol addition (at least as far as ethanol is concerned) is non-linear as far as modern engine technology is concerned [60, 61.

Blending alcohols into gasoline tends to improve engine efficiency (as evidenced in Section 4 4 and can be made to increase fuel octane. However, vapour pressure can increase markedly and under some situations there can be an increase in PN emissions. However, countermeasures for the disadvantages exist and overall, as far as engine performance and efficiency are concerned, there are improvements as alcohol is blended in. However, the approach of blanket alcohol addition into bulk gasoline arguably does not use the available volume to its maximum benefit, and several researchers have investigated its use at variable proportions as an octane enhancer, administered when needed from a second fuel system. This will be discussed in Section 4.4 .

In the following Section, the potential of using both methanol and ethanol as blend components in gasoline will be discussed.

\subsubsection{Ternary blends}

Although gasoline-alcohol blends are usually binary, more than one alcohol can be used simultaneously. An example of this approach are so called ternary blends, which can for example comprise gasoline, ethanol and methanol (so called GEM blends). Turner et al. 62, 63, 64, presented such a concept in which the stoichiometric air-to-fuel ratio is controlled to be the same as that of conventional E85 alcohol-based fuel. In fact, starting from any binary gasolineethanol mixture, a ternary blend of gasoline, ethanol and methanol can be devised in which the fraction of each component is chosen to yield the same 
stoichiometric air to fuel ratio (for E85, this is $~ 9.7-9.8: 1$ depending on the AFR of the gasoline which can vary somewhat). E85 can be used in a flexfuel vehicle, which is capable of using ethanol in concentration levels of up to $85 \%$ (E85) by volume. However, despite the registration of over several million flex-fuel vehicles, representing $4 \%$ of the light duty vehicle fleet in the United States, only $1 \%$ of the total ethanol use in the USA has been in the form of E85 sales 65. This is because E85 has suffered both from limited availability and uncompetitive pricing on an energy basis.

It was shown by Turner et al. [66, 63, that all the possible iso-stoichiometric ternary blends starting from a binary blend of gasoline and ethanol are practically invisible for the engine control unit (ECU) of flex-fuel vehicles calibrated to run on any ethanol-gasoline blend up to E85. This opens the possibility to use these ternary blends as drop-in fuels for flex-fuel vehicles without the danger of upsetting the on-board diagnostics of the engine management system. If the methanol used is of a renewable and energy-secure nature then, for a fixed volume of ethanol in the fuel pool dependent on the biomass limit, an increased level of renewability and energy security is achieved. This overall situation is made possible by the fact that there are more E85/flex-fuel vehicles in existence than can currently be serviced by the E85 fuel supply chain. The formulation of ternary GEM blends and the properties of these blends will be discussed in Section 2.9.

Turner et al. 66, 63] tested the drop-in ability of the iso-stoichiometric gasoline-ethanol-methanol (GEM) blends in two flex-fuel vehicles. One vehicle was provided with a physical sensor for alcohol content and the other vehicle had a 'virtual' sensor. A physical sensor directly measures the alcohol concentration of the fuel relying on the electric permittivity or the resistance of the fuel, while a virtual sensor utilizes an algorithm based on the information of the other sensors of the engine to calculate the alcohol concentration. A 'virtual' sensor has the advantage that there is no additional cost in hardware. During vehicle testing, the hypothesis that iso-stoichiometric GEM blends can function as drop-in alternatives to binary ethanol-gasoline blends was confirmed. There were only two malfunction lights when running on the binary gasoline-methanol blend with the vehicle with the 'virtual' sensor. Turner et al. [62, 49] stated that this could be due to phase separation as the vehicle was not subjected to road shocks or accelerations on the test bench and that some form of cosolvent might be necessary when methanol and gasoline are blended together, which was not present in their splash blend\$ ${ }^{6}$ Compared to the gasoline tests on the same vehicles, there was an overall efficiency improvement of approximately $5 \%$ when using the alcohol blends. Turner et al. 66, 63] also performed cold start tests. The only fuel blend which failed the cold start test was the normal E85 blend. This is to be expected since ethanol is harder to start than gasoline or methanol (see Section 3.3), and so reducing the proportion of this component and replacing it with larger amounts of the other two would only be expected

\footnotetext{
${ }^{6}$ Blends made by mixing retail gasoline with methanol.
} 
to improve the situation.

Consequently there is the possibility with GEM blends to effectively extend gasoline displacement during winter months when currently, with existing commercial E85 fuels, the ethanol content is decreased to levels close to $70 \%$ in order to maintain cold startability. A year-round fixed blend ratio is therefore a possibility. It is important to note that these tests were conducted on a vehicle and the emissions were measured at the end of the tailpipe without knowing what the ECU was actually doing. This is addressed in Section 4.2 where the results of testing of different GEM blends on engine test benches are discussed.

Next to the hypothesis, another benefit of the GEM-blends is the potential economic advantage. Turner et al. 63 showed that with wholesale prices (i.e. without taxes) of $\$ 3.11, \$ 2.30$ and $\$ 1.11$ per US gallon for gasoline, ethanol and methanol respectively (as was the case at the time that paper was written, i.e. around 2011), the price of the blends can be made significantly lower than gasoline on an energy basis. With these prices, with ternary blends containing more than $25 \%$ by volume of methanol, a reduction in motoring costs could be realized just through a reduction in the relative price of the fuel versus gasoline. Since the vehicles would be expected to become more efficient when operated on the high-blend alcohol fuels, one would expect another reduction in operating costs for the user.

Another advantage is that for flex-fuel vehicles, there is no need for range anxiety, which is a major obstacle for electric vehicles, because these flex-fuel vehicles are still able to run on gasoline. The user would be able to run on a high-alcohol GEM blend, on which the vehicle would be significantly cheaper to operate but with a lower range due to the lower volumetric energy content of the alcohol fuel, or on gasoline, when he or she would like to travel longer distances before refueling.

\section{Fundamentals}

Understanding an engine's behaviour when fueled with methanol, in terms of power output, efficiency and emissions, their trade-offs, and their response to engine settings, requires an understanding of how methanol's physical and chemical properties affect the engine operation. In the following sections, we discuss the impact of basic properties on the engine, with separate sections devoted to the more complex properties that change with e.g. pressure and temperature, such as burning velocities and ignition delay times.

\subsection{Physical and chemical properties of methanol relevant to engines}

In this section, we will discuss the properties of methanol, compare them to other fuels, and link them to expected consequences for engine design, engine parameter settings or engine performance. Here, this will be done in a qualitative way. Later Sections will quantify them. The properties are listed in Tables 1 (physical properties), 2 (chemical properties), 3 (fuel-air mixture properties) 
and 4 (other). They are also included for gasoline, iso-octane as a primary reference fuel for gasoline, the alcohols ethanol and 1-butanol (a higher alcohol), methane as the prime constituent of natural gas, and hydrogen.

First, looking at the elemental composition (Table 2), it is clear that the hydrogen to carbon ratio of methanol is higher than that of gasoline, and equal to that of methane. Thus, when calculating the carbon dioxide $\left(\mathrm{CO}_{2}\right)$ emissions on an energy specific basis ( $\mathrm{g} \mathrm{CO}_{2} / \mathrm{MJ}$ ), methanol leads to $7 \%$ lower specific $\mathrm{CO}_{2}$ emissions compared to gasoline. Of course, this assumes a similar conversion efficiency (brake thermal efficiency, BTE) whereas methanol enables notably increased efficiencies as will be discussed later on (thus further lowering the specific $\mathrm{CO}_{2}$ emissions in operation).

Using methane or hydrogen as a fuel further lowers the specific $\mathrm{CO}_{2}$ emissions. However, in both cases it is important to look at the overall picture, i.e. include well to tank (WTT) $\mathrm{CO}_{2}$ emissions and emissions of other greenhouse gases. This was discussed in Section 1.4 .

The oxygen content, amounting to half of methanol's molecular mass, has important consequences for methanol's properties as an engine fuel. The high oxygen content leads to a low (mass-based) stoichiometric air requirement (air/fuel ratio, AFR), the lowest of all the fuels listed in the table. This also means that the fraction of methanol in a stoichiometric mixture is high, see Table 3 (the highest on a mass basis, and second to hydrogen on a volume basis). Thus, it is important to know the definition for volumetric efficiency that is used, when looking up published values, as there will be substantial differences depending on whether the fuel vapour fraction has been included or not. Despite the high methanol fraction, fuel-air mixture properties such as the viscosity, thermal diffusivity and speed of sound, are close to those of gasoline-air.

Methanol's density is higher than that of gasoline, despite its low molecular mass. This is due to the methanol molecule being polar due to its $\mathrm{OH}$ group, causing hydrogen bonding. At $32 \mathrm{~kg} / \mathrm{kmol}$, it has the same molecular mass as oxygen, and so from a physicochemical standpoint one would expect it to be a gas. The hydrogen bonding however gives rise to the formation of quasi-super molecules, or cyclic tetramers, that ensures that they are liquid at STP [67. The hydrogen bonds explain several characteristics of methanol: high latent heat, infinite miscibility with water, low vapour pressures, etc. A significant disadvantage of the $\mathrm{OH}$ group is that it makes methanol phase separate in hydrocarbons, depending on the temperature and water concentration, since it makes it non ideal mixtures. The low vapour pressure is replaced by the tendency to cause very high vapour pressures when methanol is mixed with hydrocarbons. This is due to the intramolecular forces between the pure hydrocarbon molecules and methanol, breaking the hydrogen bonds of the cyclic tetramers and the small 'real' molecules rising through the mixture and leaving the surface of the mixture easily. This will be further discussed in Section 2.8.2

The high oxygen content obviously reduces the energy content (heating value). The volumetric energy content is important for fuel injection system design and fuel storage. Methanol's higher density is more than offset by a heating value less than half that of gasoline, thus the volumetric energy content 
is half that of gasoline and consequently injection durations need to be twice as long in order to introduce the same energy into the engine, thus necessitating suitable injectors (see Section 3). This also implies larger vehicle fuel tanks are needed for a similar driving range, or that with the same size of vehicle tank as a gasoline vehicle, driving range decreases and the driver will need to refuel more often. Note that increases in efficiency can alleviate this somewhat.

Looking at the volumetric energy content of the fuel/air mixture (energy per unit mole of stoichiometric mixture), it can be seen that this is $5 \%$ lower for methanol relative to gasoline. Thus, an engine with external mixture formation (e.g. port fuel injection) would have a lower maximum specific torque (hence, peak brake mean effective pressure, BMEP) on methanol. However, there are other factors also influencing the specific torque, such as charge cooling and engine efficiency, changing this picture as discussed below. The energy per unit of air on the other hand is $6 \%$ higher for methanol relative to gasoline, so an engine with internal mixture formation (direct injection) can be expected to have a higher BMEP on methanol.

Methanol's polarity also causes a low vapour pressure. This lower volatility, in combination with a higher lower flammability limit in air (so a higher concentration to reach before a flammable mixture is obtained), leads to a more difficult cold start. Measures to overcome this are discussed in Section 3 .

The hydrogen bonding resulting from methanol's polar nature also leads to a high heat of vaporization. When also taking the lower stoichiometric air requirement into account, this means a sevenfold increase of the energy needed to evaporate the fuel, relative to gasoline. When methanol is introduced in the engine's intake port, this can lead to very low temperatures, which needs to be addressed in the engine design (Section 3). The lower temperature resulting from methanol's evaporation (either in the port or in the combustion chamber), leads to lower temperatures throughout the engine cycle. Additionally, the adiabatic flame temperature of methanol-air combustion is the lowest of all fuels in Table 2. This points to multiple potential benefits. Lower wall heat losses can be expected (benefiting engine efficiency), as well as lower emissions of $\mathrm{NO}_{\mathrm{X}}$. For spark ignition (SI) operation, the danger of autoignition is lower, thus enabling the use of higher compression ratios (again benefiting engine efficiency) and/or using optimal spark timing throughout the engine operating map. The cooling effect also leads to increased intake air densities, increasing volumetric efficiency. As will be shown later, this more than offsets the lower volumetric energy content of a methanol-air mixture, improving the engine's power density. An additional downside of the low temperatures is that obtaining a fast catalyst light-off can be a challenge.

Next to improved resistance to autoignition (engine knock) because of lower in-cylinder temperatures, the higher autoignition temperature of methanol also indicates a higher chemical resistance to knocking. Furthermore, as will be detailed below, methanol-air mixtures have a higher laminar burning velocity than gasoline. Thus, end-gas autoignition is less likely to occur as the flame propagation is faster, consuming the end-gas before it can get to autoignition conditions. A higher laminar burning velocity typically also corresponds with an 
increased tolerance for dilution, i.e. allowing leaner operation or higher amounts of exhaust gas recirculation.

The effect of charge cooling causes difficulties when attempting to determine the octane number of alcohols according to common methods. Yates et al. 68] reviewed several published values for RON and MON of alcohols and concluded that most of these are affected by the evaporative cooling effect. Based on this observation, they selected octane values from work which controlled the intake charge temperature, irrespective of the evaporation effect. These values are given in Table 4 and reflect the knock resistance of alcohols due to factors such as chemical autoignition behaviour and flame speed. Clearly, methanol is very well suited for spark ignition combustion. The autoignition temperatures of methane and hydrogen might be even higher, but being typically introduced into the engine in gaseous state, they do not take any advantage of charge cooling. This is especially true in engines with direct injection, as the evaporation energy is mainly extracted from the mixture and not from the engine structure. Based on several studies investigating the octane number benefit due to evaporation cooling, Anderson et al. concluded that a temperature reduction of $7 \mathrm{~K}$ corresponds to an ON benefit of approximately 1 [65]. This is in good agreement with the experimental study of Milpied et al. on a downsized, turbocharged flex-fuel engine with direct injection [69. They reported a benefit of $1 \mathrm{ON}$ for an increase in cooling power of $2-8 \mathrm{~kJ} / \mathrm{kg}$ mixture. Based on a computational model, describing the kinetics of alcohol autoignition, Bromberg et al. found even higher values for the effective octane number for alcohols in direct injection engines (150 for ethanol and 180 for methanol) 70]. Stein et al. [16 assessed the knock resistance of different ethanol-gasoline blends in a single cylinder engine with three injection systems: upstream, prevaporized fuel injection; port-fuel injection and direct injection. They found that the chemical and evaporative charge cooling anti-knock effect are of comparable importance with direct injection. For port-fuel injected engines, the cooling effect is considerably smaller.

Methanol's high octane numbers, with a RON of 109 and a MON of 92, gives it a sensitivity of 17 , this property being defined as:

$$
S=R O N-M O N
$$

where $S$ is sensitivity and RON and MON are the octane numbers defined in the relevant tests. Both a high RON and a high sensitivity have been shown to be directionally important with regards to the present evolution of SI engines towards 'beyond RON' operation [71, 72, 73, 74, 75]. The high sensitivity is due to a combination of effects, but mainly that of the heat of vaporization. The RON and MON tests are performed with different fuel preparation approaches. For the RON test, only the air is heated, the fuel being introduced after this process. This means that the high latent heat of methanol causes the temperature in-cylinder to drop considerably, and the knock limit to extend commensurately. For the MON test, however, the entire mixture is heated after the fuel has been introduced, nullifying this effect. Luef and co-workers [76] investigated this ef- 
fect further by using direct injection in a modified CFR engine, and attempted to quantify it for different fuels.

Methanol's very low cetane number means that special measures are needed to enable the use of methanol in compression ignition (CI) engines (see Section 5).

Looking at the properties of the burned mixture (Table 3), first of all it is noteworthy that with methanol combustion there is a molar expansion instead of a contraction as is the case for e.g. hydrogen combustion. This can be expected to increase the efficiency [77]. Also, the ratio of triatomic molecules (i.e., $\mathrm{CO}_{2}$ and $\left.\mathrm{H}_{2} \mathrm{O}\right)$ to diatomic molecules $\left(\mathrm{N}_{2}\right.$ and $\left.\mathrm{O}_{2}\right)$ in the burned gas is higher for methanol compared to gasoline (due to the low AFR and thus lower amount of nitrogen in the combustion chamber), which leads to a higher heat capacity of the products, lowering peak temperatures and decreasing heat losses. Exhaust temperatures can also be expected to be lower than with gasoline. On the other hand, due to the lower amount of nitrogen in the mixture, the mass fraction of water vapour in the burned gas is higher than for gasoline or methane, leading to a higher thermal conductivity (this also affects fuel reforming using exhaust gas, see Section 6. Section 7.1.5 will discuss the net effect on in-cylinder heat transfer.

Reviewing methanol's flammability limits, first of all it is clear that the lower flammability limit (LFL) is much higher than for gasoline. Once the LFL has been reached, the methanol-air mixture remains flammable over a relatively wide range. The higher air-to-fuel equivalence ratio $\lambda$ corresponding with the LFL, indicates a potentially slightly wider range for qualitative load control (controlling power output through mixture richness i.e. the range in output power offered between stoichiometric operation and the leanest mixtures for which stable operation is still possible).

The minimum ignition energy and quenching distance of methanol are the second lowest values in Table 3, with only hydrogen having even lower values. The lower minimum ignition energy relative to gasoline could mean more issues with surface ignition (preignition) in the engine, especially combined with the higher laminar burning velocity [78. Note, however, that very few references can be found reporting data for the minimum ignition energy and quenching distance, and all are relatively old, so these data should be treated with care. Recently, Fernández-Tarrazo et al. [79] elaborated a computational approach for determining the minimum ignition energy. They found the minimum ignition energy to be reached for an equivalence ratio $\phi=1.25$. Based on their calculations using a reduced chemical kinetic scheme, they proposed a simple equation for calculating the minimum ignition energy (MIE) of methanol-air mixtures as a function of temperature $(\mathrm{T}): \mathrm{MIE}=0.24 \times 2.59^{-T / 300 K}$, with MIE given in mJ.

Finally, the flash points of the alcohol fuels are higher than for the other fuels, which was mentioned in Section 1.5 when discussing safety of fuel storage.

Summarizing the properties reviewed above, methanol has the potential to increase engine performance and efficiency over that achievable with gasoline thanks to a variety of interesting properties. The high heat of vaporization, 
combined with low stoichiometric air/fuel ratio, leads to high degrees of intake charge cooling as the fuel evaporates. This is especially true for engines with direct injection. The charge cooling not only leads to increased charge density, and thus higher volumetric efficiency, but also considerably reduces the propensity of the engine to knock [80, 18].

\subsection{Reaction kinetics and emission formation mechanisms}

As mentioned above, the minimum ignition energy of methanol-air mixtures has recently been calculated using a reduced kinetic scheme. Kinetic schemes describing the detailed oxidation chemistry are important tools for understanding the magnitudes and dependencies of key engine combustion parameters such as the minimum ignition energy, autoignition delay times, laminar burning velocities etc.

The reaction kinetics of the methanol-air system are reasonably well understood, methanol being a simple molecule. Its oxidation is also the basis for the oxidation of longer chain alcohols, which has been an additional motivation for studying its reaction kinetics. Sarathy et al. 78 reviewed alcohol combustion chemistry, including methanol, listing the most important comprehensive kinetic mechanisms and detailing the primary reaction channels. They also point to remaining uncertainties in certain rate constants, for example for the reaction $\mathrm{CH}_{3} \mathrm{OH}+\mathrm{HO}_{2} \leftrightarrow \mathrm{CH}_{2} \mathrm{OH}+\mathrm{H}_{2} \mathrm{O}_{2}$, which is important for the ignition delay time. Furthermore, they stress the need for laminar burning velocity data at high pressure (see next Section). Burke et al. concur in their recent paper [81, proposing a comprehensive reaction mechanism for methanol oxidation validated against the available experimental data obtained from shock tubes, rapid compression machines, jet-stirred reactors etc., concluding that additional data at high pressure and low temperature are needed.

Next, we discuss a result from (among other things) reaction kinetics: emission formation mechanisms for methanol combustion. Emission levels obtained from actual measurements will be discussed in later Sections.

Svensson et al. 82 ran stochastic reactor simulations using detailed chemistry, including a soot model, to compare emission formation pathways between methanol and diesel (represented by a mixture of n-heptane and toluene). They constructed maps for the different emission species, as a function of equivalence ratio $\phi$ and temperature $T$, and then investigated the trajectories in $\phi, T$ coordinates that could be expected during engine operation. Figure 4 shows the regions where $\mathrm{NO}_{\mathrm{X}}$ and soot are formed, for the two fuels. The plots also show the adiabatic flame temperature, computed for an initial temperature of 1000 $\mathrm{K}$ and an initial pressure of 75 bar, which would be the end-of-compression conditions for the engine experiments that were used for validation of some of the results. The plots clearly illustrate that methanol combustion will not result in soot formation: first, the soot region (delineated by $0.01 \mathrm{ppm}$ of soot formed) is much smaller than for diesel combustion, it is limited to $\phi>2.6$ and $T>1950 \mathrm{~K}$. Second, because of methanol's long autoignition delay (see Section 2.5 and high heat of vaporization, mixing times are long and ignition 
only occurs when the methanol fuel has already mixed with air to equivalence ratios lean of stoichiometric.

The plot also shows the region in which $\mathrm{NO}_{\mathrm{X}}$ is formed to be quite similar between methanol and diesel. The production of $\mathrm{NO}_{\mathrm{X}}$ depends on the temperature, oxygen content and residence time of the combustion gases in the cylinder 83. Thus, the way in which the engine is operated (i.e. the temperatures occurring during the cycle) can dominate over the fuel effect in determining the actual $\mathrm{NO}_{\mathrm{X}}$ emissions. When compared to gasoline, methanol reduces the incylinder temperatures because of its lower adiabatic flame temperature, high burned gas heat capacity and evaporation cooling. Consequently, $\mathrm{NO}_{\mathrm{X}}$ can be expected to be lower if the engine is operated at the same equivalence ratio 20 .

Carbon monoxide $(\mathrm{CO})$ is mainly formed by incomplete combustion and thus is very dependent on the mixture equivalence ratio. Additionally $\mathrm{CO}$ can be formed by dissociation of $\mathrm{CO}_{2}$, albeit this route occurs mainly at higher temperatures 83 . Different authors have suggested that the oxygenated nature of alcohols can lead to more complete combustion and consequently to reduced engine-out $\mathrm{CO}$ emissions (the so-called premixed oxygen effect) [84, 85, 20]. However, slight deviations from stoichiometry, for example during cold start, will have a more defining impact on CO levels.

For unburned hydrocarbons (UHC) the situation is similar. These emissions are mainly caused by failed or incomplete combustion, unburned fuel in combustion chamber crevices or wall wetting during engine warm-up [83. Methanol can enable slight reductions in engine-out UHC levels thanks to the premixed oxygen effect 85]. Unlike gasoline, methanol does not have components that only boil at high temperatures and thus can cause UHC emissions [86. These benefits can be cancelled out by increased wall wetting due to the elevated heat of vaporization of methanol, especially during cold start.

A compound of concern is formaldehyde, $\mathrm{HCHO}$. This plays an important role in photochemistry and is a human carcinogen [87. Formaldehyde emissions have been reported to potentially be higher on methanol (-blends) than on gasoline [22], so could be a concern for methanol-fuelled vehicles as these emissions are not always regulated currently (they are limited in U.S. regulations for vehicle exhaust emissions). Engine-out emissions of HCHO are a balance between the formation of formaldehyde and its subsequent oxidation, since formaldehyde is an intermediate species in the reaction pathway of methanol oxidation [78. Thus, formaldehyde emissions will peak when the mixture experiences intermediate temperatures 82 (around $1000 \mathrm{~K}$ ) and then is prevented from getting to higher temperatures that would lead to full oxidation of the formaldehyde. Such can be the case for PFI engines, where methanol gets into crevices during compression and then escapes these crevices during expansion, when pressures are dropping. With properly controlled DI engines, it should be possible to prevent at least some of the emission of formaldehyde. Section 4 will continue this discussion by looking at how effective aftertreatment is for formaldehyde emissions. Note that formaldehyde is also an intermediate species in the combustion of hydrocarbons such as gasoline and diesel and thus can also be found in the exhaust emissions of engines running on these fuels. 
It is important to note that, in the past, some authors have concluded that light alcohols can contribute to significant reductions in hydrocarbons (HC) based on Flame Ionization Detector (FID) measurements. Note that carbonyl compounds do not belong to the definition of hydrocarbons. Hydrocarbons consist of only hydrogen and carbon, while carbonyl compounds consist also of oxygen. In the U.S. regulation, non-methane organic gases (NMOG) are defined, and this definition includes also carbonyl compounds. Today, we know that FID measurements have a low relative sensitivity to oxygenated compounds and thus other methods, such as FTIR (Fourier transform infrared) should be used to measure HC levels in alcohol engines [88, 89, 90. Wei et al. point out that an FID has a very low response to formaldehyde, and use a fast chromatographic method with a pulsed discharge helium ionization detector instead 87. Geng et al. compare the FTIR method to gas chromatography (GC) and high performance liquid chromatography [91. The latter two prove to be more accurate, but are offline measurements. As the FTIR results were consistently higher, and are obtained online, the FTIR method can be seen as a more practical measurement.

\subsection{Laminar burning velocities}

Instead of including a single value for the laminar burning velocity (LBV), at some reference condition, in Table 3 this parameter is discussed here separately. Note that the LBV of methanol-gasoline blends will be discussed in a separate section (Section 2.8.7). First of all, it is worth remembering the importance of this parameter for engine combustion. The initial stage of combustion in spark-ignition engines, is the quasi-laminar flame growth of the original ignition kernel 92 . Thus, the duration of this phase (in practice denoted by the crank angle duration it takes to burn the first 2, 5 or $10 \%$ of the cylinder charge), is to the first order inversely proportional to the laminar burning velocity. It has been shown that this phase has a defining influence on the combustion stability, affecting cyclic variation. This is illustrated by how the dilution tolerance increases with laminar burning velocity $[93$. The main combustion phase, governed by turbulent flame propagation, is also affected by the laminar burning velocity, albeit to a lesser degree 94.

Vancoillie et al. 95] reviewed the available experimental data on the LBV of methanol-air mixtures. They concluded that data at engine-like conditions are very scarce, in particular for elevated pressure and diluted mixtures. Part of the data was also noted to be compromised as it was derived using techniques later proven to be inaccurate (e.g. data obtained from spherically expanding flames not accounting for the effects of flame stretch). The limited available data deemed to be reliable were subsequently used as validation data for LBV calculations using chemical kinetic schemes for the methanol-air system. The authors selected the mechanism of Li et al. [96] as the most promising one, being widely validated and not too demanding in terms of computational time (including 39 species and 238 elementary reactions). Here, we use computed results using the $\mathrm{Li}$ et al. mechanism to compare the LBV dependence on equivalence 
ratio, pressure, temperature and dilution level, of methanol to that of some other fuels.

First of all though, it must be stressed that reliable LBV data is relatively scarce in general, and even more so for different fuels at similar conditions. Thus, it is mostly necessary to extrapolate values using reported temperature or pressure dependencies. These dependencies in turn have typically been derived from a limited set of measurements where temperature or pressure has been changed, so the uncertainty on the dependencies is higher than on the LBV data itself.

In the following, we compare LBV calculations for methanol, against data for iso-octane, methane and hydrogen. Figure 5 shows the LBV for varying equivalence ratio, at a pressure of 1 bar and a temperature of $360 \mathrm{~K}$. The data for iso-octane has been taken directly from Sileghem et al. 97. For hydrogen, the values were calculated using the correlation proposed by Verhelst et al. [98, derived from chemical kinetic calculations using a scheme validated for enginelike conditions. The methane data were taken from $\mathrm{Gu}$ et al. 99, requiring calculation at $360 \mathrm{~K}$ based on measured values at $300 \mathrm{~K}$ and a temperature exponent derived from measurements up to $400 \mathrm{~K}$.

It can clearly be seen that hydrogen burns much faster than any of the other fuels. After hydrogen, methanol can be seen to have the highest value, its burning velocity at stoichiometry being a third higher than that of isooctane. As mentioned earlier, the increased burning velocity contributes to a higher knock resistance, next to allowing shorter combustion duration which also increases efficiency. The equivalence ratio at which the peak LBV is reached, is shifted to the rich side for methanol compared to iso-octane and methane (note that for hydrogen this is even richer).

Next, we take a look at how the LBV changes with temperature. Sileghem et al. 100, 97. measured the LBV of methanol, iso-octane and gasoline for different temperatures and equivalence ratios (at atmospheric pressure). They confirmed that the influence of initial temperature on the LBV can be described well by the following correlation:

$$
u_{l}=u_{l 0}\left(\frac{T_{u}}{T_{u 0}}\right)^{\alpha}
$$

with $u_{l}$ being the laminar burning velocity at initial temperature $T_{u}, u_{l 0}$ the LBV at the reference temperature $T_{u 0}$, and $\alpha$ the temperature exponent. Sileghem et al. calculated the temperature exponent over a temperature range of $298 \mathrm{~K}$ to $358 \mathrm{~K}$. Results are shown as a function of equivalence ratio in Fig. 6 . The graph shows no significant differences between methanol and gasoline, although qualitatively for methanol the temperature dependence is more constant around stoichiometry. Unfortunately, the studied temperature range is quite small which leads to rather high uncertainties for the temperature exponent, and moreover the temperatures are very low compared to engine conditions. Values for burning velocities at higher temperatures have been reported, but these are compromised by e.g. neglecting effects of flame stretch [95. Consequently, the behaviour of methanol flames at engine-like temperatures and possible dif- 
ferences with other fuels can currently only be derived from chemical kinetic calculations, which have only been validated for LBVs at lower temperatures, or for other metrics at higher temperatures (e.g. ignition delay times). Very recently, Katoch et al. 101] reported LBV measurements for methanol-air mixtures at temperatures up to $650 \mathrm{~K}$. They point out that older LBV correlations use either a constant temperature exponent $\alpha$, or one which linearly decreases with equivalence ratio $\phi$, and that the measurements of Sileghem et al. [97] were the first time that a parabolic dependence of $\alpha$ on $\phi$ was reported. Using a new method involving the stabilization of a near to planar flame in a heated quartz diverging channel, Katoch et al. confirmed this parabolic dependence. Their measurements also indicate an increased divergence from predictions using chemical kinetic mechanisms at higher temperatures and stoichiometric to rich mixtures.

The situation is worse still when looking for the pressure dependence. As reviewed by Vancoillie et al. [95] and Beeckmann et al. [102, reliable data at elevated pressure is scarce. Discarding all data that is potentially compromised by the occurrence of flame instabilities, or has not correctly accounted for flame stretch, leaves only the measurements reported by Zhang et al. 103] (up to 7.5 bar) and Beeckmann et al. 102 (10 bar). The data reported by Beeckmann et al. also includes other alcohols. Interestingly, methanol's LBV is found to be around $15 \%$ faster than the other alcohols for rich conditions, whereas differences are smaller for lean to stoichiometric mixtures. Also, the peak LBV is found to be obtained for richer mixtures in the case of methanol (around $\phi=1.2$, as was also seen at 1 bar in Fig. 5, as opposed to around $\phi=1.1$ for the other alcohols). Both features are reproduced by kinetic schemes [78. The authors also report an increasing deviation between measured laminar burning velocities and predictions using several kinetic schemes at higher pressure.

As will be discussed in Section 7, uncertainties on the LBV value have a large impact on engine cycle simulations. Clearly, there is still a need for experimental confirmation of the existing data at higher pressure, and preferably an extension to higher pressures.

Finally, for engine combustion, in general and in particular for new concepts relying on highly diluted combustion, it is important to know how the LBV is affected by combustion residuals. Unfortunately, very few data can be found. The only recent data are those of Vancoillie et al. 104, who measured the effects of dilution to validate the dilution term in their LBV correlation [95].

\subsection{Turbulent burning velocities}

The turbulent burning velocity $u_{t}$ of a fuel-air mixture obviously has a large impact on engine combustion. The turbulent burning velocity is not solely a function of the turbulence (as assumed in some turbulent combustion models 92]) but the fuel's properties also affect the sensitivity of a fuel-air flame to turbulence 94. Understanding the turbulent burning velocity and its dependencies helps in explaining observed engine behaviour and is necessary for properly modelling engine combustion. Hence, this section discusses the turbulent burning velocity for methanol mixtures. 
A large body of literature, comprehensively reviewed by Lipatnikov and Chomiak 94, indicates that, depending on the conditions and mixture properties, flame stretch and instabilities can considerably affect $u_{t}$. The high pressures in engines will lead to flames being increasingly unstable [105. This was confirmed for ethanol-air mixtures by Ohara et al. 106. Using experiments in a fan-stirred bomb for rms turbulent velocities $u^{\prime}$ between 0.8 and $1.6 \mathrm{~m} / \mathrm{s}$ they observed that as the initial pressure increased, the flame front became more finely wrinkled, leading to an increase in $u_{t} / u_{l}$ for the same $u^{\prime} / u_{l}$.

For methanol, the influence of preferential diffusion effects can be expected to be lower than for very diffusive fuels such as hydrogen, because the mass diffusivity of methanol ( $M=32 \mathrm{~kg} / \mathrm{kmol})$ is comparable to that of oxygen $(M=32$ $\mathrm{kg} / \mathrm{kmol}$ ). Also the change in Lewis number with varying equivalence ratio is less than for some other fuels (see Fig. 7), limiting thermo-diffusive effects. This was confirmed in closed vessel experiments by Lawes et al. [107] and Ohara et al. [106]. These studies showed that $u_{t} / u_{l}$ remained almost constant for a wide range of equivalence ratios. For methane and iso-octane mixtures, on the other

hand, there was a clear effect of differential diffusion instabilities: in the case of methane, lean mixtures exhibit a much higher ratio of $u_{t} / u_{l}$ compared to rich mixtures whereas for iso-octane the opposite behaviour is found. Only for very lean $(\phi<0.7)$ and very rich mixtures $(\phi>1.8)$ there was a noticeable rise in $u_{t} / u_{l}$ for methanol, probably caused by the rise in $u^{\prime} / u_{l}$.

At low $u^{\prime} / u_{l}$ the effects of counter-gradient transport and flame-generated turbulence can become important. In this respect, methanol combustion in SI engines is comparable to hydrocarbon combustion: $u^{\prime} / u_{l}$ can be expected to be high enough to ignore these effects [108. This is important, since a lot of turbulent combustion models rely on this assumption (see Section 7).

Vancoillie et al. 104 measured turbulent burning velocities of methanol-air mixtures in a fan-stirred constant volume bomb. The obtained data was then used to assess the performance of a number of widely used turbulent burning velocity models. The authors concluded that the effect of rms turbulent velocity on $u_{t}$ is predicted well by most models, whereas the effect of equivalence ratio was best reproduced by the models that incorporate thermodiffusive mixture properties. The effect of pressure was less well predicted.

\subsection{Ignition delay}

Methanol has an elevated chemical resistance to autoignition 68. This is due to the single-stage autoignition behaviour of methanol. The autoignition of gasoline is typically a two-stage process, where at temperatures below $900 \mathrm{~K}$, low-temperature oxidation of the mixture takes place. These so-called cool-flame reactions release heat, which boosts the high-temperature oxidation responsible for knock. At temperatures between $800 \mathrm{~K}$ and $1000 \mathrm{~K}$ the low-temperature oxidation is inhibited by degenerate chain branching. This phenomenon occurs when the precursors of chain branching decompose back to the reactants at high temperatures due to their instability. So between $800 \mathrm{~K}$ and $1000 \mathrm{~K}$ increasing the temperature will reduce the cool flame temperature rise, leading to less promotion of the main, high temperature autoignition reaction. This 
results in autoignition delay times rising with temperature at these conditions. The autoignition delay time $\tau$ is the time it takes for a quiescent, homogeneous mixture to spontaneously ignite. This ignition is generally characterized by a certain temperature or product concentration threshold being exceeded. The temperature frame of rising $\tau$ with increasing temperature is called the negative temperature coefficient (NTC) region. This will be illustrated in Section 2.8 for gasoline-methanol mixtures. For methanol, degenerate chain branching reactions are of low importance in the oxidation mechanism [109. Consequently, methanol does not have a NTC region. This is a characteristic it shares with ethanol 68].

Models to predict the autoignition of unburned mixture in spark-ignition engines range from simple empirical expressions to complex formulations featuring reduced or full chemical kinetics 110. A widely employed empirical approach is to apply the conservation of delay principle of Livengood and $\mathrm{Wu}$ [11]. According to this principle the overall ignition delay time can be found by integrating its instantaneous value during the compression and combustion stroke. This is analytically expressed by the knock integral reaching unity:

$$
\int_{t_{I V C}}^{t_{K O}} \frac{\mathrm{d} t}{\tau(t)}=1
$$

Where $t_{I V C}$ and $t_{K O}$ are the time at intake valve closure and knock onset respectively, and $\tau(t)$ is the instantaneous autoignition delay time.

The autoignition delay time $\tau$ (in s) at instantaneous cylinder pressure $p$ [bar], unburned mixture temperature $T[\mathrm{~K}]$ and composition is typically given by an Arrhenius expression representing the rate limiting step of autoignition:

$$
\tau=A p^{n} e^{\frac{B}{T}}
$$

Where $A, n$ and $B$ are parameters depending on the mixture composition (fuel, $\phi$, residual gas ratio). The most widely used parameter set for Eq. 5 was introduced in 1978 by Douaud and Eyzat based on recording the knock onset in a CFR engine for a range of running conditions and PRFs (primary reference fuels) with octane numbers between 80 and 100 [112. It has also been extensively used in simulations for non-PRF fuels, including ethanol [113, 114. Another well known parameter set is that of Frankzke, based on knock studies with gasoline in production engines [115.

For neat methanol a number of correlations were proposed over the years based on shock tube experiments [116, 117], rapid compression machine (RCM) tests 118 and chemical kinetics calculations [68, 95]. Table 5 shows that the correlations proposed by Yates et al. 68] and Vancoillie et al. [95] cover the widest range of engine-like conditions. However, only that of Vancoillie et al. includes the effect of residual gas dilution on $\tau$.

In Fig. 8 the correlations of Douaud \& Eyzat $(\mathrm{ON}=109)$ [112, Frankzke 115, Yates et al. 68, and Vancoillie et al. 95, are compared for an adiabatic compression from $10 \mathrm{bar} / 575 \mathrm{~K}$ to $80 \mathrm{bar} / 1042 \mathrm{~K}$. Note that the correlation of Douaud \& Eyzat has been used outside its range of validity (ON between 80 
and 100). The most recent correlation, of Vancoillie et al., is seen to yield very similar results to that of Yates et al. However, compared to that correlation, it comprises the effect of mixture composition ( $\phi$, residuals) on the autoignition delay time, so the correlation of Vancoillie et al. 95. can be recommended. The temperature-pressure dependence is much steeper than that predicted by Douaud \& Eyzat. Although the correlation of Frankzke was developed for gasoline, its temperature-pressure dependence is remarkably comparable to that of the correlation of Vancoillie et al. In Section 7 we will discuss the performance of these correlations when used in knock prediction models.

\subsection{Sprays}

Here, we briefly touch on methanol fuel sprays. Fuels are typically introduced in engines through sprays, either in the intake port (port fuel injection, PFI), or directly in the combustion chamber (direct injection, DI). The morphology of the fuel spray and its characteristics (spray penetration, spray angle, droplet size distribution etc.) are dependent on many parameters. Here, we focus on the effect of fuel properties on the spray behaviour. As methanol engines are currently mostly derivatives from e.g. gasoline engines, it is important to know how the spray will be affected when switching fuels. For instance, if the spray changes in such a way that wall wetting would change, this will have an important effect on efficiency (through combustion efficiency and potentially wall heat loss) and emissions. Section 3 will discuss how fuel injection equipment itself has to be adapted for methanol use.

We first look at 'normal' injection, i.e. where the fuel is injected into an environment that is at a pressure above the fuel's saturation pressure. In this case, the primary breakup depends on a competition between spray jet inertia, surface tension, viscous forces, and drag [119. Thus, the fuel properties of primary importance here are density, viscosity and surface tension. The spray behaviour is understood to depend on the Reynolds number, as the ratio between inertial and viscous forces; the Weber number, as the ratio between inertial and surface tension forces; and on the ratio between ambient density and fuel density (since this affects the ratio of drag to inertial forces).

Fuel density is higher for methanol compared to gasoline, viscosity is slightly higher, and surface tension is comparable (see Table 1). Zeng et al. [119] showed how the resulting Reynolds and Weber numbers are quite comparable between methanol and gasoline. They also looked at ethanol, which showed different numbers due to its significantly higher viscosity. This would indicate a more difficult primary breakup for ethanol. However, even for ethanol, the spray properties have been reported to be very close to those of gasoline [120, 121. Zeng et al. reported spray penetration differences between gasoline and methanol to be small.

In the case of flash boiling, i.e. when injecting fuel into an ambient pressure that is below the fuel's saturation pressure, such as could occur during idle or part load operation with injection during the intake stroke or when the fuel temperature is high, enhanced vaporisation will occur. This is due to bubbles being created inside the liquid due to its vaporising, and disintegrating the jet. 
Zeng et al. 122 also studied flash boiling, reporting 'collapsing' sprays that, for fuel temperatures between 50 and $90^{\circ} \mathrm{C}$, looked very similar between n-hexane and methanol.

The picture above is far from complete, as for instance in-nozzle cavitation will also be influenced by vapour pressure, viscosity and density, and can have a large influence on primary breakup [123. However, the literature on methanol sprays is very limited. Based on the few data discussed above no major differences in spray behaviour seem to be expected.

\subsection{Properties of methanol-water blends}

The infinite miscibility of the light alcohols in water has led to some investigation of water-alcohol solutions in combustion systems, water being known to be a knock suppressant. Also, as discussed in Section 1.3, the direct use of 'raw' methanol could lead to lower fuel cost. Most and Longwell tested pure methanol and mixtures with 5 and $10 \%$ water by volume in a CFR single-cylinder engine and found that water increased the octane number of the mixture [124. Their data in this respect is reproduced in Table ब1. The elevated knock resistance is due to the larger cooling effect and the water vapour dilution which both contribute to lower in-cylinder temperatures.

One thing apparent in the data of Most and Longwell is the non-linearity of the effect of adding water to methanol. This would be worthy of more study, and is likely to be important in any use of water/methanol as ADI mixtures in octane-on-demand (OOD) systems. This is discussed in Section 4.4 . Note that adding a certain volume percentage of water to methanol does not scale linearly to a mole percentage. In Figure 9 the relationship between mole and volume fraction for hydrous methanol and hydrous ethanol is plotted. This relationship can be important to keep in mind: adding a small volume of water to methanol can result in a significant change in the molar composition, e.g. $10 \%$ water by volume represents a mole fraction of $20 \%$.

When considering the use of these mixtures in practical systems, the freezing temperature is obviously important. Figure 10 shows the effect on the freezing point of the resulting binary mixtures of adding methanol or ethanol to water. In Fig. 10 note that methanol has a greater effect; by mass $25 \%$ methanol in water would suppress the freezing point of the resulting ADI mixture to $21^{\circ} \mathrm{C}$. The equivalent value for ethanol in water is $-15^{\circ} \mathrm{C}$. For the $50: 50$ water methanol mixture commonly used in ADI systems in aircraft piston engines, the freezing point is $-44^{\circ} \mathrm{C}$, which would have been an important consideration in that application for any residual mixture in the system at altitude. Finally, the azeotrope for both types of mixture is interesting, and is maximized for methanol: at $82 \%$ methanol by mass the freezing point of the mixture is $-124^{\circ} \mathrm{C}$, lower than either the freezing point of water $\left(0^{\circ} \mathrm{C}\right)$ or methanol $\left(-97.6^{\circ} \mathrm{C}\right)$.

\footnotetext{
${ }^{7}$ Note that the MON value is lower that the value in Table 4 which is probably due to Most and Longwell's measurement predating the modifications to the CFR test that were suggested some years later for determining octane numbers of alcohols and alcohol blends [125].
} 
Water has a higher latent heat of vaporization and a higher specific heat capacity than methanol, ethanol or gasoline (heat of vaporization of water is 2257 $\mathrm{kJ} / \mathrm{kg}$ vs. $1100 \mathrm{~kJ} / \mathrm{kg}$ for methanol). Because the stoichiometric air quantity also decreases with water addition in the fuel blend, the latent heat of vaporization per $\mathrm{kg}$ air increases significantly and this leads to an even larger cooling effect of the intake charge. How this translates to the achievable engine power output can thus be expected to depend on the competition between the higher volumetric efficiency obtained through the charge cooling, and the lower energy content of the fuel. The higher specific heat capacity of the water vapour results also in a more isothermal compression and thus the compression work decreases which should have a positive effect on the efficiency.

One limit to the amount of water that can be allowed in the methanol fuel is the combustion stability, since burning velocities are reduced due to the presence of the inert water. Recently, Liang and Stone measured the effect of adding up to $40 \mathrm{vol} \%$ of water, on the laminar burning velocity [126], reporting the mixture diluted with 40 vol\% of water to burn $55 \%$ slower. The addition of water also influenced (delayed) the onset of flame instability, indicating that turbulent burning velocities might be even more affected. Section 4.3 reports the results of engine tests on water-methanol blends.

\subsection{Properties of methanol-gasoline blends}

Solutions of methanol and/or ethanol in gasoline behave as non-ideal mixtures: the alcohol-alcohol interactions are different from the alcohol-gasoline or gasoline-gasoline interactions due to the polarity of the alcohol molecules and the resulting hydrogen bonding between alcohol molecules. As the blend ratio changes, certain interactions can become stronger or weaker resulting in a non-linear behaviour with the molar content of the individual component. For example when the alcohol is mixed with increasing quantities of gasoline, which is a non-polar liquid, the hydrogen bonds are progressively weakened and become less extensive. In the case of methanol, the methanol molecule starts to behave as a low molecular mass component in gasoline, which is a mixture of hundreds of hydrocarbons, instead of a cyclic tetramer with four times the mass of an individual methanol molecule.

In this Section, properties with a non-linear behaviour will be discussed.

\subsubsection{Volume versus mole concentration}

As mentioned above, the concentration of fuel blends is usually quantified in terms of volume fraction, whereas the mole fraction of a component should provide the more meaningful insight into the variation of physico-chemical properties since fuels combust in the gaseous phase. Blends of different fuels for which there is a large difference in the ratio of density of the component to the molar mass of the component will exhibit a large difference in concentration expressed in terms of mole fraction and volume fraction. This is especially true for lower carbon count alcohols blended in gasoline. This is shown in Figure 11 in which the relationship between mole and volume fraction for alcohols blended in standard gasoline (molar mass $=107 \mathrm{~kg} / \mathrm{kmol}$ and density $=740 \mathrm{~kg} / \mathrm{m}^{3}$ ) is plotted. 
For ethanol and methanol there is a significant difference, e.g. M10 and E10 on a volumetric basis become respectively M28 and E22 on a molar basis. For higher alcohols, there is less difference because of the higher molecular mass of these molecules.

\subsubsection{Vapour pressure}

The most commonly used measure of vapour pressure is the Reid vapour pressure (RVP), defined as the vapour pressure measured at $37.8^{\circ} \mathrm{C}\left(100^{\circ} \mathrm{F}\right)$ in a chamber with a vapour-to-liquid volume ratio of $4: 1$. This is an indication of the presence of very light fractions that vaporize at low temperatures. Methanol and ethanol, when mixed with gasoline, have very pronounced peaks in RVP around 10 vol\% alcohol fraction while this behaviour diminishes with increased alcohol chain length [127. This is shown in Figure 12.

This non-intuitive behaviour of ( $\mathrm{m}$ ) ethanol-gasoline blends is a consequence of molecular interactions between the gasoline components and (m)ethanol. For an ideal mixture of components, the vapour pressure would follow a molar concentration weighting and the vapour pressure can be expressed by Raoult's law:

$$
p=\sum p_{i} x_{i}
$$

where $\mathrm{p}$ is the vapour pressure of the mixture, $p_{i}$ is the vapour pressure of compound $\mathrm{i}$ and $x_{i}$ is the mole fraction of compound i. Solutions of methanol and/or ethanol in gasoline however behave as non-ideal mixtures. As explained earlier, when gasoline is added to alcohol with increasing quantities, the hydrogen bonds are progressively weakened and the alcohol starts to behave as a low molecular mass component and the gasoline-alcohol interactions change [127]. The non-polar hydrocarbon molecules in gasoline interfere with the intermolecular hydrogen bonding between the polar (m)ethanol molecules, and the (m)ethanol interferes with molecular interactions between the gasoline hydrocarbons [67, 128, 129]. These interferences with intermolecular bonding allow the respective molecules to more readily escape the liquid as vapour, increasing vapour pressure, and result in the formation of near-azeotropes of (m)ethanol and gasoline components. The effect of the low molecular mass component eventually falls away as more gasoline is added and the alcohol concentration drops to zero.

As can be seen in Figure 12, the magnitude of the increase of RVP is less pronounced with ethanol addition compared to methanol addition. This is due to the lower vapour pressure and lower polarity of ethanol [127].

This behaviour of the vapour pressure can influence the cold-start performance of an engine and explains how evaporative emissions using methanol and ethanol in high level blends can be lower than those of gasoline while they can be higher using low level blends [67.

\subsubsection{Distillation curve}

The vaporization behaviour of a fuel is important in order to ensure proper cold start and normal operation of the engine. For U.S. gasoline, the distillation 
curve has to meet the ASTM standard D4814, with similar standards applying to other regions. $10 \mathrm{vol} \%$ of the fuel must be evaporated at a temperature of $70^{\circ} \mathrm{C}$ (T10), $50 \mathrm{vol} \%$ between 77 and $121^{\circ} \mathrm{C}$ (T50) and $90 \mathrm{vol} \%$ at a maximum temperature of $190^{\circ} \mathrm{C}$ (T90). The gasoline must be completely evaporated at a temperature of $225^{\circ} \mathrm{C}$. The inclusion of large quantities of a single component (in this case methanol) in a blend is known to distort the distillation profile near to the boiling point of that single component. The formation of near-azeotropes can cause further distortions, as is known to be the case with methanol (and ethanol). Because of the near-azeotropic behaviour, the distillation does not occur as discrete segments of compounds but rather as vaporization of mixtures with gradually varying composition and with decreasing volatility 130 .

In Figure 13, the near-azeotropic behaviour of methanol-gasoline blends is visible as a more slowly rising distillation curve indicating a lower volatility than that of the base gasoline. For increasing methanol content, this slowly rising curve expands to cover a larger portion of the distillation curve [130]. Note that for high-level ethanol-gasoline blends, problems can arise because of the low volatility at the front end of the distillation curve for low temperatures. As mentioned earlier, because of the low volatility, the ethanol fraction in 'E85' blends is decreased to typically $70 \%$ by volume during winter months.

Other solutions could be adjusting the calibration of engine parameters or installing a second fuel tank with another fuel which would be used during cold start. A second fuel tank makes the system more complex and expensive but an additional gasoline fuel tank is already used in Brazilian flex-fuel vehicles which are running on hydrous ethanol. Section 3 gives an overview of possible engine-related changes to ensure cold start.

\subsection{4. $R O N / M O N$}

Anderson et al. [59] studied the Research Octane Numbers (RON) and Motor Octane Numbers (MON) of gasoline-alcohol blends and found that these properties behave non-linearly on a volumetric basis but can be estimated to first order by calculating the average of the octane numbers of the components using the mole fraction. The difference between mole fraction and volume fraction of methanol-gasoline and ethanol-gasoline blends was shown in Fig. 11. Because the octane numbers of alcohol-gasoline blends can be estimated using mole fractions, it follows that the sensitivity, $S=R O N-M O N$, can also be estimated by molar weighting.

Still, the behaviour of the RON and MON is not completely linear with molar content as shown for ethanol in Fig. 14 131. Anderson et al. 65 proposed to use a non-linear term to improve the molar-weighted estimate of RON and MON values for ethanol-gasoline blends because measured RON values were up to $3 \mathrm{RON}$ higher than values estimated by molar weighting. They explained the non-linear behaviour by interactions between ethanol and certain hydrocarbons. Similar work on methanol-gasoline blends would be useful.

Note that Anderson et al. 59] point to the subtleties of interpreting results from RON and MON tests for alcohols: "the MON test specifies the temperatures of the inlet air $\left(38^{\circ} \mathrm{C} / 100^{\circ} \mathrm{F}\right)$ and the air-fuel mixture $\left(149^{\circ} \mathrm{C} / 300^{\circ} \mathrm{F}\right)$, 
whereas the RON test specifies a higher temperature for the inlet air (nominally $52{ }^{\circ} \mathrm{C} / 125^{\circ} \mathrm{F}$ ) and does not specify a temperature for the air-fuel mixture. This means that the inherently beneficial high heats of vaporization of alcohols are a factor in the RON test but not the MON."

\subsubsection{Density}

Due to the way liquids having different molecular size group together, the total volume of a blend of different liquid components can be different from the sum of the volumes of the components prior to mixing. The volume occupied by a number of molecules depends on the molecules that surround them. This can affect the density of alcohol-gasoline blends, especially when water addition is involved. For example, when 1 mole of water is added to a large volume of water at $25{ }^{\circ} \mathrm{C}$, the volume increases by $18 \mathrm{~cm}^{3}$. When 1 mole of water is added to a large volume of ethanol at $25{ }^{\circ} \mathrm{C}$, the volume increases by only $14 \mathrm{~cm}^{3}$ because of the higher density packing of the water molecules [132. For most applications involving anhydrous alcohol-gasoline blends, the density can be approximated with enough accuracy using linear combinations. Turner et al. 63] measured the density of different ternary gasoline-ethanol-methanol blends, discussed in the next Section, at $20^{\circ} \mathrm{C}$ using a pycnometer. The measured densities were observed to be near linear combinations of individual component densities.

\subsubsection{Water tolerance of methanol-gasoline blends}

An important aspect of the storage of fuels is that the fuel must be stable. Contrary to methanol and ethanol, gasoline is not miscible with water. As a result, blend stability and by extension water tolerance are important factors for hydrous alcohol-gasoline blends. The major issue encountered when blending water, methanol and gasoline is phase separation, the dispersion of the blend in an aqueous and an organic liquid phase. Cold start problems, a fluctuating knock resistance and a suboptimal mapping are the main disadvantages related to phase separation in a vehicle's fuel tank (with a lower octane gasoline layer on top and a corrosive alcohol-water blend below).

The water tolerance in blends is the amount of water (volume percent) that a blend can dissolve before separating into two phases at equilibrium. Skinner et al. [133] pointed out that the tendency of water induced phase separation is a function of the amount of water, the type of alcohol, the temperature and the alcohol/gasoline ratio. Qi et al. 134] produced critical phase separation temperatures for a range of methanol/gasoline blends as a function of water content, see Fig. 15. The critical phase separation temperature of methanol-gasoline blends increases with the amount of water present in the blend. Additionally, they stated that the addition of ethanol will reduce the phase separation temperature. Donnelly et al. [135] concluded that, when as little as $0.1 \mathrm{vol} \%$ water is added to a M20 blend, phase separation can occur at a temperature of 20 ${ }^{\circ} \mathrm{C}$. Because of this very small water tolerance of the methanol-gasoline blend, water contamination during methanol transport and storage has to be avoided.

In order to assist with the stability of methanol-gasoline blends, other alcohols are often used. Qi and co-workers [134] discuss the use of ethanol specifically 
as a co-solvent in methanol-gasoline blends and show data on the stability limit with temperature. Pearson and Turner [23] later discussed an apparent irregularity in this and proposed a minimum value and how it would relate to ternary blends of gasoline, ethanol, and methanol.

Sileghem [32] used Aspen software to get insights into the phase separation process of alcohol-gasoline blends. The UNIFAC-LiquidLiquid model was used to get qualitative results of phase separation for gasoline-alcohol-water blends. For gasoline, a toluene reference fuel (blend of iso-octane, n-heptane and toluene) was used as representation of gasoline. In Fig. 16, the results are shown. The alcohol in the gasoline-alcohol-water blends is a mixture of methanol and ethanol going from $100 \%$ methanol to $100 \%$ ethanol as can be seen in the Figure. Under the lines, the blend is unstable and phase separation is expected. As expected from literature, blends with a high fraction of alcohol are more water tolerant and addition of ethanol will reduce the chance of phase separation [134, 136].

\subsubsection{Burning velocities}

Sileghem et al. [137] investigated the possibility to use simple 'mixing rules' to determine the laminar burning velocity (LBV) of a methanol-gasoline blend out of the laminar burning velocities of its components, methanol and gasoline. They evaluated different mixing rules by comparing their results to measured as well as computed data (using 1D chemical kinetic simulations) of blend LBVs.

The evaluation showed that the blend's LBV is not linear in the blend composition, proven by poor predictions of the blend LBV using mixing rules based on averaging by volume fraction or mass fraction. Good predictions were obtained using the energy fraction mixing rule, the mixing rule developed by Hirasawa et al. [138, and a Le Chatelier's rule based on the energy fraction. These three mixing rules were reported to perform very well for binary, ternary and multi-component fuels, and for 'binary' blends of fuels, which are themselves a blend of components, even at higher temperature and pressure. Keeping in mind the uncertainties of both the laminar burning velocity of the mixture and the laminar burning velocity of the pure fuels, the authors concluded that the three proposed mixing rules can be used in simulation models to calculate the laminar burning velocity with acceptable accuracy.

To illustrate this, the energy based mixing rule for estimating a blend's LBV is given here. First, the energy fractions $\gamma_{i}$ need to be calculated, as follows:

$$
\gamma_{i}=\frac{\Delta c H_{i} \cdot x_{i}}{\sum_{i=1}^{n} \Delta c H_{i} \cdot x_{i}}
$$

with $\Delta c H_{i}$ the heat of combustion of the mixture's components, and $x_{i}$ the mole fraction of the blend's components. The blend's LBV can then be estimated using the energy fractions and the LBVs of the blend's components, 
$u_{l, i}$, using Eq. 8 .

$$
u_{l, b l e n d}=\sum_{i=1}^{n} \gamma_{i} u_{l, i}
$$

\subsubsection{Autoignition delay time}

In Section 2.5. we described the autoignition behaviours of methanol (single stage) and gasoline (two stage) separately. Figure 17 displays the autoignition delay time $\tau$ as a function of temperature for methanol, gasoline, and two blends, as calculated by Yates et al. 68. (lines). Gasoline is represented by primary reference fuel (PRF) 80, which is a mixture of $80 \mathrm{vol} \%$ iso-octane and 20 vol\% n-heptane. As methanol is added to PRF80 in Figure 17, the cool-flame temperature rise decreases and the NTC region gradually diminishes. Since autoignition in SI engines takes place at unburned mixture temperatures between 750-900 K, the cool-flame reactions are the prime reason for the lower chemical resistance to knock of gasoline compared to methanol [139].

Sileghem et al. 140 investigated the possibility of determining mixing rules for predicting autoignition delay times of methanol-gasoline blends. They used the empirical model of Yates et al. 68 to calculate the ignition delays of blends of primary reference fuels and methanol. As discussed in the preceeding section, the simplest mixing rules are based on mole, mass, volume or energy fraction. They found the mixing rules to over-predict the ignition delay for lower temperatures because of the very different values for the ignition delay of methanol and the PRF fuel that was used to simulate gasoline, due to the cool flame behavior

of the PRF fuel. They solved that by using logarithmic values of the ignition delay as follows:

$$
\tau_{\text {blend }}=\sum_{i=1}^{n} \alpha_{i} \log \left(\tau_{i}\right)
$$

or

$$
\tau_{\text {blend }}=\prod_{i=1}^{n} \tau_{i}^{\alpha_{i}}
$$

Figure 17 shows the resulting ignition delays using the mixing rule based on the energy fractions of the different fuels (symbols) as, similar to what was observed for the mixing rules for the laminar burning velocity of methanolgasoline blends, the energy fraction mixing rule was found to give the best agreement. This mixing rule was then tested for engine simulations (see Section 7.1.4.

\subsection{Properties of ternary blends}

In order to have ternary blends which could have the potential to be 'dropin' fuels for binary ethanol blends in flex fuel vehicles (see Section 1.6.2), two properties of the blends are absolutely necessary: the blends should have very 
similar stoichiometric air-to-fuel ratio and volumetric energy density as the target binary blend. With nearly identical volumetric energy densities, the opening duration of the fuel injectors can remain the same without the need to recalibrate the ECU. The stoichiometric air-to-fuel ratio condition is required to not upset the ECU with signals from the lambda sensor which are outside the expected range.

\subsubsection{Volumetric relations}

A simple expression can be derived to quantify the volume fractions of methanol, gasoline and ethanol required to generate iso-energetic ternary mixtures [141. These mixtures have the same volumetric energy density as a target binary blend of gasoline and ethanol. The volume fraction of methanol as a function of the volume fraction of ethanol can be expressed as:

$$
\frac{V_{M}}{V}=\frac{V_{E}}{V} \frac{\left(\rho_{E} L H V_{E}-\rho_{G} L H V_{G}\right)}{\left(\rho_{G} L H V_{G}-\rho_{M} L H V_{M}\right)}+\frac{\left(\rho_{G} L H V_{G}-\rho L H V\right)}{\left(\rho_{G} L H V_{G}-\rho_{M} L H V_{M}\right)}
$$

in which the subscripts 'G', 'E' and 'M' stand for gasoline, ethanol and methanol; $\rho$ is the density and $L H V$ is the lower heating value.

Using Eq. 11, the concept of these ternary blends is shown in Fig. 18 for equivalent 'E85' blends. On the right side of Fig. 18 the composition of normal E85 can be seen. On the left side of Fig. 18, the binary mixture of gasoline and methanol is shown in which all the ethanol is replaced with gasoline and methanol. This results in a M56 blend. In between these two blends, any isostoichiometric ternary blend can be determined by drawing a vertical line in Fig. 18 and reading the blend ratios on the left axis of the Figure (for example the dotted line in Fig. 18). In Fig. 18, the concept of iso-energetic GEM blends has been shown for equivalent 'E85' blends, but iso-energetic GEM blends can be formulated for any binary ethanol-gasoline blend. The limit case where all the ethanol is removed and substituted by methanol and gasoline can easily be calculated from Eq. 11, i.e. when $V_{E} / V=0$ :

$$
\frac{V_{M}}{V}=\frac{\left(\rho_{G} L H V_{G}-\rho L H V\right)}{\left(\rho_{G} L H V_{G}-\rho_{M} L H V_{M}\right)}
$$

The possible deviation of the stoichiometric AFR from that of the target binary blend can now be quantified for the iso-energetic GEM blends, see Fig. 19 As the AFR of the blends also depends on the AFR of the gasoline which is used to formulate the blends, the AFR ratios of E85 and M56, which are assumed to be iso-energetic, are plotted in Fig. 19 as a function of different gasolines with changing AFR while assuming the other properties of the different gasolines stay equal. The deviation between the two limiting binary GEM blends, E85 and M56, becomes larger as the AFR of gasoline increases. The deviation is 1.7 $\%$ when the AFR ratio is 14.7 for gasoline and only $0.014 \%$ for an AFR of 14.1. These deviations should however never be a problem for the ECU. 


\subsubsection{Ternary blend properties}

Turner et al. 66, 63, 64 found that all the possible iso-stoichiometric and iso-energetic ternary blends starting from a binary blend of gasoline and ethanol have, beside the same AFR and identical volumetric energy content, essentially constant octane numbers and constant latent heat. The fact that these ternary blends show very few differences in physical properties opens the possibility to use these ternary blends as drop-in fuels for flex-fuel vehicles without the danger of upsetting the on-board diagnostics of the engine management system. The octane numbers of four different GEM blends, measured by Turner et al. 66, are shown in Fig. 20. As can be seen, octane numbers do not vary much for the different blends and therefore the sensitivity (RON-MON) is essentially constant as well.

In a comprehensive study of GEM blend characteristics, Waqas et al. 142 investigated the autoignition characteristics of GEM blends in terms of their applicability to SI, HCCI and CI combustion systems. Their investigation, using a modified CFR engine for measurement of RON and HCCI number and an IQT for cetane measurements, also included the effect of the composition of the base gasoline used in the blend; this was in terms of base gasoline RON (defined as being high if it was $84 \mathrm{RON}$ and low at $70 \mathrm{RON}$ ) and the aromatic concentration in the fuel. While they did not attempt to match distillation curves, the use of fuel injection in their modified CFR engine would have helped to suppress the effects of this parameter. They related all of their results back to RON numbers. This comprehensive study determined that when high concentrations of alcohols were used the iso-stoichiometric blending rule was valid regardless of the combustion mode tested provided a high RON base fuel was used; the same was not found to be true if a low RON base gasoline was used. In this respect their results mirrored those of Anderson et al. for ethanol blends where low gasoline blendstock octane numbers were found to give more non-linearity of predicted blend RON and MON [131, albeit that the range of blendstock ONs used by Anderson et al. was different, with a range of 88 to $95 \mathrm{RON}$.

In SI and CI mode, the aromatic content of the fuel was found to have a non-linear effect on the iso-stoichiometric blending rule but in HCCI combustion mode it was found to hold almost independently of this. The alcohol concentration was found to yield some saturation at high levels in HCCI and CI operation, but this was not the case for SI.

Generally then, from the work of researchers in the SI field, it can be said that the RON of iso-stoichiometric GEM blends is indeed constant for conventional blendstock RONs of above $85 \mathrm{RON}$ or so, and hence methanol can be used to augment ethanol availability and help to displace fossil gasoline from the fuel pool.

The GEM blends have the potential to be used as drop-in alternatives to binary ethanol-gasoline blends such as E85 from a combustion and control point of view but it is also important to understand their aggressivity towards materials, volatility properties, blend stability, etc. This was investigated by Turner et al. 63. for several GEM blends. 
As discussed in Section 2.8.3, a single component in a blend will distort the distillation profile around the boiling point of that single component, with further distortions possible due to azeotropic behaviour. For different E85equivalent GEM blends, Turner et al. 63] found that the biggest distortion for the front end of the distillation curve (low temperatures) occurred for the E85 blend (without methanol), indicating low volatility. With increasing methanol content, the distillation curve approaches that of the base gasoline. This indicates that GEM blends containing higher levels of methanol will be less compromised regarding cold temperature startability.

As the alcohol content decreases in alcohol-gasoline blends, the RVP increases with a peak around 10-15 vol\% (see Section 2.8.2). Increased RVP has been linked to increased evaporative emissions. Because the alcohol content decreases when GEM blends with higher methanol fractions are formulated and the vapour pressures of methanol-gasoline blends are higher than the vapour pressures of ethanol-gasoline blends, RVP increases as more methanol is added in the GEM blends. This may lead to increased evaporative emissions and overloaded carbon canister traps, especially for GEM blends with lower alcohol content, e.g. such blends equivalent to E15 63. Instead of standard gasoline,

a reformulated blendstock for oxygenate blending or "RBOB" could be used to counteract these issues to some extent.

Qi et al. 134] investigated the blend stability of methanol-gasoline blends. At lower temperatures, a methanol-gasoline blend can become unstable (i.e. phaseseparate) and ethanol was used as a co-solvent in order to yield stable mixtures. The data of Qi et al. 134. was corrected by Turner et al. 49] and is shown in Fig. 21. This data at $-15^{\circ} \mathrm{C}$ shows that there is a boundary between stable and unstable mixtures and that the E85-equivalent GEM blend without ethanol, M56, would not be stable. This suggests that ethanol should always be used as a co-solvent in some concentration in order to have stable mixtures.

The material compatibility issue is discussed in Section 3.2 .

\section{Methanol engine and vehicle design features}

\subsection{Introduction}

The properties of methanol and methanol blends, discussed in Section 2 , necessitate some hardware changes to engines and vehicles to be run on these fuels. Note that all vehicles currently on the market, using gasoline engines, are able to run on low level blends, i.e. where the methanol fraction falls within current gasoline specifications (e.g. in the case of EN228, up to 3 vol\% of methanol). The latter is very important: as discussed in Section 2.8.2, blending methanol in with gasoline will increase the vapour pressure, for low methanol concentrations. Thus, as is the case with ethanol, for the blend to fall within gasoline vapour pressure specifications it is required to change the formulation of the base gasoline. A 'splash blend' will have a higher vapour pressure. One has to be careful with some findings from literature, where this important distinction has not been made. For example, work has been reported on much higher diurnal 
losses of methanol, from a vehicle fuelled with M15 [143]. However, this work used a splash blend, probably explaining this result. Older vehicles (generally from before 2002) can develop problems even with these low level blends, as the alcohol can act as a solvent, loosening deposits in the fueling system making blockages further down the line a possibility.

In the following, hardware changes are discussed that are needed when running on mid to high level blends, or neat methanol. Note that measures on the fuel-side are also possible: additives are typically used to improve the fuel's lubricity, reduce carbon residues, increase anti-corrosion and anti-rust properties, and protect certain metals [144.

\subsection{Material compatibility}

Methanol's polarity also leads to a well-known challenge concerning material compatibility, which requires modifications to engine fuel systems. Both metals as well as elastomers (soft components used for seals and fuel lines) can be attacked by methanol, if not chosen properly. This holds for all alcohols but with methanol being the most aggressive agent while higher order alcohols form less of an issue. However, even for methanol, work done in California and elsewhere has demonstrated that there are no technical hurdles to design compatible vehicles [145, 146, 52, 147. The material compatibility of alcohol fuels has been the subject of many reviews [148, 145, 146. Some basic considerations are summarized below.

Generally, light alcohols are more corrosive to both ferrous and non-ferrous metals than gasoline. The polarity of methanol and ethanol causes dry corrosion, but often this corrosion is reinforced by ionic impurities such as chloride ions in the fuel [146]. As alcohols are hygroscopic, dissolved or separated water molecules can trigger wet corrosion phenomena. When using hydrous methanol as a fuel, special attention should thus be paid to this. It has also been documented that a combination of three contaminants (chloride ion, acetic acid, and ethyl acetate) produces a synergistic effect in hydrous ethanol, and any resulting corrosion is many times greater than that by any single contaminant [149.

Methanol is electrically conductive. Corrosion behaviours that are dependent on conductive fluid behaviour, such as electrochemical and galvanic corrosion, can be enhanced by an increase of the alcohol fuel's electrical conductivity due to absorbed water and contaminants [146].

Alcohol fuels can be extremely aggressive toward magnesium, aluminium and copper. Steel and other ferrous metals are usually only slightly affected [52. It is interesting to note that the corrosion process is very sensitive to temperature, with most damage occurring during hot soak cycles [147. For components that are in frequent contact with the fuel, austenitic stainless steel is often used or other metals coated with a zinc or nickel alloy. Additives and properly formulated engine oils have also been found to reduce corrosive effects in low level blends [52.

Alcohol-rich fuels have been shown to cause shrinkage, swelling, hardening or softening of elastomers in the fuel system. This is especially true for high 
level methanol blends. For these applications, alcohol-compatible elastomer classes are used such as fluorocarbon elastomers or nitrile butadiene rubbers [147, 146]. The Methanol Institute provides technical bulletins on their website on the suitability of elastomers and metals for neat methanol use 29].

In the case of the ternary blends, or GEM blends, because methanol has a lower molar volume than ethanol, it is expected that the take up and swelling of elastomeric materials would increase for GEM blends containing higher levels of methanol [150. Turner et al. 63. evaluated the elastomeric material swelling properties of three different elastomers using different GEM blends and found that the blends containing higher levels of methanol indicated more severe swelling. Turner et al. stated that materials typical for M85 applications can be used with any GEM blend because none of the blends indicated more swelling than M85.

As a closing remark on material compatibility, it must be noted that alcohol refueling systems at the service stations must also be designed with care. Tanks, pumps, lines and spigots should be alcohol-compatible. The California Energy Commission has identified the design elements for methanol compatibility [52]. Fuel line compatibility in service station equipment was one of the few potential issues identified at the end of the Californian M85 trial [19.

\subsection{Cold start}

Cold starting of very high blend alcohols in gasoline has long been challenging. This is symptomatic of the fact that the light alcohols do not form an ignitable mixture at STP; indeed, this is a reason why they are inherently more safe than gasoline.

To successfully start a cold engine, there are two prerequisites. A combustible fuel-air mixture is required at spark timing and the combusted mixture needs to generate enough work to keep the engine running. For light alcohols these conditions are not always met for various reasons (see Table 33) [145, 23, 86]:

- Because of their lower energy density more mass needs to evaporate.

- The higher heat of vaporization means more energy is needed to evaporate the fuel.

- The lower flammability limit of methanol (and ethanol) is higher than for gasoline.

- Although the saturated vapour pressure of alcohols is slightly higher than for gasoline, their low stoichiometric AFR means a much higher vapour pressure is needed to obtain a stoichiometric mixture.

- Methanol and ethanol are single component fuels with a single, defined boiling point. Unlike gasoline they do not contain volatile components that can improve cold startability.

- The conductivity of light alcohols can cause short circuiting between the spark electrodes if not all fuel has evaporated. 
This is illustrated in Fig. 22, where isooctane is used as a surrogate for gasoline, and in this figure it can be seen that both of the alcohols are significantly leaner than the alkane; it is interesting that methanol is actually significantly closer to being ignitable than ethanol at $0^{\circ} \mathrm{C}$ (by about one 'lambda' unit).

Nakata et al., in a study of the cold startability of ethanol compared its performance to that of methanol and isooctane. There results reinforce the above observations: methanol starts much faster than ethanol (and in fact almost as quickly as gasoline); isooctane was easily the fastest starter [86. Related to all of the above is the fact that when $15 \%$ gasoline is added to methanol, its ignitability is lowered from being close to that of diesel to about halfway to that of gasoline 53. This reinforces the earlier observations of Ingamells and Lindquist who reported that "cold starting is not a problem with methanol/gasoline mixtures containing up to $40 \%$ methanol" 151.

Cold start nevertheless is a well-known issue with alcohol engines and many solutions have been developed over the years. These can be roughly divided as either focusing on the fuel or on the engine operation. Solutions focusing on the fuel include the use of additives such as highly volatile gasoline, butane or pentane, dissociation of methanol to hydrogen and $\mathrm{CO}$ or conversion of methanol to dimethylether. The latter two solutions require additional fuel conversion systems and energy (see Section 6).

More recent solutions tend to focus on the engine operation, minimizing the need for additional systems. Various components can be optimized for cold startability:

- engine block: The engine block and intake can be electrically heated to reduce cold start problems [152, 18].

- injector: Fuel temperature has been shown to be a decisive factor in the vapour formation of alcohols [153, so heating the fuel rail or individual injectors is often applied to improve startability. Compared to fuel temperature, the air temperature is only of secondary importance [154, 155]. Injection duration can be increased in order to obtain a rich, combustible mixture, but this will also worsen $\mathrm{CO}$ and $\mathrm{HC}$ emissions [153. Additionally, elevating the injection pressure can improve atomization and vaporization of the spray. Fuel puddling on the intake or cylinder structure can be minimized by injecting the mixture during the intake stroke.

- valves: Some authors have investigated the effect of valve timing on cold startability and found that both intake and exhaust timings can be optimized to this end [86, 155. For example, a retarded intake valve opening will lead to more underpressure in the cylinder, increasing the velocity at which air is aspirated, which aids evaporation. This effect can be augmented by reducing the maximum valve lift or deactivating one intake valve.

- cranking rpm: Brusstar et al. found that increasing the cranking rpm improves startability through a higher effective compression ratio and air 
velocity [156. Conversely Colpin et al. [155] and Aikawa et al. [157] found no significant improvement and stated that the cranking rpm of 1500 used by Brusstar et al. is not realistic.

- ignition: Ignition timing can be adapted during cold start. The use of multiple sparks can sometimes be beneficial. Some authors have proposed special plasma jet forming spark plugs to improve startability, but this has never been implemented [158.

- direct injection: Stratification and late injection are very effective strategies to improve cold start performance. Siewart and Groff reported successful cold starts at temperatures below $-29^{\circ} \mathrm{C}$ for methanol and other fuels [159]. More recently, Marriot et al. [160] confirmed that these injection strategies solve the cold start issue.

Finally, note that dedicated methanol engines would have an increased compression ratio which would at least partly alleviate the cold start issue.

\subsection{Ignition and fueling systems}

The lower volumetric energy content of methanol, and by extension blends containing a substantial methanol fraction, requires fuel pumps and injectors with an increased flow capacity, otherwise peak power cannot be maintained. Obviously, material compatibility issues also hold for pump and injector internals (see Section 3.2).

Concerning spark plugs, light alcohols and methanol in particular have been shown to be more easily pre-ignited by hot spots in the combustion chamber, relative to gasoline. The low minimum ignition energy (see Table 3 and the thinner flame thickness arising from the faster LBV [161, makes methanol susceptible to pre-ignition. As methanol produces non-sooting flames, the ignition source is usually an overheated spark plug electrode, and not some combustion deposit. Typical electrode temperatures are between 700 and $925{ }^{\circ} \mathrm{C}$, which is acceptable for gasoline, but not so for alcohols. A classical solution consists of reducing this temperature by choosing a lower heat grade spark plug [152.

Other factors are important as well. Suga et al. assessed the pre-ignition tendency in an M85 engine using different spark plugs of identical heating range 162. They found that a configuration using platinum-tipped electrodes was highly susceptible to pre-ignition and hypothesized that noble metals can catalyze a reaction in which methanol dissociates through formaldehyde to $\mathrm{CO}$ and $\mathrm{H}_{2}$ which then autoignites (see also Section 6). The high pre-ignition tendency with spark plugs using noble metals was confirmed by Pearson et al. 23] and Bergström et al. [18. These authors further reduced the electrode temperatures by using copper-cored electrodes, which do not cause autocatalysis, effectively eliminating pre-ignition risks for most conditions.

\subsection{Engine cylinder head and peripherals}

The greatly increased evaporation cooling when fueling methanol in the intake ports can lead to very cold temperatures in the intake. This leads to 
increased thermomechanical stress in the head and countermeasures may be required 18 .

Standard valves and valve seat inserts suffer from increased recession during alcohol operation. This occurs because alcohols are non-lubricating and their combustion produces less 'lubricating' soot. Additionally they experience higher contact forces due to increased combustion pressures and thermal shocks due to significant cooling of the inlet valve by fuel evaporation [18. Solutions usually comprise of increasing the hardness and chrome content of the materials [163, 164.

Because of the increased knock resistance of methanol, ignition retard is usually not needed to alleviate knock at maximum power, and this can lead to significantly increased peak cylinder pressures. Ignition retard might then be necessary, not for knock suppression but to keep engine operation within the allowable peak pressure range. If one wants to take advantage of the higher knock resistance of methanol, the higher peak pressures as well as the thermal stresses due to significant evaporation cooling call for adjustments to the base engine's structure and cylinder head. The resulting lower exhaust temperatures make application of variable geometry turbines more easy [156].

Similarly, should one develop a dedicated methanol engine, variable valve timing systems should be revisited since due to methanol's higher dilution tolerance it might be beneficial to have a wider timing window to take advantage of increased internal EGR rates.

\subsection{Vehicle adaptations}

As discussed in Section 2.2, increased aldehyde emissions may arise from methanol operation. Combined with the cold start challenge discussed earlier, specific catalyst formulations may be necessary. To reduce catalyst light-off times, closed-coupled catalysts or electrically heated catalysts have sometimes been used 152. Unfortunately, the literature on catalysts for methanol vehicles is limited and dates back to the 1990s. Some performance figures were published, but actual catalyst formulations were not disclosed. For example, EPA tested 2 catalysts provided by manufacturers and found up to $95 \%$ reduction of formaldehyde emissions over the FTP cycle [165]. Clearly, given the enormous change in emission legislation over the past 25 years, this is an area that needs investigation.

Obviously, to counteract the reduced volumetric energy density, a larger fuel tank is needed if the driving range is to be preserved. As a simple example, assuming identical overall efficiency, a vehicle equipped as standard with a 60 liter gasoline tank would need to be able to store an additional 60 liter of methanol (methanol having half the volumetric energy density as gasoline, see Table 2). This translates to an additional $47 \mathrm{~kg}$ of vehicle mass when fully fuelled. This would be the most extreme case - when using blends instead of pure methanol the required additional volume would be lower, with the exact value depending on the blend level. Concerning evaporative emissions, a carbon 
canister of similar size as for gasoline vehicles has been found to be sufficient ${ }^{8}$

\section{Spark ignition engine experiments}

Here, we discuss how methanol's properties translate to SI engine power output, efficiency and emissions. Note that low level blends, falling within gasoline specifications, are not discussed. Again, it is worth pointing out that caution is needed when consulting results from work using splash blends, i.e. where gasoline and methanol have been mixed by the authors. This usually uses pump gasoline not tailored to the introduction of methanol in the fuel blend, resulting in increased volatility (see Section 2.8.2) and possibly issues with evaporative emissions.

Results obtained using ternary (or GEM) blends are discussed in Section 4.2 methanol-water blends in Section 4.3. Section 4.4 treats work where methanol, or a methanol-water blend, is used as a second fuel to suppress high load knock.

\subsection{Mid to high level blends and pure methanol}

The potential for increased engine performance and efficiency has been extensively validated experimentally [145, 23]. Published work indicates that the level of improvement compared to gasoline operation mainly depends on whether the methanol is used in a dedicated or a flex-fuel engine. To illustrate this, some relevant experimental work on neat methanol and high level methanol blends is discussed below.

\subsubsection{Dedicated methanol engines}

Obviously, the best results are obtained in dedicated methanol engines. Even the first generation of M85 engines featured considerable advances in power and efficiency, mainly thanks to the increased knock resistance of methanol. This resistance enabled them to reach MBT spark timing (Minimum spark advance for Best Torque) over a wide range of operation points and allowed the compression ratio to be raised to 12:1 and above. For example, the 1981 M85 Ford Escort produced $20 \%$ more power while being $15 \%$ more efficient relative to its gasoline equivalent 20]. Clemente et al. reported similar figures for a more recent dedicated ethanol engine designed for the Brazilian market [166].

Recent work on modern alcohol engines has demonstrated further potential for increasing efficiency and performance. Nakata et al. used E100 in a high compression ratio (13:1) naturally aspirated port-fuel injected SI engine [86. They were able to run MBT timing and found that engine torque increased by $20 \%$ compared with operation on 92 RON gasoline. The full-load brake thermal efficiency at $2800 \mathrm{rpm}$ was $39.6 \%$ and $31.7 \%$ on E100 and gasoline respectively. Even in operating points that were not knock limited, efficiency improvements of over $3 \%$ pt were possible due to the benefits of faster flame speed and lower heat losses using ethanol. This is supported by work by Marriott et al. [160].

\footnotetext{
${ }^{8}$ Private communication with the Methanol Institute
} 
Apart from the benefits induced by knock resistance, the elevated burning velocity and wider flammability limits of light alcohols open up some alternative options for load control, especially for methanol [148, 167. Pannone et al. 168] have published results from an experimental turbocharged lean-burn methanol engine. The reported BTEs were up to $14 \%$ better relative to stoichiometrically fuelled engines with throttled load control. The tailpipe $\mathrm{NO}_{\mathrm{x}}$ penalty of the lean burn strategy reached up to $150 \%$, making the practical use of such a strategy questionable without advanced aftertreatment such as a lean- $\mathrm{NO}_{\mathrm{x}}$ trap. Similarly, while Li et al. 169 report indicated efficiencies of over $50 \%$ on a heavy duty directly injected SI engine using a compression ratio of 16:1 and stratification, they do not discuss implications for emissions and aftertreatment, and fail to mention the overall equivalence ratio.

More interesting is to exploit the wider dilution limits of alcohols in a strategy using stoichiometric fueling and EGR to control the load, thus reducing throttling losses and enabling the use of a three-way catalyst for aftertreatment. Brusstar et al. demonstrated this using a 1.9 liter turbocharged diesel engine with a CR of 19.5:1 that was converted for SI operation on methanol [156]. The high compression ratio enabled peak brake thermal efficiencies higher than the baseline diesel engine (40\%) for operation on methanol (42\%). Similar peak BTEs were obtained earlier by Koenig et al. on a dedicated methanol engine with a compression ratio of 12:1 170. Elevated levels of cooled EGR (up to $50 \%$ ) were used to reduce knock and pre-ignition concerns and spread the high efficiency regions to part-load operating points. Throttleless operation was possible down to a BMEP of 6 bar. Similar work by Brusstar and Gray on a converted 4.5L V6 diesel engine established throttle-less operation down to 4 bar BMEP on pure methanol [171].

The work of Brusstar et al. was repeated by Ghent University researchers on an identical VW TDI diesel engine with a compression ratio of 19.5:1 [172]. This engine was converted to methanol operation by adding spark plugs, port fuel injection and a cooled EGR loop. Two operating strategies with stoichiometric combustion of methanol were compared on the engine: normally aspirated throttled operation and turbocharged WOT operation with EGR. Measurements were done at loads between 3.31 and 11.60 bar BMEP. In much of the high load points, the spark timing had to be retarded using the throttled operating strategy due to knock. For the WOT EGR strategy this was not the case thanks to the cooling effect of EGR and throttleless operation was possible down to 3.3 bar BMEP thanks to the high burning rate of methanol without unacceptable cycle-to-cycle variations (which the authors defined as $\mathrm{CoV}<10 \%$, which is a rather high limit). This corresponded to an EGR tolerance of nearly $50 \%$ EGR by mass.

Figure 23 compares the BTE obtained using the throttled stoichiometric strategy (left) to that obtained using the turbocharged WOT EGR strategy (right). Both peak brake thermal efficiency and part load efficiencies can be seen to be considerably higher when using the WOT EGR strategy. The same value for peak BTE (42\%) when employing the WOT EGR strategy on a similar engine was reported by Brusstar et al., as mentioned above. These results demonstrate 
that methanol can be used in dedicated engines with diesel-like efficiencies while still operating stoichiometrically. As a result, diesel-like efficiencies while still using cheap aftertreatment (TWC) are possible.

The results on the converted VW TDI engine were also used to determine to what extent these operating conditions stand over an entire drive cycle [173]. The analysis was done using Lotus Vehicle Simulation [174 and was based on the steady state experimental results described above. Compared to stoichiometric throttled control, the WOT EGR strategy reduced $\mathrm{CO}_{2}$ emissions by 23 $\mathrm{g} / \mathrm{km}$ on the NEDC (corresponding to $18 \%$ ) and $43 \mathrm{~g} / \mathrm{mi}$ on the FTP75 cycle (corresponding to $20 \%$ ). The $\mathrm{CO}_{2}$ reduction was entirely due to efficiency improvements enabled by the WOT/EGR strategy (see Figure 2.29), that could be applied even at low loads, so its advantages are noticeable throughout the driving cycles.

\subsubsection{Flexible fuel vehicles}

In the first generation of FFVs (1990s) the knock resistance of alcohols could not be exploited as the compression ratio had to be low enough to ensure reliable operation on gasoline. Still, these vehicles attained about $5 \%$ more power and efficiency in alcohol mode thanks to increased volumetric efficiency, lower flow losses and more isochoric combustion [145. Experiments in the 1970s for neat methanol showed improvements of around $8 \%$ and $12 \%$ in brake thermal efficiency and power respectively, for an engine with a compression ratio of 8.2:1 [170].

In more recent flex-fuel engines a combination of pressure charging and active knock control (by aggressive spark retarding) enable the exploitation of the anti-knock properties of light alcohols without sacrificing the ability to run on gasoline. However, only few experimental engine data of flex-fuel engines running on methanol have been published. Vancoillie et al. [175] converted two gasoline engines to operation on alcohol fuels: a port fuel injected 4 cylinder $1.8 \mathrm{~L}$ production engine and a port fuel injected single cylinder research engine. A comparison of methanol against gasoline on these two flexible-fuel engines confirmed the potential for relative power and efficiency benefits up to $10 \%$. Engine-out $\mathrm{CO}_{2}$ and $\mathrm{NO}_{\mathrm{X}}$ levels dropped by $10 \%$ and $5-10 \mathrm{~g} / \mathrm{kWh}$ respectively, while the other harmful emissions did not change significantly.

Sileghem et al. 176 have presented measurements on a direct injected 4cylinder Hyundai 2.4L engine fueled with pure methanol, ethanol, gasoline and butanol. For the non-knock-limited operating points, methanol had better efficiency compared to the other fuels but the biggest differences were seen for the knock-limited operating points. For methanol, there was an improvement of 2.7 percentage points on average at 2.66 and 4 bar BMEP compared to gasoline, which were non-knock-limited operating points. For the knock-limited case at $150 \mathrm{Nm}$ and $1500 \mathrm{rpm}$ ( 8 bar BMEP) this difference increased to 5.6 percentage points with the brake thermal efficiency on methanol reaching almost $40 \%$ which resulted in a decrease in $\mathrm{CO}_{2}$ emissions of $20.7 \%$ compared to gasoline.

Recently, Nguyen et al. [177] have published a comparison between gasoline and pure methanol used in a Volvo T3 engine. This is a four cylinder, tur- 
bocharged DISI engine. Next to a comparison of the efficiency and emissions on gasoline and methanol, the maximum output of the engine on gasoline and methanol was explored following a design of experiments approach with two control parameters: valve timing and intake boost pressure. With this approach, the maximum BMEP that could be reached on gasoline was 16.3 bar. The ignition timing at this output had to be retarded on gasoline operation due to knock occurrence. For methanol operation however, optimal ignition timing could be used at every operating point. This resulted in a brake thermal efficiency of $30.1 \%$ and $37.9 \%$ on gasoline and methanol respectively, for this output. On methanol, using higher boost pressure, the output could be increased to over 20 bar BMEP without having knock limitation issues. However, at these operation points, the maximum allowed (because of mechanical strength limitations) incylinder pressure of 100 bar was exceeded. Nguyen et al. [177] estimated that, if the maximum in-cylinder pressure is limited to $100 \mathrm{bar}$, the maximum output would be 18.2 bar BMEP on methanol and that the additional downsizing potential of methanol was $10.7 \%$ compared to gasoline.

Whereas advantages in power density and efficiency are clear with the use of methanol, results concerning emissions are confusing. Wei et al. 87] ran a small gasoline engine on gasoline, and various methanol blends (splash blended). They noted that engine-out emissions of unburned methanol primarily were a function of exhaust temperature, with no such emissions when exhaust temperatures were high. Tailpipe emissions of unburned methanol were negligible when the three way catalyst was operating at a minimum temperature of $270{ }^{\circ} \mathrm{C}$. Their study also showed formaldehyde emissions to actually be higher on gasoline in some operating points, and at high speeds the three way catalyst seemed to produce formaldehyde. The latter is behaviour that was reported by Johnson Matthey in the 1990s to potentially occur, caused by the partial oxidation of unburned methanol in the catalyst [178.

Concerning particle number $(\mathrm{PN})$ concentrations, very limited data is available, that seems to suggest PN emissions to first decrease for low level blends and then increase for mid level blends, to levels higher than gasoline [179, 57. Different hypotheses are offered to explain this (increased oil dilution by the fuel, for the PFI engine in [179]; flash boiling and consequently poor mixture preparation, for the DI engine in [57]) but clearly this needs more investigation. Piston wetting due to longer injection durations might also be a contributing factor for the higher level blends [180. $\mathrm{NO}_{\mathrm{X}}$ emissions have been reported to decrease 172 or increase [181. In the latter case, this was for mid-level blends, used in a gasoline vehicle without recalibration. Given the higher burning velocity of methanol (see Section 2), the ignition timing (optimized for gasoline) would probably have been too advanced, resulting in higher temperatures and thus increased $\mathrm{NO}_{\mathrm{X}}$ emissions. Also, given the decreased energy content of the mid-level blend it is unlikely that the engine control unit could keep the equivalence ratio at stoichiometry, affecting both engine-out emissions and aftertreatment efficiency. Other work also reported an increase in $\mathrm{NO}_{\mathrm{X}}$ even for a low level blend [143], however, a splash blend was used in a gasoline engine without any recalibration. 


\subsection{GEM blends}

The hypothesis that iso-stoichiometric ternary blends of methanol, ethanol and gasoline can be used as drop-in fuels for spark-ignited flex-fuel engines has also been investigated on engine test benches. Sileghem et al. 97, 176] evaluated the performance of different GEM blends on a naturally aspirated $1.8 \mathrm{~L}$ engine with port fuel injection and a direct injected $2.4 \mathrm{~L}$ engine. On the $1.8 \mathrm{~L}$ engine, four different GEM blends were investigated: two ternary blends and two binary blends, E85 and the iso-stoichiometric methanol-gasoline blend. The hypothesis that all iso-stoichiometric blends have similar brake thermal efficiency was confirmed as all values fell within the experimental uncertainty.

On the DI engine only the two iso-stoichiometric binary blends, E85 and M56, have been studied by Sileghem et al. as it was expected that the results of the ternary iso-stoichiometric blends would fall in between the results of these two binary blends. After performing measurements on E85, all parameters regarding injection (start of injection and injection pressure) and ignition were kept the same for the measurements on M56. The ECU data was used to investigate if there could be a significant difference between these two blends with very similar fuel properties. At the low load cases, 2.66 and 4 bar BMEP, only for one operating point (engine speed variation), the difference in injection duration between E85 and M56 was larger than 1\%. For the medium load case, 8 bar BMEP, the differences were larger but still only $2.7 \%$ at maximum which would cause no issues for the ECU.

\subsection{Methanol-water blends}

As mentioned in Section 1.3 , it can be economically attractive if the methanol fuel can be allowed to contain water. Engine tests have therefore been reported using methanol-water blends.

Clearly an important consideration with such mixtures in combustion systems is the implications for ignition robustness and extinction of the flame, although Most and Longwell [124] did successfully operate their engine on mixtures up to $30 \%$ water, reporting that for any given operable equivalence ratio, an increase in water content reduced $\mathrm{NO}_{\mathrm{X}}$ emissions at a constant $\mathrm{CR}$ and spark advance of $12: 1$ and $14^{\circ} \mathrm{btdc}$ respectively. They also show that under the same conditions the addition of water generally increased specific energy consumption (i.e. decreased brake thermal efficiency BTE), while still being better than isooctane up to $20 \%$ water in methanol; however in a test with pure methanol increased CR showed a large improvement in BTE. Thus there appears to be some further potential in BTE for methanol-water mixtures with higher CR.

Sileghem et al. 182 measured the effects of water content in methanol, on a PFI engine. They tested blends with up to $10 \mathrm{vol} \%$ of water and compared them to operation on neat methanol as well as on gasoline, for low to medium engine speeds and loads. The water-containing blends showed essentially the same BTE as the pure methanol operation, which itself resulted in a 1 to 2 percentage points increase in BTE compared to gasoline operation. The main reasons for this improvement are the higher burning velocity of methanol and 
the lower cooling losses due to the high heat of vaporization and high heat capacity of methanol and water.

They also found $\mathrm{NO}_{\mathrm{X}}$ emissions to be lowered for the methanol-water blends compared to neat methanol operation, concurrent with the expected decreases in in-cylinder temperatures and adiabatic flame temperature (and offsetting the expected increase in combustion duration, prolonging the time available for $\mathrm{NO}_{\mathrm{X}}$ formation).

\subsection{Octane on demand}

A significant new avenue for light alcohols in combustion systems is that of 'octane on demand' (OOD), the concept of which is to use a relatively low-octane fuel by itself for much of the operating map, and to introduce a second fuel as an octane booster at higher loads, providing the necessary knock suppression to a tailored degree only when it is required. In its recent incarnation the concept was first conceived by Ethanol Boosting Systems (EBS) who originally suggested PFI of low-octane gasoline with direct injection of ethanol, seeking not only to utilize the high $\mathrm{ON}$ of ethanol but also its high latent heat in order to extend the knock limit [183, 184. In reality there are some synergies between this and with what was termed 'anti-detonant injection' (ADI) in piston aircraft engines, where typically a 50:50 water:methanol mixture was introduced while operating at high boost pressures at low altitudes to provide knock suppression while generating maximum power, for instance at take-off [185].

There may be benefits in terms of mixing water with an alcohol as an octane enhancer/knock suppressor. This clearly combines aspects of OOD and water injection and brings the concept back to the original use of ADI on piston aircraft engines. Making use of infinite miscibility of the two fluids, Berni et al. have performed calculations using $25 \%, 50 \%$ and $75 \%$ by mass methanol-water mixtures in a PFI delivery system in a turbocharged V8 engine, employing gasoline in the DI system [186. Here there are similarities with the work of Morganti and co-workers [10, 11]. Berni et al. reported that the methanol makes the ADI mixture evaporate faster and show the best results with $25 \%$ methanol in their full-load investigation. Gasoline consumption is significantly reduced by $17-19 \%$. This concept may also have synergies with water injection, recently discussed by Böhm et al. as a knock suppressant [187, insofar as, in addition to potentially making water evaporate faster, the methanol can also suppress freezing of the water in a vehicle-mounted storage tank, a problem highlighted in related work by Böhm et al. [188. This concept is being studied at the moment by other workers, and to illustrate the potential of this approach Fig. 10 showed the effect on the freezing point of the resulting binary mixtures of adding methanol or ethanol to water.

The use of a pure alcohol as an octane booster for automotive use was investigated early on by Porter in a dual-fuel carburetted engine [17. Both ethanol and methanol were investigated as octane boosters, and a vacuum switchover system was used in the carburetter. In comparison tests with isooctane for the octane booster methanol was found to give slightly higher power, which he believed was due to an improvement in volumetric efficiency (the same spark advance 
apparently being used for both tests). This result was despite an enleanment being forced at high loads when using methanol because of inadequate flow rates in the carburetter. Bromberg and Cohn compared the use of ethanol as a knock suppressant to methanol using direct injection and found that methanol has a much greater effect in terms of the fraction of fuel energy supplied which would translate to a lower volumetric usage [189]. They also suggested that when the high ONs of the alcohols were combined with their high latent heats, their effective ONs rose significantly in OOD applications; they reported ethanol having a calculated equivalent $\mathrm{ON}$ of 160 , and methanol 180. In recent work, Cohn and Bromberg have investigated the potential of a dual PFI (gasoline/alcohol) system as an alternative to a HD diesel engine [190].

Whitaker et al. reported tests performed in an OOD engine using the EBS approach with direct-injected E85 as the knock suppressant, and showed that for a given volume of available E85, proportionally more gasoline can be displaced with the approach than if an engine were to be globally fuelled on E85 (i.e. monovalent operation on the alcohol fuel) 191]. Their results showed that over 1000 miles of the US Metro-Highway Cycle, an EBS V8 engine would displace 5.2 times as much gasoline as the E85 used. Conversely, if operation on E85 alone were compared with gasoline, the relative consumptions would be aligned with the volumetric energy contents of the fuels (i.e. $42 \%$ more E85 would be used than gasoline). Thus, given that nowhere near sufficient ethanol can be manufactured to supply E85 for all vehicles, the OOD approach would have a better gasoline displacement effect.

More recently, significant further experimental research into the OOD concept has been conducted using pure alcohols as knock suppressants. Daniel and co-workers presented results which show that per unit of energy supplied, methanol was a slightly better knock suppressant than ethanol, with significantly less volume requirement [15]; this supports the work of Bromberg and Cohn [184]. In their work, the alcohol was supplied via a DI fuel system and gasoline via a PFI system. They showed better emissions for the OOD approach, too. In a study intended to show that OOD can facilitate the use of less refined, lower-octane fuels to the benefit of overall system $\mathrm{CO}_{2}$ emissions, Morganti et al. have presented significant studies using methanol as an octane enhancer [10, 11]. In a significant departure to other work they utilized the pure hydrocarbon fuels in their DI system and methanol in a PFI system, reasoning that since the hydrocarbon is used all of the time, whatever benefit can be accrued from its latent heat and DI injection timing should be made available to the combustion system continuously. They showed major improvements in efficiency, both for the engine and the overall fuel and engine system, although there was a significant interaction with the overall RON of the 'main' fuel. The use of less-refined fuels (they tested two forms of naphtha and a gasoline blendstock) led to an improvement of the hydrocarbon hydrogen-carbon ratio in that part of the energy delivery, which with the benefits of the methanol as well, led to marked reductions in $\mathrm{CO}_{2}$ emissions across the operating map. They also show improvements in emissions are possible.

In related work, Bourhis et al. have begun a programme to create a vehicle 
demonstrator using ethanol as the octane enhancer. To date they have used monovalent DI fuelling but with various volumetric blends of hydrocarbons and octane boosters to establish an octane requirement map. The octane boosters described in [12] were ethanol, a proprietary blend of butanol and other components, and a reformate stream. Of these, ethanol was found to be the best. In later work, by fitting a PFI rail to a production DI engine they showed that "As a general rule, it can be seen that the lower octane booster consumption is obtained at low loads with the base-fuel in GDI mode whereas it is the opposite at higher loads (octane booster in GDI mode). This is consistent with the better anti-knock properties conferred by GDI versus PFI, mainly due to the evaporative cooling effect" 13 .

In a comprehensive study of the octane on demand concept using low-octane naphtha as the base fuel, Chang and co-workers [192] investigated the use of methanol, MTBE, and ETBE as the octane booster component, and found that of these methanol was the best choice. This was considered to be due in part to its very high latent heat. In related work using methanol as the octane booster, Viollet and co-workers [193] studied whether it was better to introduce it via the DI system of an engine and the naphtha via PFI or vice-versa; they determined that the optimum was to inject it through DI using relatively late injection, suggesting that some stratification of the resulting charge would cause a faster overall charge burn rate to assist in suppressing knock. Chang and co-workers also studied the well-to-wheels fossil carbon intensity of the approach, determining that the result depended on the source used to make the octane booster, but as long as coal was avoided as the feedstock to synthesize it methanol was the best choice [192.

Thus from the experimental work carried out one can conclude that the alcohols make excellent octane boosters for OOD concepts, and generally one sees that methanol is marginally more effective than ethanol [194. There is scope to use a cheaper or more-simply refined hydrocarbon stream for the main fuel, but clearly this would be a problem in any transitional phase as the technology was introduced. Instead, using existing standard but relatively low-octane gasoline fuels for the base fuel with methanol being supplied as and when needed in an engine more optimized for efficiency would seem to be a pragmatic step (for example via increased compression ratio, increased downsizing etc.). Generally the implication is that for base fuels with higher octane then DI of methanol would appear beneficial; whereas for lower octane main fuels, introduction of the methanol at the PFI position would appear to be acceptable, but there are unknowns in terms of which is the best position to introduce the octane booster insofar as an engine employing PFI systems for both base fuel and octane booster may enable the deletion of the DI system with minimal effect on engine efficiency. This has obvious economic implications, and may enable easiest compliance with future PM legislation. It is considered that work in this area would be beneficial. Returning to the alcohol/water injection concept, the above observations made with respect to the potential to simplify an engine to two PFI systems (i.e. by eliminating a DI one) also apply.

While the discussion above focused on efficiency benefits, there can also be 
changes concerning emissions. The OOD approach allows more-optimized spark timing in a combustion system that is knock-limited on gasoline, so while $\mathrm{CO}$ and $\mathrm{HC}$ will not change too much one can expect $\mathrm{NO}_{\mathrm{X}}$ to increase. However, as it is a lambda $=1$ technology, there is no reason why existing aftertreatment would not be able to deal with that. Concerning particle emissions, results from testing on an engine employing both a PFI and a DI system, running one fueling system on gasoline and the other on methanol or ethanol, showed up to $95 \%$ reduction in PN emissions, with the highest reductions obtained when the alcohol was introduced using the DI system [195] (which also gave the highest efficiency benefits).

As a final note, although there are clear benefits to the OOD concept, obviously there is a challenge in terms of customer acceptance of a two-tank solution. Cohn and Bromberg focus on heavy duty and suggest this should not be too different from the current use of a ureum solution for $\mathrm{NO}_{\mathrm{X}}$ aftertreatment [190. There have also been demonstrations with on-board separation of gasoline-alcohol blends in a low octane main fuel and a high octane secondary fuel, that would enable a single fuel tank [196].

\section{Using methanol in compression ignition engines}

As evident from the octane numbers stated in Section 2, methanol is most easily used as a spark ignition engine fuel. The markets for spark ignition engines are primarily automotive, motorcycles and leisure, i.e. smaller engines. Most commercial applications use compression ignition (CI) engines. Consequently, there is a strong interest in finding ways to use methanol for CI engines. However, the high octane numbers indicate very low cetane numbers $(\mathrm{CN})$. For methanol the number is so low that it cannot be measured directly. Extrapolation of test data using additives gives a $\mathrm{CN}$ of 3 for pure methanol and a $\mathrm{CN}$ of 2 for methanol with $10 \%$ water 148 . The next section discusses various concepts enabling the use of methanol in CI engines, after which Section 5.2 discusses reported measurements using some of these concepts, and Section 5.3 explains the current interest in the marine sector and presents ongoing demonstrations.

\subsection{CI concepts}

Since CN is a measure of a fuel's auto-ignitibility pure methanol is unsuitable for use in conventional compression-ignition engines. However, it can be used in conjunction with another fuel which is more auto-ignitable, or with an 'ignition improver'. In the 1980s the Detroit Diesel Company (DDC) and MAN 197. produced modified versions of their compression-ignition engines which ran on 'ignition improved' methanol fuel (the ignition improver constituted about $5 \%$ by volume of the fuel). The MAN engine was a four-stroke engine using spark-assisted ignition whilst the DDC engines operated on the two-stroke cycle, controlling the scavenge ratio to assist ignition [198, 199]. These engines ran in service in heavy-duty automotive applications 200. More recently, VTT has tested so-called MD95, a mix of $95 \%$ methanol and $5 \%$ ignition improver 
2. This was done using a Scania ED95 engine, which is an engine modified to enable compression ignition operation on a mix of $95 \%$ ethanol and $5 \%$ ignition improver through the adoption of an increased compression ratio (28:1, to increase end-of-compression temperature for easier ignition of the low cetane fuel), and a suitable fuel injection system.

Most concepts however involve a high cetane number fuel (mostly diesel) to ensure (auto-)ignition. One option is to use a methanol-diesel mixture, injected instead of pure diesel. This has the advantage that only one injector is needed and the engine conversion is relatively straightforward. However, this requires emulsifier agents or co-solvents and even then the methanol fraction is limited because diesel and alcohols do not mix well. Additionally, higher methanol fractions reduce the resulting fuel's volumetric energy content which means the rated power could potentially be hard to maintain using the standard injectors. Finally, methanol's low lubricity compared to diesel might necessitate lubricating additives. The 'dual fuel' approach is more common, where methanol and diesel are introduced into the engine separately.

Again, several options are possible. Methanol can be injected directly in the combustion chambers, similar to the diesel injection. The diesel injection then serves as a pilot fuel for igniting the methanol. The advantage is that when the methanol injection is timed such that premixing with the compressed air is limited, knock (through autoignition of end gas) is not a concern. The downside is that this approach requires either custom cylinder heads, with separate DI methanol injectors, or custom injectors that are able to introduce both methanol and diesel to the cylinders. This concept is a commercial reality today, used by MAN for low-speed two-stroke engines and Wärtsilä for medium-speed four-stroke engines, as discussed further in Section 5.3 . In the case of the Wärtsilä medium-speed engine, injectors are used with a central diesel nozzle and 3 methanol nozzles equally positioned around the diesel nozzle, within the same injector body. Methanol is injected at 600 bar 201]. The MAN two-stroke engine uses separate injectors for diesel and methanol, adding 2 methanol injectors that inject methanol at around 500 bar 202. In both engines, a separate hydraulic oil circuit is used to actuate the methanol injectors and high pressure methanol pumps are needed, which are expensive due to methanol's low lubricity and high corrosivity.

An easier solution, particularly when looking at retrofit options (more easily introduced to the market, and a particular focus for e.g. marine engines which typically have very long lifetimes), is introducing methanol into the engine's intake ports. This 'only' requires adding a low pressure methanol fueling system and port fuel injectors. Disadvantages are comparable to natural gas dual fuel conversions. First, the premixed methanol-air mixture that results from this can limit the attainable power output, due to end-gas auto-ignition. This requires either lowering the compression ratio, or limiting the methanol fraction used at higher loads. Second, the methanol fraction at lower loads will also be limited to maintain combustion stability, with the methanol-air mixture leaning out at lower loads and approaching flammability limits. Finally, the presence of fuel throughout the combustion chamber can cause problems with engine oil life 
(with methanol ending up in the crankcase through blow-by) and emissions of unburned fuel can be an issue, especially in the case of large valve overlaps (this is an advantage of methanol versus natural gas, as the methanol molecule has a significantly lower global warming potential than methane [30). Timing the methanol injection to start only after the exhaust valves have closed might compromise the evaporation and again increases the amount of methanol ending up in the lube oil. Reducing or eliminating the valve overlap means new camshafts and a derating of the nominal engine power output. Nevertheless, due to its simplicity engine conversions using this 'fumigation' concept have been reported most widely.

Another solution that has received little to no attention makes use of the relative ease of fuel reforming of methanol (see Section 6): glow plug ignition. This would enable a compression ignition engine to run solely on methanol, without the requirement of a pilot fuel to serve as the ignition source. Instead, a hot surface (the glow plug) triggers surface ignition of methanol relatively easily, which is thought to be due to the dissocation of methanol into carbon monoxide and hydrogen, with the latter easily pre-igniting [203. This is actually the working principle of model engines (although these run on a mixture, typically about $70 \%$ of methanol and up to $20 \%$ of oil as these are two-stroke crankcasescavenged engines, with various amounts of nitromethane to increase engine power output by oxygen availability).

Finally, very recently research engines have been run on methanol in homogeneous charge compression ignition (HCCI) mode and partially premixed combustion mode (PPC) [204, 205. Both concepts rely on delaying the autoignition until after the fuel injection event has been completed to allow for sufficient mixing time so that fuel-rich zones are reduced or eliminated, to decrease soot formation and speed up combustion for higher efficiency. The high heat of vaporization and the high autoignition temperature of methanol both lead to long ignition delays, making it quite easy to get a long mixing time before autoignition. This has been shown to result in the mixture being lean at autoignition, completely eliminating any possibility for soot formation (see Section 2.2. . Unfortunately, the long ignition delays and essentially fully premixed autoignition limit the operating range due to excessive peak pressure rise rates at high loads. In research engines, this challenge is currently alleviated by preheating of the intake air. A production engine would probably require extensive engine modifications. Nevertheless, initial results are promising, as detailed in the next section.

\subsection{CI engine results}

\subsubsection{Fumigation}

Coulier and Verhelst reviewed the literature reporting results on diesel engines (both automotive and heavy duty size) converted to dual fuel operation with methanol introduced in the engine intake [206. For dual fuel engines, the maximum substitution ratio is very important, i.e. the amount of diesel fuel that can be replaced by methanol. This ratio (or the methanol energy fraction) 
was found to differ significantly between different engines, from as low as $70 \%$ 207. to as high as $85 \%$ 208. This is likely due to differences in compression ratio, turbocharging pressures etc., affecting end-gas temperature history and thus knock occurrence.

Concerning brake thermal efficiency, they concluded that using the fumigation method a drop in efficiency sometimes occurs across the load range which gets more pronounced as the substitution ratio is increased. In most cases however, a slight decrease in efficiency is observed at low loads and a slight increase at high loads. In general, the lower efficiency at low loads could be attributed to a lower combustion efficiency: the premixed methanol-air mixture can approach the flammability limits leading to higher emissions of unburned fuel (wide open throttle operation with load controlled by the air/fuel ratio). At higher loads, the faster and cooler combustion of methanol (closer to the thermodynamically ideal isochoric combustion, and with lower heat losses) enables higher efficiency compared to the slower diffusion combustion on diesel.

In most cases the conversion of the base diesel engine to dual fuel operation with methanol is targeted at decreasing the two main pollutants of concern for diesel engines: $\mathrm{NO}_{\mathrm{X}}$ and PM. Reviewing the reported results, Coulier and Verhelst concluded that dual fuel operation indeed leads to a general drop in $\mathrm{NO}_{\mathrm{X}}$ emissions across the load and speed range, ranging from a 6\% 209] reduction to over $50 \%$ 210] depending on load and achievable methanol fraction. This reduction gets more pronounced as the substitution ratio is increased. The main reason for this is the cooling effect of the methanol that is injected in the intake of the engine. It provides lower in-cylinder temperatures, greatly reducing thermal NO formation. The faster premixed combustion of methanol also shortens the combustion duration limiting the duration of high in-cylinder temperatures. This means there is less time for NO to be formed.

Noteworthy however, is the much increased ratio of $\mathrm{NO}_{2}$ to $\mathrm{NO}$ emissions with methanol. This is thought to be due to the formation of the $\mathrm{HO}_{2}$ radical during methanol combustion, which reacts with $\mathrm{NO}$ to $\mathrm{NO}_{2}$ through $\mathrm{NO}+$ $\mathrm{HO}_{2} \rightarrow \mathrm{NO}_{2}+\mathrm{OH}$. The $\mathrm{NO}_{2}$ to $\mathrm{NO}$ ratio has been found to increase sixfold for some cases, compared to diesel operation 209]. However, the ratio was found to significantly decrease when using a diesel oxidation catalyst [211]. This counterintuitive result was explained by the reaction of $\mathrm{NO}_{2}$ with $\mathrm{HC}$ and $\mathrm{CO}$ back to NO.

Soot emissions are also suppressed in dual fuel operation. This is because part of the diesel consumption is replaced by methanol which contains no aromatics, has no carbon-carbon bonds, and is oxygenated. Methanol is also a simple molecule with a low molecular weight. In addition, the methanol is premixed with air so there is a very low tendency to form locally rich zones. Moreover, because of the high heat of vaporization of methanol, the ignition delay is usually increased giving the diesel more time to evaporate and mix with air. Consequently, fewer locally rich zones of diesel are formed (less diffusion burning), lowering soot emissions by up to $80 \%$ 210]. The $\mathrm{OH}$ radicals that are formed during the oxidation of methanol also aid in oxidizing soot precursors. Yin et al. 212] studied the combustion characteristics of a diesel spray 
injected into a methanol-air atmosphere, such as in a dual fuel engine, in a constant volume combustion chamber. They looked specifically into changes of ignition delay and flame lift-off length between injection into a methanol-air atmosphere and injection into an air atmosphere. The ignition delay increased for the methanol-air case, which would lead to more mixing prior to the start of combustion and thus lower soot emissions. The flame lift-off length is related to the ignition delay, and increased for the methanol case, which would enhance the oxygen uptake into the jet again lowering soot emissions. However, as they increased the initial temperature, the differences in ignition delay and flame lift-off length to those obtained in the air case almost disappeared.

The soluble organic fraction of the particulate matter emissions is generally increased. This relates to the increase of unburnt hydrocarbon emissions that is usually encountered with dual fuel operation (see below). Overall, the particulate mass emissions generally decreased. However, the authors found no agreement in literature on the particulate number concentration. Regarding the particle size distribution, a shift towards smaller particles is often observed because of nucleation and condensation of unburnt hydrocarbons leading to a smaller mean geometric diameter.

As is clear from the above the typical trade-off between $\mathrm{NO}_{\mathrm{X}}$ and PM emissions observed in pure diesel operation disappears in dual fuel mode. In other words, methanol fumigation allows one to simultaneously reduce both $\mathrm{NO}_{\mathrm{X}}$ and $\mathrm{PM}$ emissions. Unfortunately, the downside is an increase in $\mathrm{CO}$ and $\mathrm{HC}$ emissions. CO emissions are higher in dual fuel mode than in pure diesel operation and increase with increasing methanol fraction. This is due to the lower temperatures associated with the higher heat of vaporization of methanol. The lower temperature impedes the full oxidation of the fuel. This increase is most pronounced at low loads. Unburnt hydrocarbon emissions are also higher in dual fuel mode, for the same reasons, besides $\mathrm{HC}$ emissions originating from crevices since methanol is premixed with the air.

Very few data can be found on formaldehyde emissions in dual fuel operation. Cheung et al. 209] measured formaldehyde emissions for dual fuel operation with low methanol substitution ratios (up to $30 \%$ on an energy basis) and found them to increase with load and methanol fraction, up to 3.3 times higher than for pure diesel operation. They explain the increased emissions by the lower combustion temperature, although this contradicts the increase with load. However, this could be due to the emissions being reported in ppm instead of on a brake specific basis $(\mathrm{g} / \mathrm{kWh})$. Testing with a diesel oxidation catalyst showed reductions of formaldehyde emissions with more than $90 \%$. Similar reductions were found by Wei et al. [211, who ran tests with higher methanol substitution ratios (up to 70\%). However, the engine-out emissions of formaldehyde were found to be up to a factor of 150 higher than for diesel operation, and the oxidation catalyst was less effective at low loads. The authors concluded that emissions of formaldehyde, $\mathrm{CO}$ and $\mathrm{HC}$ could be a limiting factor for the achievable methanol fraction at low loads.

Note that the overall level of emissions of the methanol dual fuel mode, compared to the base diesel operation, will depend strongly on the operational 
profile of the engine: the methanol fraction is typically zero at idling and at full load, for reasons explained above, and varies in between.

\subsubsection{Other}

As mentioned above, numerous concepts have been advanced for using methanol in compression ignition engines. Compared to the fumigation concept however, these concepts are more complicated and few results have been reported, in some cases limited to a single paper for a particular concept. As described in Section 5.1, initial attempts date back to the 1980s. Hikino and Suzuki [213] reported testing on an engine with increased compression ratio (27:1), using an external uncooled EGR system and insulated piston, all with the intention of raising in-cylinder temperatures for easier autoignition of methanol. The EGR system was added to ensure that temperatures remained sufficiently high even at part load. The aim of the work was to increase part load efficiency compared with a heavy-duty spark ignition engine. Enabling autoignition with the measures listed above greatly improved efficiency, getting close to the efficiency of a comparable diesel engine, with lowered $\mathrm{NO}_{\mathrm{X}}$ emission as well. However, it compromised peak power output and lowered peak load efficiency.

Interestingly, the heat release plots shown by the authors indicate that although the main features of a diesel-like combustion are present, it is clear that the premixed autoignition part is much more important than the diffusion combustion part. This corresponds with the findings of CFD simulations of late injection operating points of a PPC type concept 214, which show that the autoignition is actually only happening when the mixture is already lean of stoichiometric, a feature caused by the high heat of vaporization, high RON and low AFR of methanol; this causes most of the heat to be released in an "HCCI type combustion".

In 1990, Caterpillar reported results from an extensive measurement campaign with long haul trucks using methanol engines [215]. These were modified diesel engines, using glow plugs for cold start and assisting ignition. Power output and efficiency was on par with the diesel version, while combustion was essentially smoke-free. The accumulated mileage $(600.000 \mathrm{~km})$ allowed engine durability to be assessed. Cylinder liner wear appeared to be reduced compared to the diesel version, whereas valve faces showed increased wear. This was attributed to the soot-free combustion (the soot helps in lubricating the valves) and easily solved with modified valve material. However, injector and glow plug lifetimes were limited.

More recently, Roberts et al. 216] investigated the requirements for reliable compression ignition operation on methanol. They proposed a temperature at start of injection requirement of $1100 \mathrm{~K}$, which they calculated to be achievable by turbocharging, using low heat rejection cylinder surfaces and possibly by deleting the intercooler. Spray visualization in a free piston test rig and testing in a single cylinder research engine led to some interesting results. Although engine-out soot mass emissions were effectively zero on methanol, the spray imaging did show soot formation. Thus, the formation seemed to be balanced by subsequent oxidation. Even more interesting was that methanol combustion 
was soot-free even at stoichiometric conditions (likely caused by the fuel-bound oxygen [217]). This opens the possibility of using a three-way catalyst for $\mathrm{NO}_{\mathrm{X}}$ control, which is much cheaper than lean $\mathrm{NO}_{\mathrm{X}}$ aftertreatment systems such as selective catalytic reduction. The stoichiometric operation led to a drop in combustion efficiency, to $96 \%$, but if combined with waste heat recovery (which would harvest some of the thermal energy liberated by oxidation of this unburned fuel in the aftertreatment) a brake thermal efficiency of $51 \%$ should be feasible according to modelling work by the authors. Stoichiometric combustion would also increase the engine's power density, an advantage over low temperature combustion concepts such as are described next (although mode-switching to such concepts might be necessary to cope with the lowest loads).

Shamun et al. were the first to report a series of tests on methanol PPC combustion [204, 205, 218. All work was done on a heavy duty Scania D13 engine converted to single cylinder operation, using three different compression ratios. A small amount of lubricant (200 ppm of Infineum R566) was added to the methanol fuel, to prevent wear in the high pressure injection system by increasing the viscosity (with injection pressures up to 1600 bar). With the 27:1 compression ratio, results were obtained both with conventional diesel-like combustion and with partially premixed combustion [205]. Peak gross indicated efficiency reached $52.8 \%$ at the 6 bar gross IMEP and $1200 \mathrm{rpm}$ testing point. Engine-out $\mathrm{NO}_{\mathrm{X}}$ could be brought below EURO VI levels by using EGR. Relatively high hydrocarbon emissions were recorded (of the order of $2 \mathrm{~g} / \mathrm{kWh}$ ), which the authors attributed to the high compression ratio (with some of the fuel ending up in the squish regions). These $\mathrm{HC}$ emissions could be lowered somewhat by lowering the injection pressure (from 1600 to 800 bar), which did not affect any of the other measured parameters such as $\mathrm{NO}_{\mathrm{X}}$ and efficiency. The authors also reported that the very high compression ratio limited the load range, primarily because of peak pressure limitations.

In subsequent work [204], a compression ratio of 15:1 was used, similar to PPC work on other fuels in that research group. This compression ratio would alleviate peak pressure limitations but likely lead to cold start problems. The focus of that paper was on particle emissions. Ethanol and naphtha gasoline were included in the measurement campaign and so was PPC as well as diffusion combustion of methanol. Methanol PPC operation halved the particle count compared to diffusion combustion. For the alcohols, no $\mathrm{NO}_{\mathrm{X}}$-soot tradeoff was present. Some of the particle count and sizing results were puzzling and hence the authors studied this with additional measurement techniques in a follow-up paper [218]. The compression ratio now was the stock 17.3:1, and measurement equipment now included an electrostatic precipitator, transmission electron microscopy and energy dispersive X-ray spectroscopy, in addition to the micro soot sensor and particle number concentration and size distribution measurement used in the previous work. Ultrafine particles were found (mostly below $23 \mathrm{~nm}$ ), with a hollow or liquid core that upon analysis of their composition proved to originate from the lubrication oil. The authors suggested that such particles are probably always present but usually collect onto diesel soot particles. Due to the essentially soot-free combustion of alcohols (methanol and 
ethanol were tested), these particles have nothing to agglomerate with and are detected as formed, i.e. as nucleation particles.

Finally, VTT reported work using MD95 in a Scania ED95 engine [219, i.e. running a mixture of methanol and ignition improver in a compression ignition cycle. A number of different additives (ignition enhancer) were tested, with the aim of bringing the cetane number up to a minimum of 11. The best results were obtained with the same additive as used in ED95. Engine testing with MD95 showed $\mathrm{CO}$ and $\mathrm{NO}_{\mathrm{X}}$ levels to be below those on ED95 and formaldehyde emissions to be lower than those on diesel. Particle mass was comparable to diesel operation although the filter paper was completely white on MD95, possibly indicating the PM to consist of semivolatiles or unburned additive. Particle number count was above the Euro VI limit but given the particle nature, the authors suspected this might easily be removable using an oxidation catalyst (standard equipment on the commercially available Scania ED95 engines).

From the work reported above, it is clear that interesting results have been found, with high efficiencies and/or very low emissions, but most results are for isolated operating conditions or have not been confirmed yet by other researchers. These are certainly concepts requiring further research.

\subsection{Methanol as a fuel for shipping}

There is currently a growing interest in methanol as an alternative fuel, in the marine sector. The main reason for this is tightening emissions legislation. For ocean-going vessels, the International Maritime Organization (IMO) has introduced Tier $3 \mathrm{NO}_{\mathrm{X}}$ emission regulations, applicable in the so-called Emission Control Areas (ECAs), e.g. densely populated coastal areas. The allowable sulphur content of marine fuels is also coming down. This has led to a number of technologies being introduced to meet the more stringent regulations. Next to technologies that allow the continued use of heavy fuel oils (HFO) such as aftertreatment systems, alternative fuels are also gaining traction. Initially, the focus was mostly on liquified natural gas (LNG). However, making provisions for a liquified gas storage system has substantial effects on ship design or retrofits. For many applications, methanol is an easier fuel to handle as it is liquid at atmospheric conditions. It can also be made from the natural gas. A recent technical report from the EU's Joint Research Centre concluded that LNG and methanol seem to be the most promising alternative fuels for shipping at the moment [220]. This is partly based on methanol's availability in most large ports.

Methanol's suitability as a marine fuel is linked to its safety characteristics, excellent emissions compared to the bunker fuel or heavy fuel oils that large ships currently generally use and the fact that it is infinitely miscible in water, meaning that the double hulls of existing vessels can be modified to suit its storage. Double hulls are a necessity for ships carrying hydrocarbons since these fuels will not mix with water; the infinite miscibility of methanol instead means that these voids can be used to store the alcohol because with a tank breach the fuel will just dissolve. A study conducted by Malcolm Pirnie inc. 221] found 
that in case there would be a methanol spill, it dilutes so rapidly that dangerous concentrations are never reached. Next to the miscibility which leads to a more rapid dilution, this is also caused by lethal concentrations (for marine life) being 240 times higher for methanol compared to diesel, and 1900 times higher than for gasoline. Thus, it is very unlikely that such concentrations are ever reached.

A number of demonstration projects have been looking into methanol use for shipping. The most notable ones are the Stena Germanica 1500 passenger ferry conversion 222. and the Waterfront Shipping 50.000 deadweight tonnage methanol tanker vessels [223, both demonstrating vessels operating on methanol. In the case of the Stena Germanica, medium-speed four-stroke marine diesel engines were upgraded by Wärtsilä with proprietary injectors allowing the (separate) direct injection of methanol and pilot fuel (marine gasoil, MGO). The Waterfront Shipping tankers run with MAN low-speed two-stroke engines, again using separate direct injection of methanol and pilot fuel (MGO or HFO). Measurement data from these engines are limited to the few results presented by the manufacturers, showing compliance with emission regulations and reporting efficiencies to be in line with the efficiency on diesel fuel.

Generally these large marine engines are dual fuel diesel engines, directly comparable to liquified natural gas (LNG) dual fuel marine engines. Such engines have been developed for example for LNG tankers. However, methanol is much safer in use than LNG because it is a liquid, and although the (net) volumetric LHV is approximately $23 \%$ lower ( 15.9 vs. $20.5 \mathrm{MJ} / \mathrm{l})$ methanol is more easily stored aboard a vessel without the attendant storage complications arising from cryogenic storage of a gas. A very important safety consideration is that the flash point of methanol is much lower than that of LNG; the flammability

index of methanol is in fact much closer to that of diesel, and in the instance of a pool fire methanol is vastly more safe than either gases or liquid hydrocarbons [53, 54.

An increasing number of other demonstration projects are being concluded or launched (e.g. LeanShips [224, MethaShip, SUMMETH [225] and GreenPilot [226]), focusing on various aspects of using methanol as an alternative fuel, e.g. bunkering, high speed marine engines, safety, life cycle costs and environmental impacts. Recent reports covering the use of methanol for marine application contain more information [227, 228, 229].

\section{Fuel reforming using engine waste heat}

As discussed in Section 1.4 methanol is a very interesting hydrogen carrier and has therefore also been investigated as an energy vector for powering fuel cell vehicles. The methanol would then be used as fuel, for its convenience (being a liquid), and be reformed on-board to generate hydrogen, or be used directly in a direct-methanol fuel cell (DMFC) [230. Fuel reforming in ICEs has been reviewed extensively recently [231]. The fact that methanol reforms at a temperature that is low enough to make significant use of low-grade exhaust heat even at low loads makes it exceptionally attractive in terms of waste heat recovery on internal combustion engines. This thermochemical recuperation 
approach can be implemented via two different reaction pathways, as discussed by Poran and Tartakovsky [232]:

$$
\begin{array}{r}
\mathrm{CH}_{3} \mathrm{OH} \rightarrow \mathrm{CO}+2 \mathrm{H}_{2} \\
\mathrm{CH}_{3} \mathrm{OH}+\mathrm{H}_{2} \mathrm{O} \rightarrow \mathrm{CO}_{2}+3 \mathrm{H}_{2}
\end{array}
$$

The first pathway is thermal decomposition and the second is steam reforming, for which one mole of water has to be provided for each mole of methanol (representing a volume percentage of $30.75 \%$ water in methanol). Both reactions are endothermic, so for thermochemical recuperation to work, energy is absorbed by the liquid(s) from the waste heat stream. This results in a higher LHV of the resulting gaseous fuel, yielding an overall improvement in system efficiency when the gaseous fuel is used in the engine. With reaction 13, the LHV of the products is about $20 \%$ higher than of the reactant. With reaction 14 , this ratio is $13 \%$ 233.

There is a similar reaction for ethanol, which reforms at very similar temperatures, the decomposition reaction being similar to that for methanol in Eq. 13 in that one mole of ethanol produces three moles of gases [234, 232]:

$$
\mathrm{C}_{2} \mathrm{H}_{5} \mathrm{OH} \rightarrow \mathrm{H}_{2}+\mathrm{CO}+\mathrm{CH}_{4}
$$

This will be returned to later.

In addition to cyclic combustion engines, the concept of methanol reforming has been proposed and discussed for many other different types of prime mover. Carapellucci and Milazzo 235] discuss an application for power generation in a gas turbine where steam-reformed reformate is separated prior to combustion so that the $\mathrm{CO}_{2}$ can be sequestrated while the hydrogen passes into the combustion chamber, and Cocco and Tola discuss its use in a solid oxide fuel cell plant 236. In both, the recuperation approach leads to significant gains in efficiency, with Carapellucci and Milazzo showing approximately 20\% relative improvement due to the thermal energy recovery and Cocco and Tola an increase from $64 \%$ to $68 \%$ in overall SOFC-gas turbine plant efficiency.

Historically, light-duty engine operation using decomposed or steam-reformed methanol has been discussed by many researchers. Kowalewicz [237] proposed the use of methanol decomposition as a part-load strategy, stating that the improvement in lower heating value of the mixture was of the order of $20 \%$ (from 20.0 to $23.9 \mathrm{MJ} / \mathrm{kg}$ ). His approach would require two fuel systems on the engine, albeit both drawing from only one fuel tank, see Fig. 24a.

In the first fuel system, for operation at light load, the methanol is taken from the tank to a reformer where exhaust heat causes its decomposition to hydrogen and carbon monoxide, after which the gases are stored in a buffer tank. They are then introduced into the intake manifold where two effects raise the part-load efficiency of the engine: one due to the increase in LHV, and the other to air being displaced by the much less dense gases providing a significant dethrottling effect, which is very important in 4 -stroke engines. In the second fuel system, there is a switch back to liquid methanol for operation at full load, ensuring that maximum power can still be met. Prior to Kowalewicz, McCall 
and co-workers 238 presented test results using simulated mixtures of gases for both dissociated and steam reformed cases; they showed relative improvements of the order of $30 \%$ at light load, showing that there is clearly an effect beyond the increase in LHV. In the 1980s Volkswagen AG also heavily investigated methanol as a transport fuel as part of a German government initiative [239], and within this König et al. 240] reported results for dissociated gases using a reformer in the exhaust gas stream in which a copper catalyst was used. They report efficiency improvements for partially dissociated methanol of $10 \%$ over pure methanol, with improved exhaust emissions including an $80 \%$ reduction in aldehyde emissions to below those from gasoline, and included road load data.

One of the attractions of the approach is that, in an analogue of the methanol synthesis reaction, in theory a relatively cheap catalyst material can be used; König et al. 240 report tests of thirty different types of catalyst material, with copper being very advantageous, but they state that at that time for reasons of longevity a noble metal catalyst may have been needed.

Turner proposed reforming directly in an EGR stream as part of a cooled scheme 241], see Fig. 24b, this would in theory mean a much cheaper reformer geometry could be used. He suggested that the latent heat of the methanol could be used to partially cool the EGR gas, leading to an advantage for that system, and also proposed novel operating strategies with different injection nozzle and catalytic surface positions either to provide recuperation or not as the engine load changed. Part of the reason for the strategy proposed by Turner is that there are synergies between using hydrogen-rich reformate and cooled EGR in an engine: both will dethrottle the engine, but the very fast LBV of hydrogen helps to extend the EGR limit in turn permitting more to be used. In the invention, moving gradually from reforming to non-reformed liquid methanol provides a measure of mixture quantity load control across the engine operating map.

Poran and Tartakovsky have proposed high pressure thermochemical recuperation by steam reforming so that only gases are ever delivered to the combustion chamber [232, 242]. Their work, which includes a comprehensive literature review of thermochemical recuperation, is novel because it proposes the use of only one injection system so that maximum power can be maintained via closed-valve injection of the reformate. Firstly methanol is pressurized up to the direct-injection delivery pressure and is then reformed at that pressure, see Fig. 24c this removes the challenge of and energy input to compressing the eventual gaseous fuel to that pressure. Because of the direct injection strategy in their 4-stroke engine, injecting during the intake stroke displaces air and dethrottles the engine in the part load regime; as the load increases retarding injection into the compression stroke allows more air in and thus gives a window of load control. The ability to operate extremely lean (due to the wide flammability range of hydrogen) means that load control is a mixture of quality and quantity control depending on the operating strategy 232]. They also suggest that, if the reforming reactions are complete and therefore (because of the high hydrogen content) extremely lean operation is possible, so making $\mathrm{NO}_{\mathrm{X}}$ production minimal, then operation of an engine by qualitative load control could 
be afforded. Since no hydrocarbon emissions would result from fuel combustion then in this case the catalyst in the exhaust might be deleted and on a system level effectively replaced by the one in the reformer. No particulates would be formed due to the fuel molecules being gases not containing carbon-carbon bonds, meaning no particulate trap would be required. This overall strategy is considered an intriguing possibility. Note that Bromberg and Cohn proposed the reformation at high pressure as part of a Rankine cycle with methanol or hydrous alcohols as working fluid [243].

The above concepts have been directed at pure methanol as the fuel in the tank. As discussed in Section 1.6.1, methanol can be blended with other fuels, and this is sometimes advantageous in terms of cold starting, visible flame, providing an unpalatable taste to prevent ingestion etc. Therefore M85 is commonly used, but the gasoline component, essentially being a mixture of pure hydrocarbons, will not reform at temperatures that are easily reached during part load operation (i.e. $600{ }^{\circ} \mathrm{C}$ ). However, it may still be possible to reform the methanol part of the blend, as work led by Monsanto has shown for ethanol reforming, where the ethanol in E85 has successfully been dissociated in a prototype reformer leading to significant efficiency benefits: Fowler et al. 244 report 10-12\% over E85 operation; Wheeler et al. [245] measured $8.5-12.7 \%$ relative to E85 and 18-19.8\% relative to $98 \mathrm{RON}$. This is because of dethrottling as well as other effects. These researchers used a copper catalyst, linking back to the work conducted by König and co-workers, and in the work by Fowler et al. it is stated that 'Similar benefits and operability would be expected on high methanol blends such as those currently in use in China, since the catalyst is known to be active for methanol reforming in the same temperature range' 244. If this is the case, it is possible that GEM blends as discussed in Section 1.6.2 could also be used in such reformer strategies.

Note that actual efficiency improvements from methanol reforming using waste heat are still uncertain. The LHV of the reformed stream might increase, but there are competing effects - primarily a molar expansion ratio decrease. As Table 3 shows, the mole ratio of products to reactants is much lower for hydrogen compared to methanol. The same is true for CO. As hydrogen and CO are the two main products of fuel reforming, the work potential of the reformed fuel significantly decreases 77 . This needs further investigation. Nevertheless, there are other potential advantages of reforming. As already partly explained above, it could lower pollutant emissions. Additionally, one of the advantages of reforming is that, if gaseous reformate is buffered in a storage tank, it can be used to overcome the cold-start issue of light alcohols since there are no longer the latent heat and vapour pressure issues for molecular alcohol combustion arising from the hydrogen bonding of the alcohol molecules. In the work of Fowler et al. 244, for E85 reforming fueling a 3.5 liter engine, the authors used a 4 liter buffer tank which they sized to enable $50 \%$ use during the first half minute after cold start while allowing it to be packaged in a vehicle. The wide lean limit of hydrogen means that $\mathrm{NO}_{\mathrm{X}}$ emissions could be kept low (perhaps with additional application of cooled EGR) and because of the fact that the only carbon entering the engine is in the form of either $\mathrm{CO}$ or $\mathrm{CO}_{2}$ then hydro- 
carbon emissions from the fuel would be impossible (in the case of $100 \%$ efficient reforming and assuming no oil carryover). Aldehyde emissions, a challenge for molecular alcohol combustion, would be eradicated. For the dissociation case, very lean operation would be expected to fully oxidize $\mathrm{CO}$ to $\mathrm{CO}_{2}$, and for obvious reasons particulate matter would be expected to be absent (again, leaving aside any lubricant effect).

Thus emissions from such a concept would be expected to be very low where no gasoline is in the liquid fuel in the tank, and all authors who have investigated reforming of alcohols report improvements in emissions over the liquid-fuelled case. However, for systems where liquid alcohol is introduced for full-load operation, it would be necessary to transition from lean gaseous combustion through to stoichiometric (and then possibly rich) liquid fuel operation, meaning that a lean- $\mathrm{NO}_{\mathrm{X}}$ trap (LNT) may be necessary as part of the exhaust aftertreatment system. This may also be the case for systems where there is some gasoline blended into the alcohol. Wheeler and co-workers reported use of a LNT and strategies to regenerate it, including injection of reformate after the three-way catalyst and before the LNT, which is an interesting strategy possibly eliminating the need to operate the engine combustion system stoichiometrically. Also against this background the high-pressure reforming approach of Poran and coworkers would seem to be very attractive, providing the ultra-lean operation eliminates the need for $\mathrm{NO}_{\mathrm{X}}$ after treatment, and the switch to stoichiometric/rich operation at full load can be made rapidly enough.

Finally, on-board reforming of methanol has also been proposed for RCCI concepts (reactivity controlled compression ignition). This would enable storing a single fuel, but through reforming obtaining two fuels of different reactivity [246. These fuels could be dimethylether (DME), a high cetane fuel, and methanol or methanol reformer gas, high octane fuels.

\section{Simulation studies}

Obviously, with ever increasing complexity of engine technology and degrees of freedom, and ever tightening demands on engine efficiency and emission levels, there is an increasing need for simulation tools in engine research and development. In the following sections, we review the state-of-the-art for methanol engine combustion computation.

\subsection{Quasi-dimensional models}

Engine simulation based on quasi-dimensional modelling can be a useful tool for exploration of the potential of alcohol fuels and their impact on engine control strategies. The quasi-dimensional approach, or 'multizone thermodynamic', is suitable where a compromise is sought between accuracy and speed of calculation [92. The following sections review: the work done in modelling normal flame propagation for pure methanol; normal combustion for alcohol blends; abnormal combustion, again for pure methanol and then for blends; in-cylinder heat transfer; and finally methanol fuel reforming. 


\subsubsection{Modelling regular combustion of pure methanol}

Brown et al. used an entrainment combustion model to compare the combustion of iso-octane and methanol in a single-cylinder research engine 247. The turbulent burning velocity was calculated using the Damköhler model: $u_{t}=u_{l}+u^{\prime}$, where $u^{\prime}$ was estimated using an empirical expression from Mohanan and Babu 248. The laminar burning velocity of methanol was calculated using a correlation by Gibbs and Calcote [249], combined with the temperature and pressure trends predicted by Metghalchi and Keck [250] and a factor representing the effect of residual gas developed for gasoline combustion. The authors reported that the use of methanol resulted in faster combustion. They note that a correct calculation of the evaporation cooling by methanol is needed to predict the volumetric efficiency. Also, the employed laminar burning velocity correlation resulted in poor results for rich mixtures.

Pourkhesalian et al. 251 compared the performance and emissions of six different fuels, including methanol and ethanol, in a PFI engine using a quasidimensional code with the turbulent combustion model of Damköhler and a simple turbulence model comparable to that of Mohanan and Babu 248]. The laminar burning velocity of methanol was calculated using the correlation of Metghalchi and Keck [250], that of ethanol by the correlation of Liao et al. [252]. Methanol and ethanol were reported to produce the lowest $\mathrm{CO}$ and $\mathrm{NO}_{\mathrm{X}}$ emissions. The predicted peak power on methanol was lower than on gasoline, possibly because the cooling effect of methanol was underestimated.

Boretti [114] investigated the potential for efficiency improvement in a dedicated neat ethanol engine using the entrainment combustion model and $\mathrm{k}-\epsilon$ turbulence model. A laminar burning velocity correlation for gasoline was used, but the calibration constants in the turbulent combustion model were adapted to account for the higher $u_{l}$ of ethanol, based on the ratio of $u_{l}$ between gasoline and ethanol at stoichiometry and atmospheric conditions. The author reported a potential BTE of $40 \%$ and BMEP levels of 30 bar in a highly boosted, directly injected engine with an elevated compression ratio (13:1) and fully variable valve actuation.

Vancoillie et al. 172 investigated quasi-dimensional modelling of engines running on neat ethanol and methanol. A literature review revealed that existing engine codes for alcohol-fueled engines generally employ submodels developed for conventional hydrocarbon fuels. Significant differences, however, can be expected in the mechanisms of combustion, emission formation and knock. The goal of their work was therefore to develop a simulation code valid for neat methanol and ethanol-fueled engines.

An analytical study of the flame structure showed that flamelet type combustion prevails inside these engines. This means the primary influence of turbulence is limited to stretching and wrinkling of the flame front and the effects of combustion chemistry can be grouped in the laminar burning velocity. Obtaining reliable data for this crucial property at engine-like conditions (, $\mathrm{T}$ and mixture composition) formed a first major objective of the research.

From a survey of published literature, a lack of laminar burning velocity data 
at engine-like conditions became apparent for ethanol and methanol in particular. Additionally, many published values do not correctly account for flame stretch and instability. For this reason, a library of flame data was generated using selected chemical kinetics mechanisms. The resulting datasets were used to fit new laminar burning velocity and flame thickness correlations for the two fuels (see Section 2.3).

Moving on to turbulent burning velocity, a literature review showed that this quantity is significantly affected by stretch and instabilities in the underlying laminar structure. However, the molecular transport properties of light alcohols are such that these effects are less pronounced than for some other fuels (e.g. gasoline, hydrogen). A number of published turbulent combustion models were evaluated based on measurements of methanol's turbulent burning velocity obtained in a constant volume bomb 104 and an existing dataset for ethanol. It appeared that models accounting for stretch and instability effects had a slight edge on simpler formulations.

Finally, the developed submodels and correlations were implemented in a quasi-dimensional engine simulation code. An in-house code was integrated with the commercial engine simulation tool GT-Power, thereby extending its functionality, for example by enabling prediction of the gas dynamics during the breathing cycle, pollutant formation and in-cylinder turbulence. To accurately predict the volumetric efficiency of port-fuel injected alcohol engines, it proved necessary to include the dynamics of fuel puddling in the gas dynamics model (further detailed below).

The combustion routines were validated against a database of cylinder pressure traces obtained on a CFR engine for both methanol and ethanol operation and varying compression ratio, throttle position, ignition timing and equivalence ratio. The new laminar burning velocity correlations were shown to predict the effects of varying mixture composition much better than existing correlations. A comparison confirmed that turbulent burning velocity models including thermodiffusive properties (e.g. Zimont, Bradley KaLe [253, 254] performed better than simpler models (Damkohler [255]). Validation on a second engine confirmed these findings. Additionally, it was found that the effect of engine rpm was best predicted by the Damkohler model, but this could be due to uncertainties regarding the turbulence levels inside this engine.

\subsubsection{Modelling regular combustion of alcohol blends}

In the early 1990's Mohanan and Babu simulated the performance and emissions of different engine configurations fueled with gasoline-methanol blends 248 using a two-zone quasi-dimensional model. The turbulent burning velocity was calculated based on an empirical expression obtained using a CFR engine: $u_{t}=u_{l}+4 u^{\prime}$, where the rms turbulent velocity $u^{\prime}$ was assumed to decay continuously during combustion and considered to scale linearly with engine speed. The authors report a lack of data for the laminar burning velocity of methanol and calculated this quantity using chemical kinetics results of Westbrook [256]. $\mathrm{NO}_{\mathrm{X}}$ levels were calculated using the Woschni heat transfer model 
and the extended Zel'dovich mechanism. The model was successfully validated for three operating points of different charge pressure and equivalence ratio.

Bougrine et al. [113] used their reduced Coherent Flame Model to predict the performance, emissions and knock occurrence in a directly injected single cylinder engine fueled with stoichiometric gasoline-ethanol blends up to $30 \mathrm{vol} \%$ ethanol. They used Gülder's laminar burning velocity correlation 257, but mentioned the lack of a correct expression for the pressure sensitivity of $u_{l}$ for these blends. The influence of residual gases was implemented using an expression developed for gasoline. Knock was predicted using the model of Douad and Eyzat developed for primary reference fuels [112. The authors reported that indicated mean effective pressure (IMEP) was predicted within 1 bar for $70 \%$ of the operating points, knock-limited spark advance was predicted within 2 degrees crank angle and good trends were obtained for $\mathrm{NO}_{\mathrm{X}}$ and $\mathrm{CO}$, with some error due to the uncertainty in residual gas content.

Sileghem et al. [32, 258, investigated the modeling of the combustion of alcohol-gasoline blends in a quasi-dimensional engine model, focusing on improving the accuracy of the laminar burning velocity of alcohol-gasoline blends by using 'mixing rules' (see Section 2.8.7). The predictive capabilities of the simulation model were first tested for measurements on a CFR engine. Measurements were performed on methanol-gasoline blends for a fixed ignition timing, fixed throttle position and fixed engine speed. The predictive performance of newly developed laminar burning velocity correlations of gasoline and methanol together with a mixing rule was assessed. The sensitivity was investigated for fuel blends going from pure gasoline to pure methanol. The results showed the importance of the laminar burning velocity correlation, the initial flame kernel creation and the estimation of the residual gas fraction. The experimental trends of combustion properties such as ignition delay, 10-90\% mass fraction burned, 0-CA50 and maximum pressure could not be reproduced in the simulations for lean and stoichiometric mixtures while the agreement was better for rich mixtures. Uncertainty about the initial flame kernel size, uncertainty about the laminar burning velocity at higher pressure and temperatures or the inability of the turbulent combustion model to adequately capture the chemical effects were claimed as possible reasons. After changing some parameters of the laminar burning velocity correlation of methanol, the experimental trend could be reproduced. Further study of the laminar burning velocity at higher temperatures and pressures is thus needed to lower the uncertainty on this parameter. Because the initial flame kernel size had a big influence on the ignition delay, it was decided to adjust this initial flame kernel creation depending on the operating point. After optimizing the initial flame kernel creation to reproduce the same ignition delay as in the measurements, the trends in burn rate and peak pressures were reproduced much better. The authors stressed that a flame kernel (growth) model that properly accounts for fuel effects could be very effective to improve the simulation results.

Next to the measurements on a CFR engine, measurements on a direct injected 2.4L Hyundai engine were also used to evaluate the simulation model. A broader measurement range than on the CFR engine was used to get a more 
general view of the simulation output. First, simulations were again performed with the newly developed laminar burning velocity correlations of methanol and gasoline in combination with the mixing rule. In general, the simulations agreed well with the experimental values. Similar to what was found for the CFR engine, the trend going from gasoline to methanol was not fully captured. Additionally, the results were plotted as a function of equivalence ratio. Only for pure methanol, the trend was captured although the equivalence ratio range was limited in the case of methanol. Several other laminar burning velocity correlations of methanol were tested. It was clear that the newly developed correlation for methanol outperformed the other correlations. Finally, the influence of the flame initialization and turbulent burning velocity models was investigated in the same way as on the CFR engine. It was again shown that changing the flame kernel depending on the fuel and on the operating point could be very effective to improve the simulations.

\subsubsection{Knock modelling of pure alcohols}

The development of a knock prediction model valid for light alcohols was discussed by Vancoillie et al. 259, 260. As described earlier (Section 2.5), the chemical kinetics of alcohol autoignition significantly differ from those of gasoline. Existing knock prediction models, developed for gasoline, will therefore likely fail.

A knock prediction model was developed based on the knock integral approach. The principal building block for such a model is an expression for autoignition delay time at instantaneous in-cylinder conditions ( $\mathrm{p}, \mathrm{T}$ and mixture composition). This quantity was calculated using chemical kinetics and the resulting values were fit into a correlation. The employed mechanism was validated for autoignition kinetics using published delay time data. From this study it appeared that trends for varying temperature, pressure and equivalence ratio are well predicted, but the absolute value of autoignition delay might be slightly too low at the temperature conditions relevant to engine knock.

A preliminary validation of the knock prediction routines against measurements obtained on the same engine illustrated that despite the gross simplifications, the developed model can yield useful results for quantities relevant to knock. The effects of load and compression ratio on knock were adequately predicted. The largest model inaccuracies occurred for varying equivalence ratio. The authors stated that this is probably caused by an incorrect representation of the thermal effects of changing equivalence ratio and that the use of more advanced wall heat transfer models and inclusion of evaporation cooling in future work might resolve this.

\subsubsection{Knock modelling of alcohol-gasoline blends}

In order to better understand and predict the knock behavior of alcohol blends, a mixing rule for the autoignition delay time of alcohol-gasoline blends was proposed by Sileghem et al. 32 (see Section 2.8.8) and evaluated in a simulation model. This energy-based mixing rule was used together with an autoignition delay time correlation of gasoline and an autoignition delay time 
correlation of methanol in a knock integral model that was implemented in a two-zone engine code. To validate the proposed model, knock occurrence was experimentally investigated on a CFR engine for four methanol-gasoline blends (gasoline, M50, M75 and M100). Experimental metrics of knock included knock limited spark advance (KLSA), fraction of knocking cycles, knock onset timing and knock intensity based on the signal energy of heat release rate oscillations. The proposed correlation and knock integral approach performed satisfactorily despite the gross simplification associated with two-zone modeling (no hot spots, no cyclic variation). The experimental KLSA was more advanced than the simulated KLSA. The knock integral exceeded 1 before the end of combustion at less advanced spark timing than the experimental KLSA. Therefore, a second condition was used in this study to identify knock based on unburned mass fraction and the crank angle at knock onset which gave better agreement. Secondly, the agreement between the simulated knock intensity and the experimental knock intensity was better if the pressure and temperature at knock onset were taken into account because the temperature and the pressure will change going from gasoline to methanol and both have an influence on the gas properties and as a result on the knock oscillations. This was done by including the crank angle of knock onset at KLSA into the knock intensity equation as this reflects the necessary conditions for autoignition of the fuel which are influenced by temperature and pressure. Finally, the model was able to predict almost all the knock onsets within the error margins of the experimental knock onset.

\subsubsection{In-cylinder heat transfer sub-model}

Demuynck evaluated experimental data obtained in a CFR engine covering a wide range of fuels and engine operation conditions in an attempt to develop a fuel independent heat transfer model for spark ignition engines [261, 262, 263. Existing heat flux correlations were shown to reproduce the heat flux trace at constant operating point for methane and methanol. However, Demuynck demonstrated that, for methanol and especially hydrogen, existing heat flux correlations are unable to predict changes in heat flux during combustion for large variations in mixture equivalence ratio. It was also shown that, if properly calibrated, the Woschni correlation could accurately reproduce the heat flux trace at a certain operating point. However, the model failed to predict trends in peak and total heat flux for large variation in equivalence ratio.

Adjustments were proposed by Demuynck to improve the existing heat transfer models: the correct determination of the gas properties and the coupling to a two-zone combustion model. The results showed that these two adjustments indeed significantly increased the accuracy. Calculating the gas properties with the correct polynomials and mixing laws enabled the accurate simulation of the variation in the heat flux during the compression stroke. The coupling to a two-zone combustion model resulted in accurate simulations for methane over the entire parameter space, but not for hydrogen and methanol. Finally, the proper definitions of the characteristic length and velocity were investigated to further improve the simulations for hydrogen and methanol. The results showed that significant steps were taken towards a fuel independent heat transfer model. 
However, the improved model formulation suggested by Demuynck has not been evaluated yet on other alcohol engine datasets.

When modelling alcohol engines it has been proven to be important to include "puddling" submodels, to account for the time needed for fuel evaporation. Especially DI engines require a description of cylinder wall wetting and subsequent fuel evaporation. Marriott et al. 160, reported this is particularly important for fuels with a high latent heat of vaporization such as light alcohols. If fuel evaporation is assumed to be either instantaneous and complete on injection, or happening instantaneously at time of ignition this will result in incorrect predictions of wall heat transfer and volumetric efficiency. Marriott proposed a simple model based on geometrical and empirical spray parameters.

Commercial simulation software such as GT-Power 264 offers the ability to model the deposition of fuel, subsequent evaporation, droplet entrainment and transport of liquid fuel to the cylinder by shear forces. This model is generally only required to study transient phenomena, but proved crucial to accurately predict the volumetric efficiency in alcohol-fueled engines 260. Vancoillie demonstrated this by successfully predicting both volumetric efficiency and compression slope in the gas dynamics models of a methanol fueled CFR engine [259].

\subsubsection{Fuel reforming}

To further boost the efficiency of a methanol fueled engine, a fuel reformer can be added to reform the methanol to syngas, as explained in Section 6. By doing this, the complexity of the system increases a lot. Thus, simulations will play a key role in the optimization of such a system. Additional submodels for the reformer will have to be integrated in the predictive engine model as well as adaptations of the current heat transfer and combustion models. As the laminar burning velocity of a fuel is a base parameter for any predictive engine combustion model, Nguyen et al. 265] has developed new laminar burning velocity models for two engine concepts with methanol fuel steam reforming to support simulations. One concept uses water from an extra tank to produce hydrogen rich gas (syngas) in a reformer heated by the exhaust gases and the other concept employs the water vapor in the exhaust gas recirculation stream to produce reformed EGR. A 1D flame simulation tool with a comprehensive chemical kinetic mechanism to predict the laminar burning velocities of methanol/syngas blends was used to generate data. This data was used to develop new correlations. The simulations were performed over syngas ratios, fuel-air equivalence ratios, temperatures, pressures and EGR levels ranging from $0 \%$ to $50 \%$ by volume, 0.5 to $1.5,550$ to $800 \mathrm{~K}, 10$ to $85 \mathrm{bar}$, and $0 \%$ to $30 \%$ by mass, respectively. Some experimental data for laminar burning velocity of reformates is available in literature [266]. Although this is limited to atmospheric conditions for temperature and pressure, the database covers a wide range of mixture compositions and can thus be used to validate chemical kinetic simulations.

Nguyen et al. 233 also calculated that the concept with the reformed EGR technology was the more promising approach to support high levels of EGR dilution in SI engines for increased thermal efficiency due to faster laminar 
burning velocities. However, no experiments have yet been reported validating this.

Poran and Tartakovsky are one of the few that have done extensive research on fuel reforming of methanol in combination with an internal combustion engine [267, 232, 242. They ran simulations using a GT-Power model of an engine with a reformer utilizing steam reforming of methanol [267]. They focused on direct injection of the reformate in order to maintain the power output of the engine and to prevent abnormal combustion phenomena. They found that compressing the reformate gas to high pressures to enable late fuel injection is not energetically efficient and nonviable if reforming is carried out at atmospheric pressure. It was shown that it is possible to reduce the energy required for fuel compression by compressing the liquid fuel prior to its evaporation and by reforming the methanol at high pressure. In this way, efficiency improvements of $12-14 \%$ compared with a DI gasoline fueled engine were simulated. In a later stage, Poran and Tartakovsky investigated these findings experimentally [232] by feeding an engine with a mixture of $75 \% \mathrm{H}_{2}$ and $25 \% \mathrm{CO}_{2}$ from gas bottles. They showed an improvement in efficiency of 18-39\% compared to the base, carburetted gasoline engine.

\subsection{Multidimensional models}

Multi-dimensional simulations can be used to investigate certain enginerelated phenomena in more detail. Fuel impingement and puddling, a particular problem for light alcohol fuels, have often been studied this way. Ramadan et al. 268 have used the KIVA-3V code to investigate the effect of swirl and fuel impingement on methanol combustion in several engine configurations with direct injection and a compression ratio of 17:1. Pontoppidan et al. 269 used the same code to perform a cold start study for a pure ethanol PFI engine, focusing on intake port fuel puddling. In both studies the alcohol combustion was modeled as a single-step irreversible reaction in Arrhenius form.

Zhen et al. 270] performed a multidimensional study of combustion and knock occurrence in a high compression ratio methanol engine using the Coherent Flame Model for turbulent combustion with a knock prediction model developed for primary reference fuels. They found that knock can be suppressed by retarding spark timing, leaning or enriching the mixture, diluting the mixture with EGR and changing the shape of the combustion chamber.

Lauer et al. 271] used information obtained using 3D CFD to create a model of wall film formation in inlet ports and thermal models of port walls, for use in quasi-dimensional models of ethanol-fueled engines. They reported that ignoring the fuel puddling dynamics can lead to overestimations of the unburned gas temperature of $20{ }^{\circ} \mathrm{C}$, leading to incorrect predictions of volumetric efficiency and knock tendency. Similarly, Marriott et al. [160] report that simulation of engines with direct injection of light alcohol fuels must consider fuel impingement to provide accurate results of volumetric efficiency and wall heat loss. The authors therefore developed a geometry based fuel impingement model. Vaporization dynamics are especially important during cold start. For this reason, Yao et al. 272] and Liebsch et al. 273 have recently developed models for the 
vaporization of ethanol-blended fuels in port fuel injected and direct injected engines respectively, in order to predict the required enrichment for cold start.

The simulation results of Jangi et al. 274, also illustrate the effects of methanol evaporation. They used unsteady RANS simulations for the gas phase and Lagrangian particle tracking for the spray, of a Scania D13 heavy duty diesel engine running on pure methanol, with a compression ratio of $15: 1$ in which the start of injection (SOI) was varied. Early SOI resulted in HCCI-type combustion and needed almost 70 crank angle degrees to evaporate the injected methanol. Delaying the SOI led to PPC combustion, with the start of combustion only happening 7 crank angle degrees after the injection had ended. This is caused by the high heat of vaporization and the high autoignition temperature of methanol. As a consequence, the mixture is lean everywhere, on ignition. Pucilowski et al. 214 continued work on this case, including SOI timings that led to diesel-like combustion (partly premixed, partly diffusion burn) and investigating the effects of a double injection. This was done in an attempt to lower the pressure rise rate, that was excessive for the PPC-type combustion. They showed a high sensitivity to SOI, with combustion changing from HCCI-like combustion to diesel-like combustion on variation of SOI over some 30 crank angle degrees. They also found the inherently long mixing times to potentially lead to unburned methanol emissions by ending up with a lot of fuel near the chamber walls, something that can be improved upon with SOI timing and multiple injections. Turbulence-chemistry coupling was assumed to be properly handled by a well-stirred reactor (WSR) approach and chemistry coordinate mapping $(\mathrm{CCM})$ was used to enable the inclusion of detailed chemical kinetics without leading to excessive computational time. The use of a WSR for the later SOI with partly diffusion combustion is debatable but was still used to limit computational cost.

Summarizing the modelling work on methanol engines, important initial steps have been taken but clearly this has been much less investigated than e.g. gasoline or diesel engine modelling. Next steps are recommended in the following section.

\section{Conclusions, outlook and recommendations}

As explained in the introductory sections, methanol is a compelling fuel for internal combustion engines. It has been investigated in the past, initially as a knock-resistant fuel, then as a fuel that could be produced from non-fossiloil sources, and then - most extensively - as a fuel that enabled a substantial improvement in air quality. These last two reasons are the major drivers for the present large scale application in passenger cars and trucks in China. With upcoming tightening emission legislation for seafaring vessels, methanol is also gaining interest for marine application with some initial ship conversions having been demonstrated.

Apart from potentially burning cleaner and improving air quality, methanol has also been advanced as a long-term renewable fuel. Of the fuels that can be synthesized using renewable sources, it is the most simple fuel that is liquid at 
atmospheric conditions. It thus offers the potential of zero net carbon emissions while being practical in use. The practicality, along with not relying on any scarce resource for its manufacturing or use, translates to scalability: there are no inherent bottlenecks in scaling up the production of methanol to meet the enormous needs of today's transportation sector.

Of course, methanol's synthesis requires carbon. Initial production could make use of biomass or $\mathrm{CO}_{2}$ emitted from so-called point sources: sources emitting over 100 ktons of $\mathrm{CO}_{2}$ yearly. These sources emit approximately half of the anthropogenic $\mathrm{CO}_{2}$ emissions worldwide [4]. In the long term however, in order to reach zero net carbon emission, $\mathrm{CO}_{2}$ must also be captured from diffuse sources. This requires the development of direct air capture. Clearly, there are a lot of open questions not related to engines, on efficiency of synthesis, cost, feasibility of direct air capture etc. Data are needed so that well-to-tank numbers can be calculated. If this is broadened to life cycle analysis (LCA), i.e. it includes vehicle production and dismantling, this actually holds for all alternatives to the present day fossil fuels: there are many uncertainties on resource use, mining impact, energy needs for recycling, etc. What is certain is that change is needed, both to improve air quality and to combat global warming. Numerous alternatives to fossil-fuelled combustion engine vehicles have been advanced and those with the highest potential need to be identified by analyzing the facts. This means an urgent need for detailed data, broader than well-towheel energy use (by which simple metric every vehicle should be electrically driven). For those applications where fuels synthesized from renewable sources make sense, methanol is more attractive versus for instance synthetic gasoline from a production efficiency point of view (well-to-tank).

The present paper focussed on methanol's use in combustion engines, and thus mainly studied the tank-to-wheel part. It has reviewed methanol's properties as an engine fuel to clarify the increased engine efficiencies recorded on methanol, compared to e.g. gasoline engines. A number of properties allow higher peak efficiencies to be obtained, with relative efficiency increases of the order of $25 \%$ having been reported, for (downsized) engines designed to operate on gasoline. This begs the question of what the actual efficiency potential would be if an engine design were to be fully optimized for methanol's properties. Another 5 to $10 \%$ would seem fairly easy to obtain when looking at the more extensive data available for ethanol-fuelled engines. The review has offered a number of suggestions for tailoring design features for methanol use. Additionally, it would be interesting to investigate how such a dedicated methanol engine would still be able to run on gasoline with the necessary engine management interventions to enable this (e.g. using variable valve timing to reduce effective compression ratio, reducing boost pressure and retarding spark advance), and what the power and efficiency demerit would then be when such an engine is operated on gasoline. Importantly, offering flex-fuel capability would help with market introduction because the vehicle could still be fuelled on gasoline in extremis, alleviating any range anxiety. Also, a significant performance reduction when using gasoline might be expected to be an incentive for the driver to use only the minimum amount of gasoline to provide range to a methanol fuel 
station and so, if such methanol were of lower carbon footprint than gasoline, would help to encourage take-up of the more environmentally-friendly fuel.

Probably even more important for real-world impact is the potential for increased part-load efficiency, since this will affect driving cycle efficiency (both legislated and real-world). Actual numbers are rather limited but seem to point to $25 \%$ relative efficiency improvement over gasoline, which however would require engine adaptations so as to better exploit methanol's characteristics for dethrottling the engine. Crucially, even for non-optimized (i.e. gasoline) engines the data typically show increased efficiency (of the order of 5 to $10 \%$ ). Thus, tank-to-wheel efficiency on methanol clearly is higher than for gasoline. However, experimental results are still rather limited so more work would be beneficial, especially exploiting state-of-the-art engine technology (e.g. stratified combustion, highly flexible valvetrains, variable geometry turbines). Also, work is needed to explore potential efficiency benefits (if any) of thermochemical recuperation (fuel reforming using waste heat).

The potential of new concepts (such as partially premixed combustion or MD95), when operated on methanol, is largely unexplored but initial work looks promising so again, more data would be useful. With such data, one could study the best strategy for obtaining high overall efficiency: a stoichiometrically operated (over the entire engine map) downsized direct-injection spark ignition engine with a three-way catalyst (TWC) for aftertreatment, or a stoichiometric compression ignition engine with TWC, or a PPC engine with a simple oxidation catalyst, etc. It also seems interesting to revisit some of the older concepts such as glow plug engines. Clearly we have just started mapping the potential of methanol with state-of-the-art engine technology. As mentioned above, there is more data available for ethanol, so one could start from this fuel for LCA numbers. Application and improvement of simulation tools would also be of great help in completing the picture.

As the current use of methanol in China and the large scale demonstration in California indicate, there are no technical or safety-related reasons for discarding methanol as a viable transportation fuel. However, its properties are clearly different from gasoline's so one should bear these in mind when using methanol. For example, mixing methanol into pump gasoline can lead to problems: such a 'splash blend' is not a drop-in fuel and will lead to potential problems such as increased evaporative emissions. When blending in methanol, the base gasoline should be chosen such that vapour pressures are within acceptable bounds. There are various options to introduce at least some methanol now, without the immediate need for specifically designed vehicles. First of all, both the CEN gasoline standard EN228 and the ASTM D4814-10a standard already allows blending in methanol at low percentages. Second, GEM blends can principally be used in flex-fuel vehicles developed for the use of E85, of which over 50 million vehicles have been sold. Nevertheless, few data are available on blend properties. More data on water tolerance, phase separation and suitable co-solvents would remove barriers for the uptake of such GEM fuels.

Also, in China flex-fuel vehicles for M85 have been developed, as well as conversion kits for retrofitting gasoline cars to be M100 compatible cars. When 
properly executed, i.e. with proper calibration for high-level methanol blends, pollutant emissions have been shown to be below gasoline levels. However, more data are needed on PN emissions, this being a fairly recent addition to some emission legislation and so a topic that has not received much attention yet, at least not for methanol fuelling. Connected to this is work on the effectiveness of aftertreatment for these emissions.

Besides the desired additional research at engine level, previous sections also highlighted a need for a better understanding of some of the processes taking place in engines. As is the case for other fuels, there is very limited data on laminar burning velocity and ignition delay at the pressures encountered in combustion engines. Such data would also serve in extended validation of reaction kinetics or improvement in the reaction schemes. Compared to commonly used liquid fuels today, little is known on methanol sprays (again, at engine conditions). Naturally, improving the understanding of the base phenomena would also enable the improvement of modelling tools. As pointed out in the section on modelling, engine cycle results are sensitive to (besides uncertainties in the laminar burning velocity) the initialization of combustion (initial flame development) and the proper inclusion of fuel evaporation, both of which are fuel dependent.

Building and operating some demonstrator vehicles would be immensely useful, since real-world data can be taken and knowledge gained of how well such technologies can be deployable in society. Captive fleets, where the vehicles return to base to refuel, would seem a good initial target for a fully-optimized engine. These could include heavy-duty SI methanol engines as well as ones employing PPC; operation of such fleets with their depot-sited pumps would minimize the risk of misfuelling with gasoline (or diesel). In terms of optimized engines retaining flex-fuel capability, the SI engines with heavy optimization for methanol mentioned above could be used, but with an alcohol sensor and a protection calibration for gasoline. As mentioned this would alleviate concerns about running out of methanol between filling stations as the infrastructure is developed concurrently. Finally, another possibility is for octane-on-demand demonstration, where methanol is the octane booster; while most such research has been done with one of the fuels being directly-injected and the other provided through a PFI system, it is possible that most of the benefits could be realized with both fuels being introduced at the port. Such an engine might be very cost effective indeed and give excellent efficiency on gasoline at part load (because of the high compression ratio that the OOD approach permits), providing immediate cost of ownership benefits to the end user. Furthermore, through the reduction in tailpipe $\mathrm{CO}_{2}$ emissions in combination with the possibly eliminated requirement for a gasoline particulate filter because of the removal of direct injection, this arrangement could be extremely attractive to OEMs too.

The discussion above has been heavily condensed in the following wrap-up. First, to summarize the advantages and challenges with the use of methanol as a fuel, Fig. 25 offers a general schematic linking methanol's properties to engine performance. As previous sections showed, the reality is usually that one ends 
up with trade-offs so this figure should not be used as is but should be used together with the relevant sections where a more complete picture is given.

Second, in terms of the fuel system and fuel handling, methanol's advantages and disadvantages have been summarized in Table 7 .

Finally, the recommendations for future research and demonstration proposed by us above are, summarized:

- To enable comparison of methanol-fuelled vehicles using ICEs to other alternatives: data is needded on life cycle energy and material use as well as pollutant emissions, of methanol as well as vehicle production and use. Which itself relies on the following point ...

- Assessment of the efficiency potential of a dedicated methanol engine, at peak and part load, exploiting state-of-the-art engine technology.

- Strategies for these engines to enable the use of gasoline (for a 'limp home mode').

- Evaluation of the potential of on-board methanol reforming using engine waste heat.

- Determination of the best strategy for using methanol in CI engines, as this is a technology serving many applications.

- As another important way of introducing methanol is its blending with gasoline, more data on water tolerance, phase separation etc. of these blends are needed.

- Clarifying PN and aldehyde emissions from methanol fuelled operation (engine-out emissions and aftertreatment efficiency).

- Completing the fundamental data, e.g. on burning velocities, ignition delay times, sprays ...

- Improving simulation tools to better capture the effects of using methanol fuel.

- Demonstrator vehicles to collect real-world data and showcase methanol's potential.

- Investigating the cost effectiveness of the different octane-on-demand concepts possible with methanol.

\section{Acknowledgements}

The authors would like to acknowledge the support and encouragement of, and the insights gained from discussions with, among others, the following people (listed roughly alphabetically according to affiliation): Christoph Meichelböck from Abeking \& Rasmussen; Tony Marmont and Peter Harrison of 
Air Fuel Synthesis; Richard Pearson (formerly of Lotus Engineering), Chris Brace, Sam Akehurst and Andy Lewis of the University of Bath; Matt Eisaman of Brookhaven National Laboratory; Paul Wuebben of Carbon Recycling International; Pieter Huyskens of Damen Shipyards; Leon di Marco of FSK Technologies; Gordon Taylor of GT-Systems; Keith Waldron and David Wilson of the Institute of Food Research; Stijn Broekaert, Koen Chielens, Joachim Demuynck, Jeroen Dierickx and Duc-Khanh Nguyen of Ghent University; Philippa Oldham and Tim Fox, both formerly of the Institution of Mechanical Engineers; Steve Brueckner, formerly of Lotus Engineering Inc.; Martin Tunér from Lund University; Ben Iosefa and Michel Hamrouni of Methanex; Eelco Dekker, Greg Dolan and Matt Roberts of the Methanol Institute; Leslie Bromberg and Daniel Cohn of MIT; Frank Zeman of New York Institute of Technology; Martin Davy, Felix Leach and Richard Stone of the University of Oxford; Kenth Johansson and Kjell ac Bergström of Saab Automobile Powertrain AB; Gareth Floweday and Andre Swarts of Sasol Technology; the late George Olah and Surya Prakash and Alain Goeppert of the University of Southern California; Karl Littau of Stanford University and Matt Brusstar of the United States Environmental Protection Agency.

J. Vancoillie and L. Sileghem gratefully acknowledge Ph.D. fellowships of the Research Foundation - Flanders (FWO09/ASP/030 and FWO11/ASP/056). S. Verhelst acknowledges the LeanShips project, funded in the H2020 Work Programme of the European Union (Contract No.: 636146); and the Special Research Fund (BOF) of Ghent University for the research grants No. 01N03013 and BOF16/GOA/004.

\section{Nomenclature}

[1] ICIS, Chemical profile special, ICIS Chemical Business (26 May - 1 June 2017).

[2] I. Landälv, Methanol as a renewable fuel - a knowledge synthesis., Tech. rep., f3 - The Swedish Knowledge Centre for Renewable Transportation Fuels, available at www.f3centre.se. (2017).

[3] A. Goeppert, M. Czaun, J.-P. Jones, et al., Recycling of carbon dioxide to methanol and derived products - closing the loop, Chemical Society Reviews 43 (23) (2014) 7995-8048.

[4] J. A. Martens, A. Bogaerts, N. De Kimpe, P. A. Jacobs, G. B. Marin, K. Rabaey, M. Saeys, S. Verhelst, The chemical route to a carbon dioxide neutral world, ChemSusChem 10 (2017) 1039-1055.

[5] C. Schweitzer, Synthesizing strengths of 1st and 3rd generation biorefineries. Biomethanol as a biorefinery product, International Sugar Journal October 2014 (2014) pp.64-70.

[6] T. Boyd, Pathfinding in fuels and engines, SAE Quarterly Transactions Vol. 4 (1950) pp. 182-195. 
[7] H. Dickinson, The cooperative fuel research and its results, SAE Transactions Vol. 24 (1929) pp. 262-265.

[8] I. Baxter, B. Yeo. An international historic mechanical engineering landmark - the Waukesha CFR fuel research engine [online] (1928). url: https://www.asme.org/getmedia/ffedc33f-7e2b-4775-95ec2f633ddc16f6/50-Cooperative-Fuel-Research-Engine-1928.aspx.

[9] K. Ludvigsen, Classic Racing Engines, Haynes Publishing, Sparkford, Somerset, UK, 2001.

[10] K. Morganti, M. Abdullah, A. Alzubail, et al., Improving the efficiency of conventional spark-ignition engines using octane-on-demand combustion. part I: Engine studies, SAE paper nr. 2016-01-0679 (2016).

[11] K. Morganti, A. Alzubail, M. Abdullah, et al., Improving the efficiency of conventional spark-ignition engines using octane-on-demand combustion - part II: Vehicle studies and life cycle assessment, SAE Technical Paper 2016-01-0683 (2016).

[12] G. Bourhis, J. Solari, V. Morel, et al., Using ethanol's double octane boosting effect with low RON naphtha-based fuel for an octane on demand SI engine, SAE Int. J. Engines 9 (3) (2016) 1460-1474.

[13] G. Bourhis, J. Solari, R. Dauphin, et al., Fuel properties and engine injection configuration effects on the octane on demand concept for a dual-fuel turbocharged spark ignition engine, SAE Technical Paper 2016-01-2307 (2016).

[14] Y. S. Jo, L. Bromberg, J. Heywood, Optimal use of ethanol in dual fuel applications. effects of engine downsizing, spark retard, and compression ratio on fuel economy, SAE International Journal of Engines 9 (2) (2016) 1087-1101.

[15] R. Daniel, C. Wang, H. Xu, et al., Dual-injection as a knock mitigation strategy using pure ethanol and methanol, SAE paper no. 2012-01-1152 (2012).

[16] R. A. Stein, C. J. House, T. G. Leone, Optimal use of E85 in a turbocharged direct injection engine, SAE paper no. 2009-01-1490 (2009).

[17] J. Porter, Alcohol as a high octane fuel, SAE paper number 510086 (1951).

[18] K. Bergström, H. Nordin, A. Konigstein, et al., ABC - alcohol based combustion engines - challenges and opportunities, in: 16th Aachener Kolloquium Fahrzeug- und Motorentechnik, Aachen, 2007, pp. 1031-1072.

[19] P. Ward, J. Teague, Fifteen years of fuel methanol distribution, in: 11th Conference on Alcohol Fuels, Sun City, SA, 1996, pp. 1-12. 
[20] R. Nichols, The methanol story: a sustainable fuel for the future, Journal of Scientific \& Industrial Research 62 (January-February) (2003) 97-105.

[21] P. Wuebben, R. Nankee, R. Pefley, Gasoline tolerant methanol fueled ride share van, SAE paper no. 911630 (1991).

[22] F. Black, S. Tejada, M. Gurevich, Alternative fuel motor vehicle tailpipe and evaporative emissions composition and ozone potential, Journal of the Air \& Waste Management Association 48 (7) (1998) 578-591.

[23] R. J. Pearson, J. W. G. Turner, GEM ternary blends: Testing isostoichiometric mixtures of gasoline, ethanol and methanol in a production flex-fuel vehicle fitted with a physical alcohol sensor, SAE paper no. 2012-01-1279 (2012).

[24] C.-J. Yang, R. B. Jackson, China's growing methanol economy and its implications for energy and the environment, Energy Policy 41 (2012) 878-884.

[25] X. Wang, Y. Ge, L. Liu, et al., Regulated, carbonyl emissions and particulate matter from a dual-fuel passenger car burning neat methanol and gasoline, SAE paper number 2015-01-1082 (2015).

[26] G. Dankner, Methanol as a fuel alternative, 2017 Washington Methanol Policy Forum, available at http://www.methanol.org/wpcontent/uploads/2017/06/Dor-Methanol-Economy-June-2017.pdf (2017).

[27] Australian GEM fuel program, available at http://methanolfuels.org/wpcontent/uploads/2013/05/Grant-Lukey-Coogee-Energy-Australia.pdf (2013).

[28] Methanol fuels [online] (2017). url: http://methanolfuels.org/.

[29] The Methanol Institute [online] (2017). url: http://www.methanol.org.

[30] G. Olah, A. Goeppert, G. Prakash, Beyond Oil and Gas: the Methanol Economy, Wiley-VCH, Weinheim, Germany, 2006.

[31] G. Bozzano, F. Manenti, Efficient methanol synthesis: Perspectives, technologies and optimization strategies, Progress in Energy and Combustion Science 56 (2016) 71-105.

[32] L. Sileghem, A study of the combustion of alcohol-gasoline blends in internal combustion engines., Ph.D. thesis, Ghent University (2015).

[33] H. Keuken, T. MacDonald, E. de Jager, et al., Hydrous ethanol for gasoline blending, in: 17th International Symposium on Alcohol Fuels, Tiayuan China, 2008, pp. 1-15. 
[34] T. Johansen, J. Schramm, Low-temperature miscibility of ethanolgasoline-water blends in flex fuel applications, Energy Sources, Part A: Recovery, Utilization, and Environmental Effects 31 (18) (2009) 16341645.

[35] R. Hammerschlag, Ethanol's energy return on investment:a survey of the literature 1990-present, Environmental Science \& Technology 40 (6) (2006) 1744-1750.

[36] International Energy Agency, IEA biofuel roadmap, Tech. rep., International Energy Agency (2011).

URL http://www.ieabioenergy.com/publications/ iea-biofuel-roadmap/

[37] Energy independence and security act, available at https://www.congress.gov/bill/110th-congress/house-bill/6 (2007).

[38] C. Bergins, E. L. Fox, K. C. Tran, P. Wuebben, Commercialization of low carbon methanol, ATZextra worldwide 21(Suppl 11) (2016) 22-25.

[39] R. J. Pearson, M. D. Eisaman, J. W. G. Turner, et al., Energy storage via carbon-neutral fuels made from $\mathrm{CO} 2$, water, and renewable energy, Proceedings of the IEEE 100 (2012) 440-460.

[40] M. Gardiner. Energy requirements for hydrogen gas compression and liquefaction as related to vehicle storage needs [online] (2009).

[41] M. Specht, F. Baumgart, B. Feigl, V. Frick, et al., Storing bioenergy and renewable electricity in the natural gas grid., in: FVEE-AEE Topics, 2009, pp. 69-78.

[42] F. Amaseder, G. Krainz, Liquid hydrogen storage systems developed and manufactured for the first time for customer cars, SAE paper no. 200601-0432 (2006).

[43] U. Bossel, B. Eliasson, G. Taylor, The future of the hydrogen economy: Bright or bleak?, Cogeneration and Competitive Power Journal 18 (3).

[44] U. Bossel, Does a hydrogen economy make sense?, Proceedings of the IEEE 94 (10) (2006) 1826-1837.

[45] J. Leonard, Energy Depot, Rolls-Royce Heritage Trust, Allison Branch, 2011.

[46] M. Steinberg, Synthetic carbonaceous fuels and feedstocks from oxides of carbon and nuclear power, Fuel 57 (8) (1978) 460-468.

[47] M. Steinberg, Methanol as an agent for CO2 mitigation, Energy Convers. Mgmt Vol. 38 (1997) pp. S423-S430. 
[48] T. Weimer, K. Schaber, M. Specht, et al., Methanol from atmospheric carbon dioxide: A liquid zero emission fuel for the future, Energy Conversion and Management 37 (6) (1996) 1351-1356.

[49] J. Turner, R. Pearson, Renewable fuels - an automotive perspective, in: D. Roddy (Ed.), Comprehensive Renewable Energy, Elsevier, Amsterdam, 2012, pp. $1-74$.

[50] B. S, T. M, G. M, H. J, Electrofuels for the transport sector: A review of production costs, Renewable and Sustainable Energy Reviews 81 (2018) 1887-1905.

[51] L. France, P. P. Edwards, V. Kuznetsov, et al., The Indirect and Direct Conversion of CO2 into Higher Carbon Fuels, Elsevier, 2015.

[52] L. Bromberg, W. Cheng, Methanol as an alternative transportation fuel in the US: Options for sustainable and/or energy-secure transportation, Tech. Rep. PSFC/JA-10-49, Massachusetts Institute of Technology (2010).

[53] P. Machiele, Flammability and toxicity tradeoffs with methanol fuels, SAE technical paper 872064 (1987).

[54] P. Machiele, Summary of the fire safety impacts of methanol as a transportation fuel, SAE technical paper 901113 (1990).

[55] R. Gable, Comparison of acute lethal toxicity of commonly abused psychoactive substances, Addiction Vol. 99 (2004) pp. 686-696.

[56] Bitrex.com. About Bitrex [online] (2017). url: http://www.bitrex.com/en-us/about-bitrex.

[57] J. Turner, A. Lewis, S. Akehurst, et al., Alcohol fuels for spark-ignition engines: performance, efficiency and emissions effects at mid to high blend rates for binary mixtures and pure components, IMechE Part D: Journal of Automobile Engineering 232 (2018) 36-56.

[58] The Standards Institution of Israel. Israel M15 press release [online]. url: http://methanolfuels.wpengine.com/wpcontent/uploads/2013/05/Israel-M15-Press-Release-8_2016.pdf.

[59] J. E. Anderson, U. Kramer, S. A. Mueller, et al., Octane numbers of ethanol and methanol gasoline blends estimated from molar concentrations, Energy \& Fuels 24 (12) (2010) 6576-6585.

[60] E. Kasseris, J. Heywood, Charge cooling effects on knock limits in SI DI engines using gasoline/ethanol blends: Part 1-quantifying charge cooling, SAE paper no. 2012-01-1275 (2012). 
[61] E. Kasseris, J. Heywood, Charge cooling effects on knock limits in SI DI engines using gasoline/ethanol blends: Part 2-effective octane numbers, SAE paper no. 2012-01-1284 (2012).

[62] D. Turner, H. Xu, R. F. Cracknell, et al., Combustion performance of bio-ethanol at various blend ratios in a gasoline direct injection engine, Fuel 90 (5) (2011) 1999-2006.

[63] J. W. G. Turner, R. J. Pearson, A. Bell, et al., Iso-stoichiometric ternary blends of gasoline, ethanol and methanol: Investigations into exhaust emissions, blend properties and octane numbers, SAE paper no. 201201-1586 (2012).

[64] J. W. G. Turner, R. J. Pearson, E. Dekker, et al., Extending the role of alcohols as transport fuels using iso-stoichiometric ternary blends of gasoline, ethanol and methanol, Applied Energy 102 (2013) 72-86.

[65] J. E. Anderson, D. M. DiCicco, J. M. Ginder, et al., High octane number ethanol-gasoline blends: Quantifying the potential benefits in the United States, Fuel 97 (2012) 585-594.

[66] J. Turner, R. Pearson, R. Purvis, et al., GEM ternary blends: Removing the biomass limit by using iso-stoichiometric mixtures of gasoline, ethanol and methanol, SAe paper no. 2011-24-0113 (2011).

[67] R. Furey, J. King, Volatility characteristics of gasoline-alcohol and gasoline-ether fuel blends, SAE Technical Paper 852116 (1985).

[68] A. Yates, A. Bell, A. Swarts, Insights relating to the autoignition characteristics of alcohol fuels, Fuel 89 (1) (2010) 83-93.

[69] J. Milpied, N. Jeuland, G. Plassat, et al., Impact of fuel properties on the performances and knock behaviour of a downsized turbocharged DI SI engine - focus on octane numbers and latent heat of vaporization, SAE paper no. 2009-01-0324 (2009).

[70] L. Bromberg, D. Cohn, Effective octane and efficiency advantages of direct injection alcohol engines, Tech. rep., MIT Laboratory for Energy and the Environment (2008).

[71] G. Kalghatgi, Fuel anti-knock quality - part I. engine studies, SAE technical paper 2001-01-3584 (2001).

[72] G. Kalghatgi, Fuel anti-knock quality - part II. vehicle studies - how relevant is motor octane number (MON) in modern engines?, SAE paper number 2001-01-3585 (2001).

[73] A. D. B. Yates, A. Swarts, C. L. Viljoen, Correlating auto-ignition delays and knock-limited spark-advance data for different types of fuel, SAE paper no. 2005-01-2083 (2005). 
[74] C. Beck, P. Stevenson, P. Ziman, The impact of gasoline octane on fuel economy in modern vehicles, SAE paper number 2006-02-3407 (2006).

[75] A. Amer, H. Babiker, J. Chang, et al., Fuel effects on knock in a highly boosted direct injection spark ignition engine, SAE paper no. 2012-01-1634 (2012).

[76] R. Luef, P. Grabner, H. Eichlseder, C. Martin, J. Graf, B. Geringer, Development of a new test procedure to determine fuel and oil impact on irregular combustion phenomena with focus on highly boosted downsized S.I. engines, in: 23rd Aachen Colloquium, Aachen, Germany, 2014, pp. 1169-1204.

[77] J. Szybist, K. Chakravathy, C. Daw, Analysis of the impact of selected fuel thermochemical properties on internal combustion engine efficiency, Energy\&Fuels 26 (2012) 2798-2810.

[78] S. M. Sarathy, P. Osswald, N. Hansen, et al., Alcohol combustion chemistry, Progress in Energy and Combustion Science 44 (2014) 40-102.

[79] E. Fernández-Tarrazo, M. Sánchez-Sanz, A. L. Sánchez, et al., Minimum ignition energy of methanol-air mixtures, Combustion and Flame 171 (2016) 234-236.

[80] R. Pearson, J. Turner, B. Holland, et al., Alcohol-based fuels in high performance engines, SAE paper no. 2007-01-0056 (2007).

[81] U. Burke, W. K. Metcalfe, S. M. Burke, et al., A detailed chemical kinetic modeling, ignition delay time and jet-stirred reactor study of methanol oxidation, Combustion and Flame 165 (2016) 125-136.

[82] E. Svensson, C. Li, S. Shamun, et al., Potential levels of soot, NOx, HC and CO for methanol combustion, SAE Technical Paper 2016-01-0887 (2016).

[83] J. B. Heywood, Internal Combustion Engine Fundamentals, McGraw-Hill series in mechanical engineering, MacGraw-Hill, New York, 1988.

[84] A. Kumar, D. S. Khatri, M. K. G. Babu, An investigation of potential and challenges with higher ethanol-gasoline blend on a single cylinder spark ignition research engine, SAE paper no. 2009-01-0137 (2009).

[85] S. H. Liu, E. R. C. Clemente, T. G. Hu, et al., Study of spark ignition engine fueled with methanol/gasoline fuel blends, Applied Thermal Engineering 27 (11-12) (2007) 1904-1910.

[86] K. Nakata, S. Utsumi, A. Ota, et al., The effect of ethanol fuel on a spark ignition engine, SAE paper no. 2006-01-3380 (2006). 
[87] Y. Wei, S. Liu, F. Liu, et al., Formaldehyde and methanol emissions from a methanol/gasoline-fueled spark-ignition (SI) engine, Energy \& Fuels 23 (6) (2009) 3313-3318.

[88] C. Sandstroem-Dahl, L. Erlandsson, J. Gasste, et al., Measurement methodologies for hydrocarbons, ethanol and aldehyde emissions from ethanol fuelled vehicles, SAE paper no. 2010-01-1557 (2010).

[89] T. Wallner, Correlation between speciated hydrocarbon emissions and flame ionization detector response for gasoline/alcohol blends, Journal of Engineering for Gas Turbines and Power 133 (8) (2011) 1-8.

[90] P. Aleiferis, J. Serras-Pereira, D. Richardson, Characterisation of flame development with ethanol, butanol, iso-octane, gasoline and methane fuels in a direct-injection spark-ignition engine, Fuel 109 (2013) 256-278.

[91] P. Geng, H. Zhang, S. Yang, et al., Comparative study on measurements of formaldehyde emission of methanol/gasoline fueled SI engine, Fuel 148 (2015) 9-15.

[92] S. Verhelst, C. G. W. Sheppard, Multi-zone thermodynamic modelling of spark-ignition engine combustion - an overview, Energy Conversion and Management 50 (5) (2009) 1326-1335.

[93] J. Szybist, D. Splitter, Effects of fuel composition on EGR dilution tolerance in spark ignited engines, SAE Int. J. Engines 9 (2) (2016) 819-831.

[94] A. N. Lipatnikov, J. Chomiak, Turbulent flame speed and thickness: phenomenology, evaluation, and application in multi-dimensional simulations, Progress in Energy and Combustion Science 28 (1) (2002) 1-74.

[95] J. Vancoillie, S. Verhelst, J. Demuynck, Laminar burning velocity correlations for methanol-air and ethanol-air mixtures valid at SI engine conditions, SAE paper no. 2011-01-0846 (2011).

[96] J. Li, Z. W. Zhao, A. Kazakov, et al., A comprehensive kinetic mechanism for $\mathrm{CO}, \mathrm{CH} 2 \mathrm{O}$, and $\mathrm{CH} 3 \mathrm{OH}$ combustion, International Journal of Chemical Kinetics 39 (3) (2007) 109-136.

[97] L. Sileghem, A. Coppens, B. Casier, et al., Performance and emissions of iso-stoichiometric ternary GEM blends on a production SI engine, Fuel 117 (2014) 286-293.

[98] S. Verhelst, C. T'Joen, J. Vancoillie, et al., A correlation for the laminar burning velocity for use in hydrogen spark ignition engine simulation, International Journal of Hydrogen Energy 36 (1) (2010) 957-974.

[99] X. J. Gu, M. Z. Haq, M. Lawes, et al., Laminar burning velocity and Markstein lengths of methane-air mixtures, Combustion and Flame 121 (1) (2000) 41-58. 
[100] L. Sileghem, V. A. Alekseev, J. Vancoillie, et al., Laminar burning velocity of gasoline and the gasoline surrogate components iso-octane, n-heptane and toluene, Fuel 112 (2013) 355-365.

[101] A. Katoch, M. Asad, S. Minaev, et al., Measurement of laminar burning velocities of methanol-air mixtures at elevated temperatures, Fuel 182 (2016) 57-63.

[102] J. Beeckmann, L. Cai, H. Pitsch, Experimental investigation of the laminar burning velocities of methanol, ethanol, n-propanol, and n-butanol at high pressure, Fuel 117 (2014) 340-350.

[103] Z. Zhang, Z. Huang, X. Wang, et al., Measurements of laminar burning velocity and markstein lengths for methanol-air-nitrogen mixtures at elevated pressures and temperatures, Combustion and Flame 155 (3) (2008) $358-368$.

[104] J. Vancoillie, G. Sharpe, M. Lawes, et al., The turbulent burning velocity of methanol-air mixtures, Fuel 130 (2014) 76-91.

[105] S. Verhelst, A study of the combustion in hydrogen-fuelled internal combustion engines, Ph.D. thesis, Ghent University (2005).

[106] K. Ohara, M. Tsukikawa, Y. Araki, et al., Properties Of Ethanol Laminar And Turbulent Premixed Flames, Proceedings of the International Conference on Power Engineering 2009, Japan Soc. Mechanical Engineers, Tokyo, 2009.

[107] M. Lawes, M. P. Ormsby, C. G. W. Sheppard, et al., Variation of turbulent burning rate of methane, methanol, and iso-octane air mixtures with equivalence ratio at elevated pressure, Combustion Science and Technology 177 (7) (2005) $1273-1289$.

[108] A. N. Lipatnikov, J. Chomiak, Effects of premixed flames on turbulence and turbulent scalar transport, Progress in Energy and Combustion Science 36 (1) (2010) 1-102.

[109] F. M. Haas, M. Chaos, F. L. Dryer, Low and intermediate temperature oxidation of ethanol and ethanol-PRF blends: An experimental and modeling study, Combustion and Flame 156 (12) (2009) 2346-2350.

[110] A. A. Burluka, K. Liu, C. G. W. Sheppard, et al., The influence of simulated residual and NO concentrations on knock onset for PRFs and gasolines, SAE paper no. 2004-01-2998 (2004).

[111] J. C. Livengood, P. C. Wu, Correlation of autoignition phenomena in internal combustion engines and rapid compression machines, Symposium (International) on Combustion 5 (1) (1955) 347-356. 
[112] A. M. Douaud, P. Eyzat, Four-octane-number method for predicting the anti-knock behavior of fuels and engines, SAE paper no. 780080 (1978).

[113] S. Bougrine, S. Richard, Modelling and simulation of the combustion of ethanol blended fuels in a SI engine using a 0D coherent flame model, SAE paper no. 2009-24-0016 (2009).

[114] A. Boretti, Towards 40\% efficiency with BMEP exceeding 30 bar in directly injected, turbocharged, spark ignition ethanol engines, Energy Conversion and Management 57 (2012) 154-166.

[115] D. Frankzke, Beitrag zur ermittlung eines klopfkriteriums der ottomotorischen verbrennung und zur vorausberechnung der klopfgrenze, Ph.D. thesis, Technical University of Munich (1981).

[116] C. T. Bowman, Shock-tube investigation of high-temperature oxidation of methanol, Combustion and Flame 25 (3) (1975) 343-354.

[117] K. Natarajan, K. A. Bhaskaran, An experimental and analytical study of methanol ignition behind shock waves, Combustion and Flame 43 (0) (1981) 35-49.

[118] K. Kumar, C.-J. Sung, Autoignition of methanol: Experiments and computations, International Journal of Chemical Kinetics 43 (4) (2011) 175184.

[119] W. Zeng, M. Xu, M. Zhang, et al., Macroscopic characteristics for directinjection multi-hole sprays using dimensionless analysis, Experimental Thermal and Fluid Science 40 (2012) 81-92.

[120] P. G. Aleiferis, Z. R. van Romunde, An analysis of spray development with iso-octane, n-pentane, gasoline, ethanol and n-butanol from a multi-hole injector under hot fuel conditions, Fuel 105 (2013) 143-168.

[121] J. Gao, D. Jiang, Z. Huang, Spray properties of alternative fuels: A comparative analysis of ethanol-gasoline blends and gasoline, Fuel 86 (10) (2007) 1645-1650.

[122] W. Zeng, M. Xu, G. Zhang, et al., Atomization and vaporization for flashboiling multi-hole sprays with alcohol fuels, Fuel 95 (2012) 287-297.

[123] P. G. Aleiferis, J. Serras-Pereira, A. Augoye, et al., Effect of fuel temperature on in-nozzle cavitation and spray formation of liquid hydrocarbons and alcohols from a real-size optical injector for direct-injection sparkignition engines, International Journal of Heat and Mass Transfer 53 (21) (2010) 4588-4606.

[124] W. J. Most, J. P. Longwell, Single-cylinder engine evaluation of methanol - improved energy economy and reduced NOx, SAE Paper no. 750119 (1975). 
[125] I. Hunwartzen, Modification of CFR test engine unit to determine octane numbers of pure alcohols and gasoline-alcohol blends, SAE paper no. 820002 (1982).

[126] K. Liang, R. Stone, Laminar burning velocity measurement of hydrous methanol at elevated temperatures and pressures, Fuel 204 (2017) 206213.

[127] V. F. Andersen, J. E. Anderson, T. J. Wallington, et al., Vapor pressures of alcohol-gasoline blends, Energy \& Fuels 24 (6) (2010) 3647-3654.

[128] R. Furey, K. Perry, Vapor pressures of mixtures of gasolines and gasolinealcohol blends, SAE Technical Paper 861557 (1986).

[129] Y. R. Q. Jiao, R. Reitz, Modeling the influence of molecular interactions on the vaporization of multi-component fuel sprays, SAE paper no. 201101-0387 (2011).

[130] V. F. Andersen, J. E. Anderson, T. J. Wallington, et al., Distillation curves for alcohol-gasoline blends, Energy \& Fuels 24 (4) (2010) 2683-2691.

[131] J. E. Anderson, T. G. Leone, M. H. Shelby, et al., Octane numbers of ethanol-gasoline blends: Measurements and novel estimation method from molar composition, SAE paper no. 2012-01-1274 (2012).

[132] P. W. Atkins, Physical Chemistry, 5th Edition, Oxford University Press, 1994.

[133] H. V. W. Skinner, Corrosion of carburettor materials, Corrosion Coatings, South Africa 34 (1981) 5-9.

[134] D. Qi, Q. Liu, H. Zhang, et al., Properties, performance, and emissions of methanol-gasoline blends in a spark ignition engine, Proceedings of the Institution of Mechanical Engineers, Part D: Journal of Automobile Engineering 219 (3) (2005) 405-412.

[135] R. G. Donnelly, J. B. Heywood, J. LoRusso, et al., Methanol as an automotive fuel: a summary of research in the M.I.T. energy laboratory, Tech. rep., Energy Laboratory, Massachusetts Institute of Technology (1976).

[136] M. Gramajo de Doz, C. Bonatti, H. S'olimo, Liquid-liquid equilibria of water + ethanol + reformate, Fluid Phase Equilibria 230 (2005) 45-50.

[137] L. Sileghem, J. Vancoillie, J. Demuynck, et al., Alternative fuels for sparkignition engines: Mixing rules for the laminar burning velocity of gasolinealcohol blends, Energy \& Fuels 26 (8) (2012) 4721-4727.

[138] T. Hirasawa, C. J. Sung, A. Joshi, et al., Determination of laminar flame speeds using digital particle image velocimetry: Binary fuel blends of ethylene, n-butane, and toluene, Proceedings of the Combustion Institute 29 (2) (2002) 1427-1434. 
[139] J. Warnatz, U. Maas, R. Dibble, Combustion: Physical and Chemical Fundamentals, Modeling and Simulation, Experiments, Pollutant Formation, Springer-Verlag, Berlin, Germany, 1996.

[140] L. Sileghem, T. Wallner, S. Verhelst, A quasi-dimensional model for si engines fueled with gasoline-alcohol blends: Knock modeling, Fuel 140 (2015) 217-226.

[141] R. Pearson, J. Turner, A. Bell, de Goede S, C. Woolard, M. Davy, Isostoichiometric fuel blends: characterisation of physicochemical properties for mixtures of gasoline, ethanol, methanol and water, IMechE Part D: Journal of Automobile Engineering 229 (2015) 111-139.

[142] M. Waqas, N. Naser, M. Sarathy, et al., Auto-ignition of iso-stoichiometric blends of gasoline-ethanol-methanol (GEM) in SI, HCCI and CI combustion modes, SAE technical paper 2017-01-0726 (2017).

[143] P. Dai, Y. Ge, Y. Lin, et al., Investigation on characteristics of exhaust and evaporative emissions from passenger cars fueled with gasoline/methanol blends, Fuel 113 (2013) 10-16.

[144] H. Xiang, Introduction of Jetsun methanol fuel additives and engine oils, Tech. rep., Guangzhou Jetsun Lubrication Technology Co., Ltd. (2015).

[145] G. A. McCoy, J. Kerstetter, J. K. Lyons, Alcohol-fueled vehicles, Tech. Rep. WSE-93/25, Washington State Energy Office (1993).

[146] P. K. P. Yuen, W. Villaire, J. Beckett, Automotive materials engineering challenges and solutions for the use of ethanol and methanol blended fuels, SAE paper no. 2010-01-0729 (2010).

[147] J. Turner, R. Pearson, P. Harrison, et al., Evolutionary decarbonization of transport: a contiguous roadmap to affordable mobility for everyone using sustainable organic fuels for transport, in: 2012 IMechE Sustainable Vehicle Technologies Conference, Gaydon, UK, 2012, pp. 71-88.

[148] D. L. Hagen, Methanol as a fuel: a review with bibliography, SAE paper no. 770792 (1977).

[149] M. Walker, R. Chance, Corrosion of metals and the effectiveness of inhibitors in ethanol fuels, SAE paper no. 831828 (1983).

[150] C. M. Hansen, Hansen Solubility Parameters. A User's Handbook., CRC Press, Fort Lauderdale, FA, 2007.

[151] J. C. Ingamells, R. H. Lindquist, Methanol as a motor fuel or a gasoline blending component, SAE Technical Paper 750123 (1975).

[152] J. S. Cowart, W. E. Boruta, J. D. Dalton, et al., Powertrain development of the 1996 Ford Flexible Fuel Taurus, SAE paper no. 952751 (1995). 
[153] D. Kabasin, K. Hoyer, J. Kazour, et al., Heated injectors for ethanol cold starts, SAE paper no. 2009-01-0615 (2009).

[154] C.-M. Gong, J. Li, J.-K. Li, et al., Effects of ambient temperature on firing behavior and unregulated emissions of spark-ignition methanol and liquefied petroleum gas/methanol engines during cold start, Fuel 90 (1) (2011) 19-25.

[155] C. Colpin, T. Leone, M. Lhuillery, et al., Key parameters for startability improvement applied to ethanol engines, SAE paper no. 2009-01-0616 (2009).

[156] M. J. Brusstar, M. Stuhldreher, D. Swain, et al., High efficiency and low emissions from a port-injected engine with neat alcohol fuels, SAE paper no. 2002-01-2743 (2002).

[157] K. Aikawa, T. Sakurai, A. Hayashi, Study of ethanol-blended fuel (E85) effects under cold-start conditions, SAE paper no. 2009-01-0620 (2009).

[158] A. Markel, B. Bailey, Modeling and cold start in alcohol-fueled engines, Tech. rep., National Renewable Energy Laboratory (1998).

[159] R. M. Siewert, E. G. Groff, Unassisted cold starts to -29 deg c and steadystate tests of a direct-injection stratified-charge (disc) engine operated on neat alcohols, SAE paper no. 872066 (1987).

[160] C. D. Marriott, M. Wiles, J. M. Gwidt, et al., Development of a naturally aspirated spark ignition direct injected flex-fuel engine, SAE paper no. 2008-01-0319 (2008).

[161] G. T. Kalghatgi, D. Bradley, Pre-ignition and 'super-knock' in turbocharged spark-ignition engines, International Journal of Engine Research 13 (4) (2012) 399-414.

[162] T. Suga, S. Kitajima, I. Fujii, Pre-ignition phenomena of methanol fuel (M85) by the post-ignition technique, SAE paper no. 892061 (1989).

[163] M. B. Giroldo, E. Werninghaus, E. Coelho, et al., Development of 1.6L flex fuel engine for Brazilian market, SAE paper no. 2005-01-4130 (2005).

[164] K. Bergström, S.-A. Melin, C. C. Jones, The new ECOTEC turbo Biopower engine from GM powertrain, in: 28th international vienna motor symposium, Vienna, 2007, pp. 1-39.

[165] R. Bruetsch, R. Schaefer, G. Piotrowski, Evaluation of specialized catalysts for methanol (M100) vehicles, Tech. Rep. EPA/AA/TDG/93-03, U.S. Environmental Protection Agency (1993).

URL https://nepis . epa.gov/Exe/ZyPURL . cgi?Dockey=9100X5VW . txt 
[166] R. C. Clemente, E. Werninghaus, E. P. D. Coelho, et al., Development of an internal combustion alcohol-fueled engine, SAE paper no. 2001-01-3917 (2001).

[167] G. R. Neame, D. P. Gardiner, R. W. Mallory, et al., Improving the fuel economy of stoichiometrically fuelled S.I. engines by means of EGR and enhanced ignition - a comparison of gasoline, methanol and natural gas, SAE paper no. 952376 (1995).

[168] G. M. Pannone, R. T. Johnson, Methanol as a fuel for a lean turbocharged spark-ignition engine, SAE paper no. 890435 (1989).

[169] J. Li, C.-M. Gong, Y. Su, et al., Effect of injection and ignition timings on performance and emissions from a spark-ignition engine fueled with methanol, Fuel 89 (12) (2010) 3919-3925.

[170] A. Koenig, W. Lee, W. Bernhardt, Technical and economical aspects of methanol as an automotive fuel, SAE paper no. 760545 (1975).

[171] M. J. Brusstar, High efficiency with future alcohol fuels in a stoichiometric medium duty spark ignition engine, SAE paper no. 2007-01-3993 (2007).

[172] J. Vancoillie, J. Demuynck, L. Sileghem, et al., The potential of methanol as a fuel for flex-fuel and dedicated spark-ignition engines, Applied Energy 102 (2013) 140-149.

[173] K. Naganuma, J. Vancoillie, L. Sileghem, S. Verhelst, et al., Drive cycle analysis of load control strategies for methanol fuelled ICE vehicle, SAE Technical paper no. 2012-01-1606 (2012).

[174] Lotus engineering software [online] (2018). url: http://www.lotuscars.com/engineering/engineering-software.

[175] J. Vancoillie, J. Demuynck, L. Sileghem, et al., Comparison of the renewable transportation fuels, hydrogen and methanol formed from hydrogen, with gasoline - engine efficiency study, International Journal of Hydrogen Energy 37 (2011) 9914-9924.

[176] L. Sileghem, A. Ickes, T. Wallner, et al., Experimental investigation of a DISI production engine fuelled with methanol, ethanol, butanol and isostoichiometric alcohol blends, SAE technical paper 2015-01-0768 (2015).

[177] D.-K. Nguyen, T. V. Craeynest, T. Pillu, et al., Downsizing potential of methanol fueled DISI engine with variable valve timing and boost control, SAE Technical Paper 2018-01-0918 (2018).

[178] H. Windawi, Controlling the exhaust emissions from alternative fuel vehicles. new opportunity for platinum metals catalysts, Platinum Metals Rev. 36 (4) (1992) 185-195. 
[179] P. Geng, H. Zhang, S. Yang, Experimental investigation on the combustion and particulate matter (PM) emissions from a port-fuel injection (PFI) gasoline engine fueled with methanol-ultralow sulfur gasoline blends, Fuel 145 (2015) 221-227.

[180] J. Ketterer, W. Cheng, On the nature of particulate emissions from DISI engines at cold-fast-idle, SAE International Journal of Engines 7 (2014) 986-994. doi:10.4271/2014-01-1368.

[181] X. Wang, Y. Ge, L. Liu, et al., Evaluation on toxic reduction and fuel economy of a gasoline direct injection- (GDI-) powered passenger car fueled with methanol-gasoline blends with various substitution ratios, Applied Energy 157 (2015) 134-143.

[182] L. Sileghem, T. Huylebroeck, A. Van den Bulcke, et al., Performance and emissions of a SI engine using methanol-water blends, SAE technical paper 2013-01-1319 (2013).

[183] D. Cohn, L. Bromberg, J. Heywood, Direct injection ethanol boosted gasoline engines: Biofuel leveraging for cost effective reduction of oil dependence and CO2 emissions, Tech. rep., MIT Plasma Science and Fusion Centre, Massachusetts Institute of Technology (2005).

[184] L. Bromberg, D. Cohn, J. Heywood, Calculations of knock suppression in highly turbocharged gasoline/ethanol engines using direct ethanol injection, Tech. rep., MIT Laboratory for Energy and the Environment (2006).

[185] B. Gunston, World Encyclopaedia of Aero Engines, 3rd Edition, Patrick Stephens Limited, Sparkford, Yeoville, Somerset, BA22 7JJ, UK, 1995.

[186] F. Berni, S. Breda, A. D'Adamo, et al., Numerical investigation on the effects of water/methanol injection as knock suppressor to increase the fuel efficiency of a highly downsized GDI engine, SAE technical paper 2015-24-2499 (2015).

[187] M. Böhm, W. Mährle, H.-C. Bartelt, et al., Functional integration of water injection into the gasoline engine, MTZ Vol. 77 (01/2016) (2016) pp. $36-40$.

[188] M. Böhm, B. Durst, G. Unterweger, et al., Approaches for on-board water provision for water injection, ATZ Vol. 118 (01/2016) (2016) pp. 54-57.

[189] L. Bromberg, Benchmarking of alcohol chemical kinetic mechanism for laminar flame speed calculations, Tech. rep., MIT Plasma Science and Fusion Center (2008).

[190] D. Cohn, L. Bromberg, Dual-fuel gasoline-alcohol engines for heavy duty trucks: Lower emissions, flexible -fuel alternative to diesel engines, SAE paper no. 2018-01-0888 (2018). 
[191] P. Whitaker, Y. Shen, C. Spanner, et al., Development of the combustion system for a V8 flexible fuel turbocharged direct injection engine, SAE technical paper 2010-01-0585 (2010).

[192] J. Chang, Y. Viollet, A. Alzubail, A. Abdul-Manan, et al., Octane-ondemand as an enabler for highly efficient spark ignition engines and greenhouse gas emissions improvement, SAE paper no. 2015-01-1264 (2015). doi:doi:10.4271/2015-01-1264.

[193] Y. Viollet, M. Abdullah, A. Alhajhouje, C. J, Characterization of high efficiency octane-on-demand fuels requirement in a modern spark ignition engine with dual injection system, SAE paper no. 2015-01-1265 (2015). doi:doi:10.4271/2015-01-1265.

[194] H. Liu, Z. Wang, Y. Long, et al., Dual-fuel spark ignition (DFSI) combustion fuelled with different alcohols and gasoline for fuel efficiency, Fuel 157 (2015) 255-260.

[195] H. Liu, Z. Wang, Y. Long, et al., Comparative study on alcohol-gasoline and gasoline-alcohol dual-fuel spark ignition (DFSI) combustion for engine particle number (PN) reduction, Fuel 159 (2015) 250-258.

[196] K. Kozuoka, T. Kurotani, H. Chishima, H. Kudo, Study of highcompression-ratio engine combined with an ethanol-gasoline fuel separation system, SAE paper no. 2014-01-2614 (2014).

[197] M. Jackson, S. Unnasch, C. Sullivan, R. Renner, Transit bus operation with methanol fuel, SAE paper no. 850216 (1985).

[198] R. Toepel, J. Bennethum, R. Heruth, Development of Detroit Diesel Allison 6V-92TA methanol fueled coach engine, SAE paper no. 831744 (1983).

[199] C. Urban, T. Timbario, R. Bechtold, Performance and emissions of a DDC 8V-71 engine fueled with cetane improved methanol, SAE paper no. 892064 (1989).

[200] P. Wuebben, S. Unnasch, V. Pellegrin, D. Quigg, B. Urban, Transit bus operation with a DDC 6V-92TAC engine operating on ignition-improved methanol, SAE paper no. 902161 (1990).

[201] K. Portin. Wärtsilä gas engine development \& methanol adaptation [online]. http://classnk-rd.com/assets/pdf/V_Wartsila_Gas_Engine_ Development_Methanol_Adaptation.pdf

[202] MAN Diesel \& Turbo. Using Methanol Fuel in the MAN B\&W ME-LGI Series [online]. url: https://www.mandieselturbo.com/docs/defaultsource/shopwaredocuments/using-methanol-fuel-in-the-man-b-w-me-lgiseries.pdf. 
[203] S. Verhelst, T. Wallner, Hydrogen-fueled internal combustion engines, Progress in Energy and Combustion Science 35 (6) (2009) 490-527.

[204] S. Shamun, M. Shen, B. Johansson, et al., Exhaust PM emissions analysis of alcohol fueled heavy-duty engine utilizing PPC, SAE International Journal of Engines 9 (4) (2016) 2142-2152.

[205] S. Shamun, C. Hasimoglu, A. Murcak, et al., Experimental investigation of methanol compression ignition in a high compression ratio HD engine using a box-behnken design, Fuel 209 (2017) 624-633.

[206] J. Coulier, S. Verhelst, Using alcohol fuels in dual fuel operation of compression ignition engines: A review, in: 28th CIMAC World Congress 2016, Helsinki, 2016, p. paper no. 224.

[207] R. Song, J. Liu, L. Wang, et al., Performance and emissions of a diesel engine fuelled with methanol, Energy \& Fuels 22 (6) (2008) 3883-3888.

[208] J. Liu, Y. Li, G. Li, et al., Effect of pilot diesel quantity and fuel delivery advance angle on the performance and emission characteristics of a methanol-fueled diesel engine, Energy \& Fuels 24 (3) (2010) 1611-1616.

[209] C. S. Cheung, Z. H. Zhang, T. L. Chan, et al., Investigation on the effect of port-injected methanol on the performance and emissions of a diesel engine at different engine speeds, Energy \& Fuels 23 (11) (2009) 56845694 .

[210] C. Yao, C. S. Cheung, C. Cheng, et al., Effect of diesel/methanol compound combustion on diesel engine combustion and emissions, Energy Conversion and Management 49 (6) (2008) 1696-1704.

[211] L. Wei, C. Yao, Q. Wang, W. Pan, G. Han, Combustion and emission characteristics of a turbocharged diesel engine using high premixed ratio of methanol and diesel fuel, Fuel 140 (2015) 156-163.

[212] Z. Yin, C. Yao, P. Geng, et al., Visualization of combustion characteristic of diesel in premixed methanol-air mixture atmosphere of different ambient temperature in a constant volume chamber, Fuel 174 (2016) 242-250.

[213] K. Hikino, T. Suzuki, Development of methanol engine with autoignition for low NOx emission and better fuel economy, SAE paper no. 891842 (1989).

[214] M. Pucilowski, M. Jangi, S. Shamun, et al., Effect of start of injection on the combustion characteristics in a heavy-duty DICI engine running on methanol, SAE Technical Paper 2017-01-0560 (2017).

[215] B. Richards, Methanol-fueled Caterpillar 3406 engine experience in onhighway trucks, SAE Technical Paper 902160 (1990). 
[216] G. Roberts, B. Johnson, C. Edwards, Prospects for high-temperature combustion, neat alcohol-fueled diesel engines, SAE International Journal of Engines 7 (1) (2014) 448-457.

[217] D. R. Tree, K. I. Svensson, Soot processes in compression ignition engines, Progress in Energy and Combustion Science 33 (2007) 272-309.

[218] S. Shamun, M. Novakovic, V. B. Malmborg, et al., Detailed characterization of particulate matter in alcohol exhaust emissions, in: The Ninth International Conference on Modeling and Diagnostics for Advanced Engine Systems (COMODIA 2017), Japan Society of Mechanical Engineers, Okayama, Japan, 2017. doi:10.1299/jmsesdm.2017.9.B304. URL https://doi .org/10.1299/jmsesdm.2017.9.B304

[219] P. Aakko-Saksa, M. Westerholm, R. Pettinen, C. Söderström, P. Roslund, P. Piimäkorpi, P. Koponen, Methanol with additives for diesel engine - MD95 concept, SUMMETH final seminar, Tech. rep., VTT Technical Research Centre of Finland LTD (2017).

[220] K. Moirangthem, D. Baxter, Alternative fuels for marine and inland waterways: An exploratory study, Tech. rep., Publications Office of the European Union (2016).

[221] Malcolm Pirnie, Inc., Evaluation of the fate and transport of methanol in the environment, Tech. rep., Technical Memorandum (1999).

URL http://www.methanol.org/wp-content/uploads/2016/06/ White-Paper-The-Fate-Transport-of-Methanol-in-the-Environment-1999. pdf

[222] Stena Line Scandinavia AB. Stena Germanica's methanol conversion [online] (2018). url: https://www.stenalinefreight.com/news/Methanolproject.

[223] Waterfront Shipping Company Limited. Methanol-fueled vessels mark one year of safe, reliable, and efficient operations [online] (2018). url: https://www.wfs-cl.com/news/2017/04/methanol-fueledvessels-mark-one-year-safe-reliable-and-efficient-operations.

[224] LeanShips. Low Energy and Near to zero emissions Ships [online] (2018). url: http://www.leanships-project.eu.

[225] Summeth. Sustainable Marine Methanol [online] (2018). url: http://summeth.marinemethanol.com/.

[226] GreenPilot. Greenpilot project [online] (2018). url: https://www.greenpilot.se.

[227] J. Ellis, K. Tanneberger, Study on the use of ethyl and methyl alcohol as alternative fuels in shipping, Tech. rep., European Maritime Safety Agency (2017). 
[228] K. Andersson, C. Márquez Salazar, Methanol as a marine fuel report, Tech. rep., FCBI energy (2015).

[229] J. Dierickx, J. Beyen, R. Block, M. Hamrouni, P. Huyskens, C. Meichelböck, S. Verhelst, Strategies for introducing methanol as an alternative fuel for shipping, in: Proceedings of the 7th Transport Research Arena TRA 2018, Vienna, 2018.

[230] P. Kumar, K. Dutta, S. Das, P. Kundu, An overview of unsolved deficiencies of direct methanol fuel cell technology: factors and parameters affecting its widespread use, International Journal of Energy Research 38 (2014) 1367-1390.

[231] L. Tartakovsky, M. Sheintuch, Fuel reforming in internal combustion engines, Progress in Energy and Combustion Science 67 (2018) 88-114.

[232] A. Poran, L. Tartakovsky, Influence of methanol reformate injection strategy on performance, available exhaust gas enthalpy and emissions of a direct-injection spark ignition engine, International Journal of Hydrogen Energy 42 (23) (2017) 15652-15668.

[233] D.-K. Nguyen, S. Verhelst, Computational study of the laminar reaction front properties of diluted methanol-air flames enriched by the fuel reforming product, Energy \& Fuels 31 (9) (2017) 9991-10002.

[234] W. Hoffman, V. Wong, W. Cheng, et al., A new approach to ethanol utilization: High efficiency and low NOx in an engine operating on simulated reformed ethanol, SAE technical paper 2008-01-2415 (2008).

[235] R. Carapellucci, A. Milazzo, Membrane systems for CO2 capture and their integration with gas turbine plants, Proceedings of the Institution of Mechanical Engineers, Part A: Journal of Power and Energy 217 (5) (2003) 505-517.

[236] D. Cocco, V. Tola, Use of alternative hydrogen energy carriers in SOFCMGT hybrid power plants, Energy Conversion and Management 50 (4) (2009) 1040-1048.

[237] A. Kowalewicz, Methanol as a fuel for spark ignition engines: a review and analysis, Proceedings of the Institution of Mechanical Engineers, Part D: Journal of Automobile Engineering 207 (14) (1993) 43-52.

[238] D. McCall, T. Lalk, R. Davison, et al., Performance and emissions characteristics of a spark ignition engine fueled with dissociated and steamreformed methanol, SAE technical paper 852106 (1985).

[239] H. Menrad, W. Bernhardt, G. Decker, Methanol vehicles of Volkswagen a contribution to better air quality, SAE paper no. 881196 (1988). 
[240] A. König, K.-W. Ellinger, K. Korbel, Engine operation on partially dissociated methanol, SAE technical paper 850573 (1985).

[241] J. Turner, Processing of fuel and recirculated exhaust gas, patent number WO2012049458 A1 (2012).

[242] A. Poran, L. Tartakovsky, Performance and emissions of a direct injection internal combustion engine devised for joint operation with a high-pressure thermochemical recuperation system, Energy 124 (2017) 214-226.

[243] L. Bromberg, D. Cohn, Ultrahigh efficiency alcohol engines using optimized exhaust heat recovery, US patent number 9234482 (filed July 2013) (2013).

[244] J. Fowler, D. Morgenstern, E. Sall, et al., Integration of an E85 reforming system into a vehicle-ready package and project results, SAE technical paper 2014-01-1191 (2014).

[245] J. Wheeler, R. Stein, D. Morgenstern, et al., Low-temperature ethanol reforming: A multi-cylinder engine demonstration, SAE technical paper 2011-01-0142 (2011).

[246] X. Lu, D. Han, Z. Huang, Fuel design and management for the control of advanced compression-ignition combustion modes, Progress in Energy and Combustion Science 37 (2011) 741-783.

[247] A. G. Brown, C. R. Stone, P. Beckwith, Cycle-by-cycle variations in spark ignition engine combustion - part i: flame speed and combustion measurements and a simplified turbulent combustion model, SAE paper no. 960612 (1996).

[248] P. Mohanan, M. K. G. Babu, A simulation model for a methanol fueled turbocharged multi-cylinder automotive spark ignition engine, SAE paper no. 912417 (1991).

[249] G. J. Gibbs, H. F. Calcote, Effect of molecular structure on burning velocity, Journal of Chemical \& Engineering Data 4 (3) (1959) 226-237.

[250] M. Metghalchi, J. C. Keck, Burning velocities of mixtures of air with methanol, isooctane, and indolene at high pressure and temperature, Combustion and Flame 48 (1982) 191-210.

[251] A. M. Pourkhesalian, A. H. Shamekhi, F. Salimi, Alternative fuel and gasoline in an SI engine: A comparative study of performance and emissions characteristics, Fuel 89 (5) (2010) 1056-1063.

[252] S. Y. Liao, D. M. Jiang, Z. H. Huang, et al., Laminar burning velocities for mixtures of methanol and air at elevated temperatures, Energy Conversion and Management 48 (3) (2007) 857-863. 
[253] V. L. Zimont, Gas premixed combustion at high turbulence. turbulent flame closure combustion model, Experimental Thermal and Fluid Science 21 (1-3) (2000) 179-186.

[254] R. G. Abdel-Gayed, D. Bradley, M. Lawes, Turbulent burning velocities: A general correlation in terms of straining rates, Proceedings of the Royal Society of London. A. Mathematical and Physical Sciences 414 (1847) (1987) 389-413.

[255] N. C. Blizard, J. C. Keck, Experimental and theoretical investigation of turbulent burning model for internal combustion engines, SAE paper no. 740191 (1974).

[256] C. K. Westbrook, F. L. Dryer, Prediction of laminar flame properties of methanol-air mixtures, Combustion and Flame 37 (1980) 171-192.

[257] O. L. Gülder, Burning velocities of ethanol isooctane blends, Combustion and Flame 56 (3) (1984) 261-268.

[258] D.-K. Nguyen, L. Sileghem, S. Verhelst, A quasi-dimensional combustion model for spark ignition engines fueled with gasoline-methanol blends, IMechE Part D: Journal of Automobile Engineering 232 (2018) 57-74.

[259] J. Vancoillie, L. Sileghem, S. Verhelst, Development and validation of a quasi-dimensional model for methanol and ethanol fueled SI engines, Applied Energy 132 (2014) 412-425.

[260] J. Vancoillie, Modeling the combustion of light alcohols in spark-ignition engines, Ph.D. thesis, Ghent University (2013).

[261] J. Demuynck, A fuel independent heat transfer correlation for premixed spark ignition engines, Ph.D. thesis, Ghent University (2012).

[262] S. Broekaert, J. Demuynck, T. De Cuyper, M. De Paepe, V. Sebastian, Heat transfer in premixed spark ignition engines part I: Identification of the factors influencing heat transfer, Energy 116 (2016) 380-391.

[263] T. De Cuyper, J. Demuynck, S. Broekaert, M. De Paepe, V. Sebastian, Heat transfer in premixed spark ignition engines part II: Systematic analysis of the heat transfer phenomena, Energy 116 (2016) 851-860.

[264] Gamma Technologies. GT-SUITE overview [online] (2018). url: https://www.gtisoft.com/gt-suite/gt-suite-overview/.

[265] D.-K. Nguyen, S. Verhelst, Development of laminar burning velocity correlation for the simulation of methanol fueled SI engines operated with onboard fuel reformer, SAE Technical Paper 2017-01-0539 (2017).

[266] A. Omari, M. Shapiro, L. Tartakovsky, Laminar burning velocity of alcohol reforming products and effects of cellularity on flame propagation, SAE paper no. 2015-01-0775 (2015). 
[267] A. Poran, L. Tartakovsky, Energy efficiency of a direct-injection internal combustion engine with high-pressure methanol steam reforming, Energy 88 (2015) 506-514.

[268] B. H. Ramadan, J. Charles L. Gray, F. Hamady, et al., Multidimensional predictions of methanol combustion in a high-compression DI engine, SAE paper no. 2003-01-3133 (2003).

[269] M. Pontoppidan, S. Bonfiglioli, F. Damasceno, et al., Detailed study of ethanol in-cylinder combustion behavior by means of a numerical virtual engine model approach, SAE paper no. 2005-01-3989 (2005).

[270] X. Zhen, Y. Wang, S. Xu, et al., Numerical analysis on knock for a high compression ratio spark-ignition methanol engine, Fuel 103 (0) (2013) 892898.

[271] T. Lauer, M. Heiss, S. Fischer, et al., Prediction of the wall film formation and performance of an engine operated with the ethanol blend E85, in: 13th EAEC European Automotive Congress, Valencia, 2011.

[272] D.-W. Yao, X.-C. Ling, F. Wu, Evaporate prediction and compensation of intake port wall-wetting fuel film for spark ignition engines fueled with ethanol-gasoline blends, Journal of Zhejang University - Science A (Applied Physics and Engineering).

[273] S. Liebsch, A. Zboralski, J. Maass, et al., Cold start simulation and test on DISI engines utilizing a multi-zone vaporization approach, SAE paper no. 2012-01-0402 (2012).

[274] M. Jangi, C. Li, S. Shamun, et al., Modelling of methanol combustion in a direct injection compression ignition engine using an accelerated stochastic fields method, Energy Procedia 105 (2017) 1326-1331.

[275] J. Vancoillie, S. Verhelst, Modeling the combustion of light alcohols in SI engines: a preliminary study, in: FISITA 2010 World Automotive Congress, Budapest, Hungary, 2010, pp. 1-12.

[276] R. Pearson, J. Turner, A. Peck, Gasoline-ethanol-methanol tri-fuel vehicle development and its role in expediting sustainable organic fuels for transport, in: IMechE Low Carbon Vehicles Conference, London, UK, 2009, pp. 1-21.

[277] M. Ormsby, Turbulent flame development in a high-pressure combustion vessel, Ph.D. thesis, Leeds University (2005).

[278] N. Lange, Handbook of chemistry, 10th Edition, McGraw-Hill, New York, 1967.

[279] T. Tsuboi, K. Hashimoto, Shock tube study on homogeneous thermal oxidation of methanol, Combustion and Flame 42 (0) (1981) 61-76. 


\section{List of Tables}

$1 \quad$ Physical properties of selected fuels [260, 275, 203, 68] . . . . . . 109

2 Chemical properties for selected fuels [260, 275, 203, 68, . . . . 110

3 Mixture properties for selected fuel-air mixtures [260, 275, 203, 68 ] 111

4 Properties of selected fuels related to engine use and storage

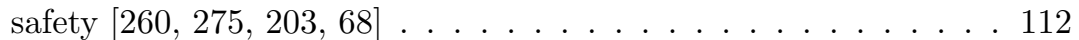

5 Overview of the range of conditions covered by published methanol autoignition delay time datasets and correlations. . . . . . . . 113

6 Effect on octane numbers of water addition to methanol. Data taken from 124 . . . . . . . . . . . . . . . . . . . . 114

$7 \quad$ Advantages and challenges associated with methanol for the fuel system and fuel handling . . . . . . . . . . . . . . . 115 


\section{List of Figures}

1 Effect of isomerization on octane numbers of various families of chemicals. Isomerization can maintain the ON of alkanes at approximately 100. Alcohols generally have higher ONs, and are the only family to be liquid at STP with four or fewer carbon atoms present $\ldots \ldots \ldots \ldots \ldots \ldots \ldots \ldots \ldots$

2 Concentration of hydrogen in various fuel compounds (all in their liquid state) in terms of kilograms per cubic metre and change in this value relative to liquid hydrogen $\ldots \ldots \ldots \ldots 117$

3 Energy storage capacity of various fuels in terms of amount of energy stored per unit mass or volume, including the storage vessel (reproduced from [276]) . . . . . . . . . . . . . . 118

4 The formation of emissions of soot (in ppm by mass, in 'island' at top of plots, i.e. at the high equivalence ratios) and $\mathrm{NO}_{\mathrm{X}}$ (in ppm by volume, bottom right of plots, i.e. at high temperatures and lower equivalence ratios) as a function of equivalence ratio and temperature, for methanol and diesel. Adiabatic flame temperatures also shown. . . . . . . . . . . . . . . . 119

5 Laminar burning velocities of hydrogen $\left(\mathrm{H}_{2}\right)$, iso-octane, methane $\left(\mathrm{CH}_{4}\right)$ and methanol $(\mathrm{MeOH})$ at 1 bar and $360 \mathrm{~K} . \quad \ldots \ldots .120$

6 Temperature exponent of laminar burning velocity dependence

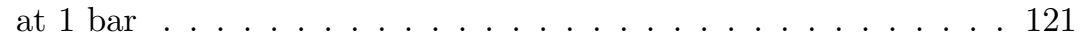

$7 \quad$ Calculated Lewis numbers for various fuels at $0.5 \mathrm{MPa}, 360 \mathrm{~K}$.

Replotted from [277] . . . . . . . . . . . . . . 122

8 Comparison of different $\tau$ correlations for an adiabatic compression from $10 \mathrm{bar} / 575 \mathrm{~K}$ to $80 \mathrm{bar} / 1042 \mathrm{~K}(\phi=1.0) \ldots . . . .123$

9 Mixtures of water with methanol or ethanol: mole fraction of water as a function of volume fraction. Reproduced from 32. . . 124

10 Freezing points of alcohol-water mixtures by mass and by volume. Data replotted and calculated from $[29,278] \ldots \ldots$. . . . . . 125

11 Mixtures of alcohols with gasoline: mole fraction of alcohol as a function of volume fraction. Reproduced from [32]. . . . . . . . 126

12 RVP of methanol-gasoline and ethanol-gasoline blends. Repro-

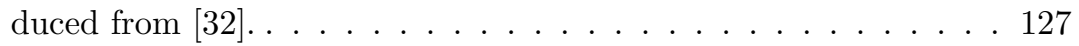

13 Distillation curve of methanol-gasoline blends. Reproduced from

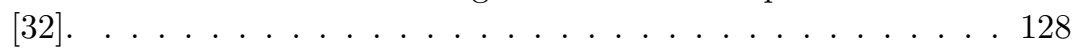

14 Non-linear behaviour of RON and MON values of ethanol blends with different gasoline blendstocks. Measurements - symbols. Re-

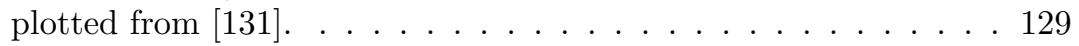

15 Effect of water on the phase separation temperature of methanolgasoline blends. Replotted from 134. . . . . . . . . . . . 130

16 Phase diagram of alcohol/water/gasoline mixtures. Reproduced

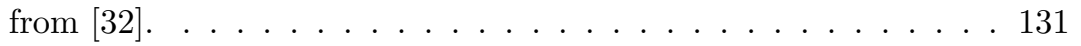


17 Ignition delays $\tau$ as a function of temperature $T$ for methanol, PRF80, and methanol/PRF80 blends (M35 and M60). Solid lines show values calculated with the model of Yates et al. [68], dashed lines show values calculated with a mixing law. Replotted from

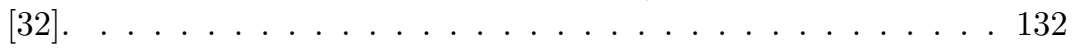

18 Iso-stoichiometric GEM blends equivalent to conventional E85.

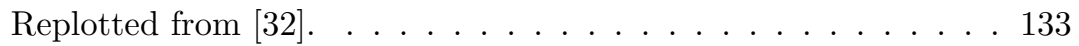

19 Variation of AFR of E85 and M56 as a function of the AFR of gasoline and the deviation of the AFR of M56 relative to E85. Reproduced from $32 . \ldots \ldots \ldots \ldots \ldots \ldots$

20 Measured Research (RON) and Motor (MON) octane numbers for several GEM blends. Replotted from [66. Component volume percentages shown as numbers after letters denoting gasoline $(\mathrm{G})$, ethanol (E) and methanol (M). $\ldots \ldots \ldots \ldots \ldots \ldots$

21 Boundary between stable and unstable region in which phase separation can occur at $-15^{\circ} \mathrm{C}$. Replotted from [134] . . . . . . 136

22 Effect of temperature on vapour-phase lambda for methanol, ethanol

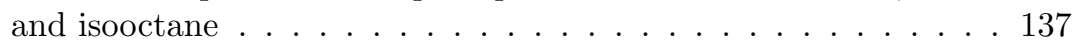

23 Brake thermal efficiency of a 19.5:1 compression ratio engine operated on pure methanol, as a function of load (BMEP) and engine speed. Left - throttled, stoichiometric operation. Right WOT EGR operation. . . . . . . . . . . . . . . . . . . . 138

24 Reforming concepts . . . . . . . . . . . . . . . . . . . . . . 139

25 Effect of methanol properties on engine performance . . . . . . 140 


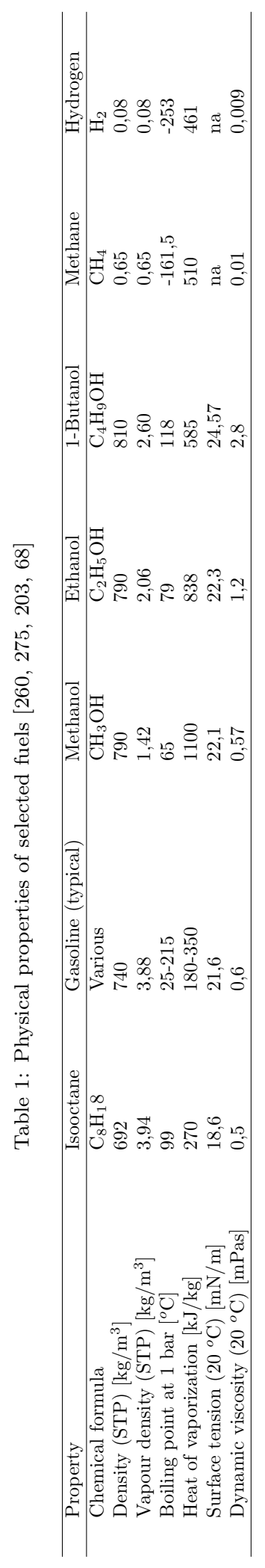

109 


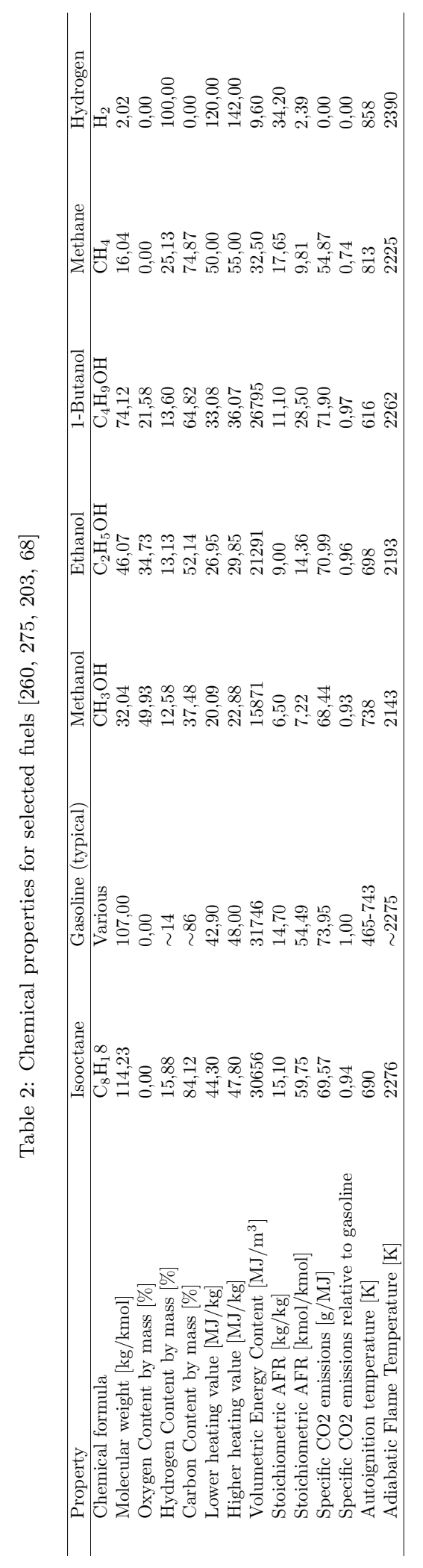

110 


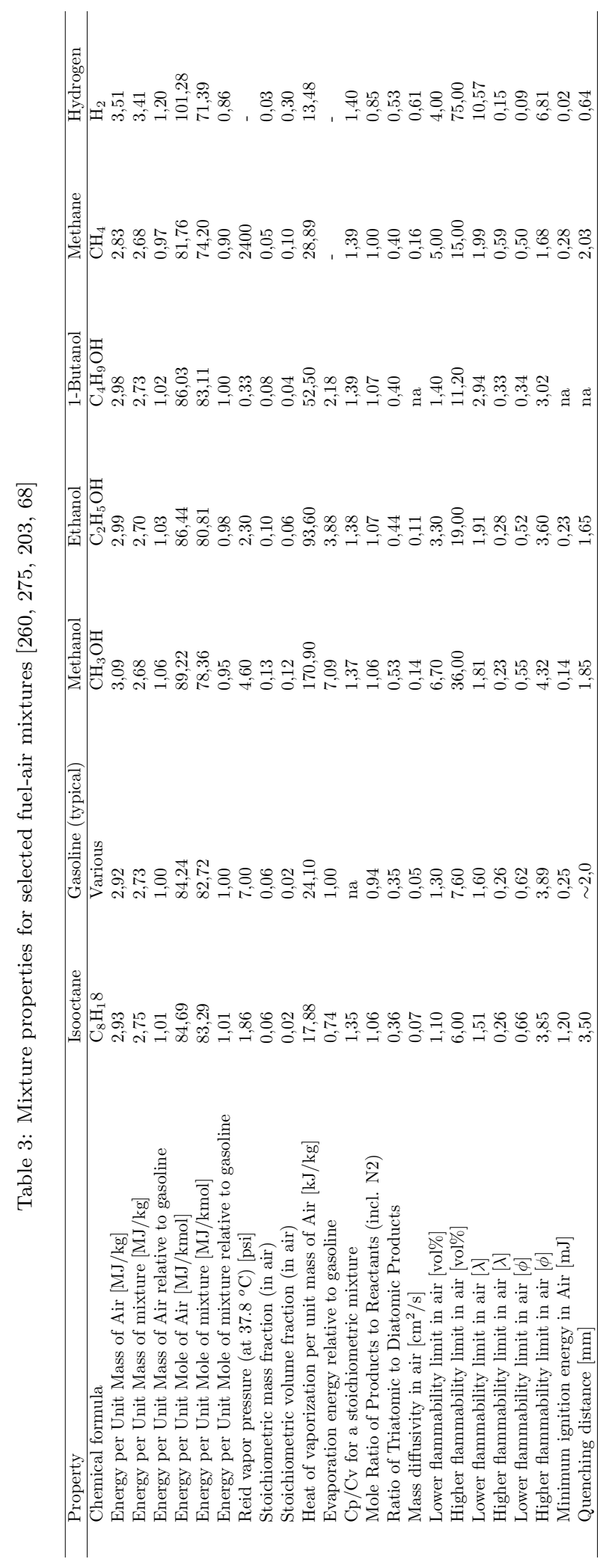




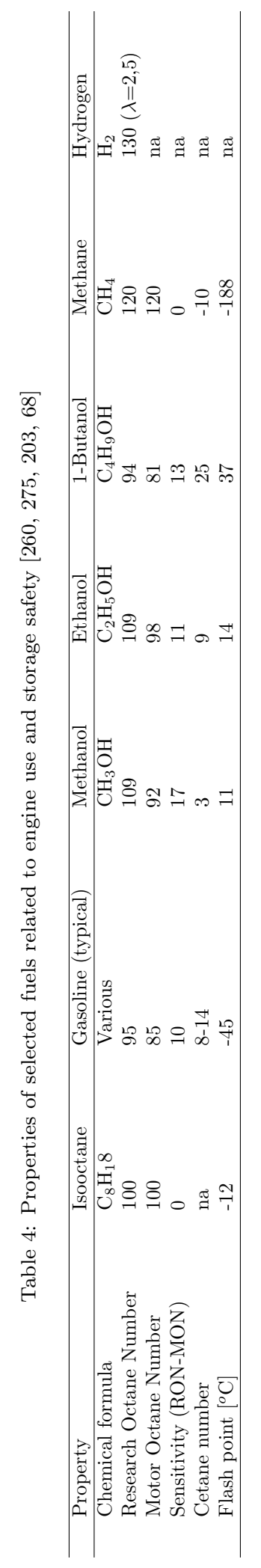




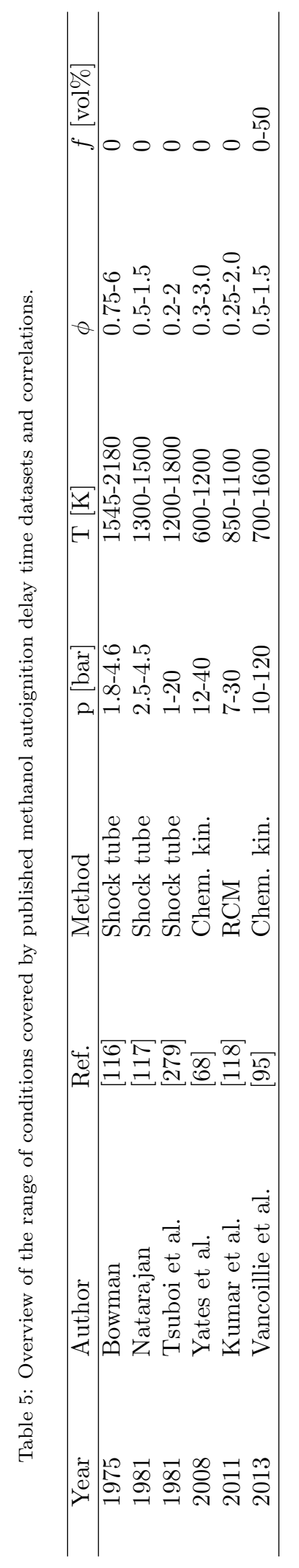

113 
Table 6: Effect on octane numbers of water addition to methanol. Data taken from 124.

\begin{tabular}{lll} 
Mixture $(\mathrm{v} / \mathrm{v})$ & Research octane number & Motor octane number \\
\hline $100 \%$ methanol & 109.6 & 87.4 \\
$95 \%$ methanol / $5 \%$ water & 110 & 89.5 \\
$90 \%$ methanol / $10 \%$ water & 114 & 92.8
\end{tabular}


Table 7: Advantages and challenges associated with methanol for the fuel system and fuel handling

Advantage

Liquid $\rightarrow$ easy to handle

High lower flammability limit $\rightarrow$ safer to store than gasoline

Miscible with gasoline, ethanol, ...

Biodegradable

Widely shipped chemical $\rightarrow$ availability
Challenge

Material compatibility

Lower flash point $\rightarrow$ less safe to store than diesel

Limited miscibility with diesel

Low energy density $\rightarrow$ reduced range

vs. gasoline or diesel

Low lubricity (fuel injectors) 


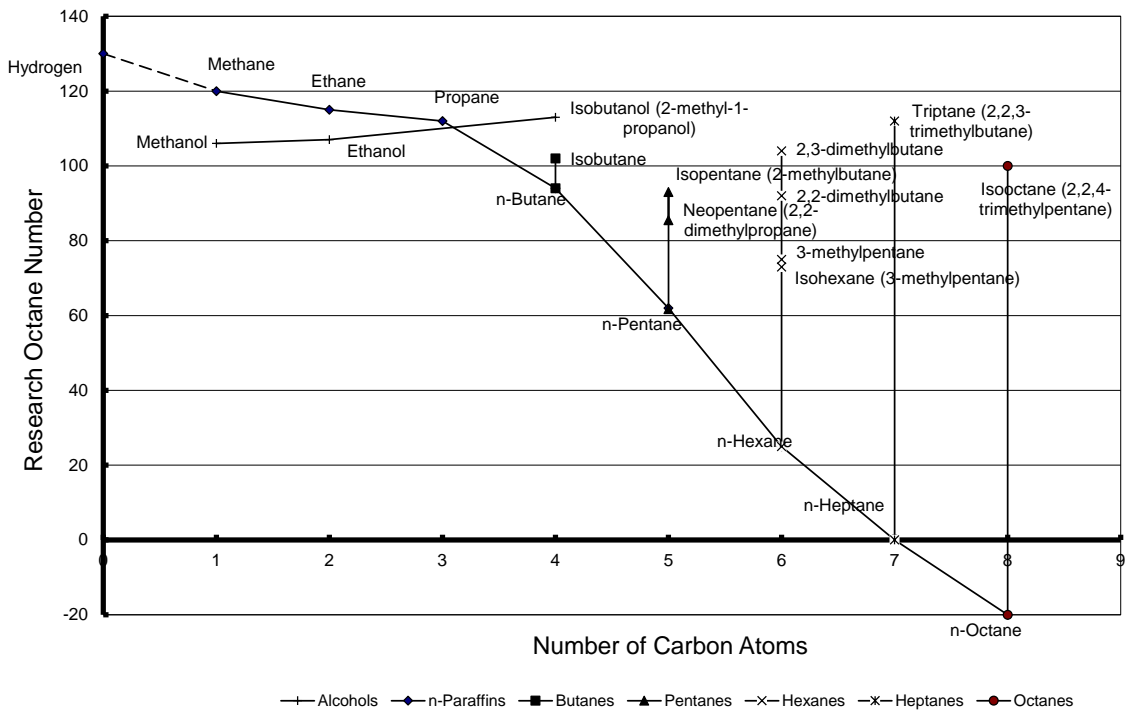

Figure 1: Effect of isomerization on octane numbers of various families of chemicals. Isomerization can maintain the ON of alkanes at approximately 100. Alcohols generally have higher ONs, and are the only family to be liquid at STP with four or fewer carbon atoms present 


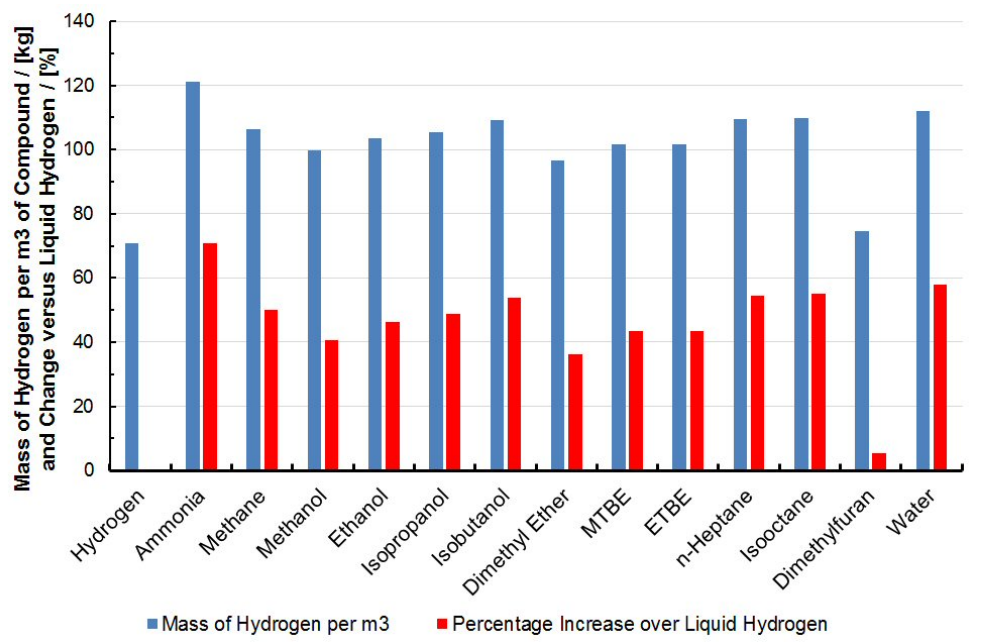

Figure 2: Concentration of hydrogen in various fuel compounds (all in their liquid state) in terms of kilograms per cubic metre and change in this value relative to liquid hydrogen 


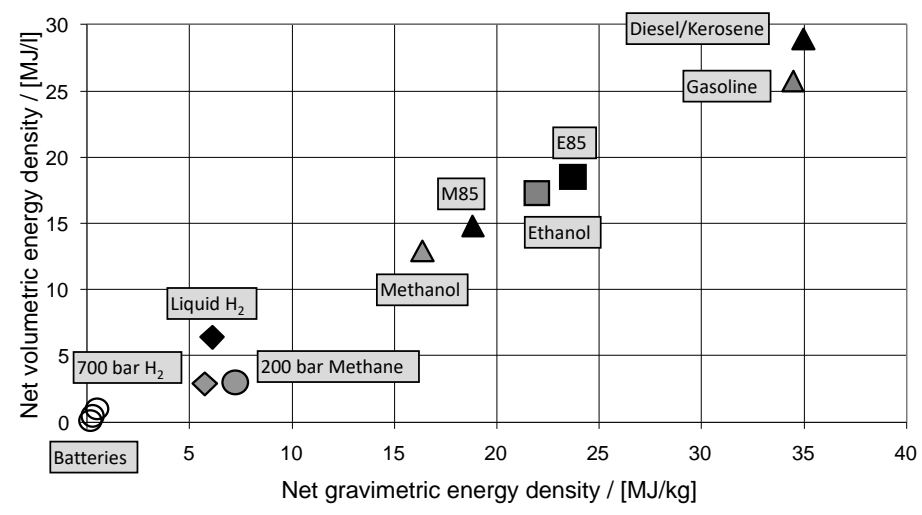

Figure 3: Energy storage capacity of various fuels in terms of amount of energy stored per unit mass or volume, including the storage vessel (reproduced from [276]) 


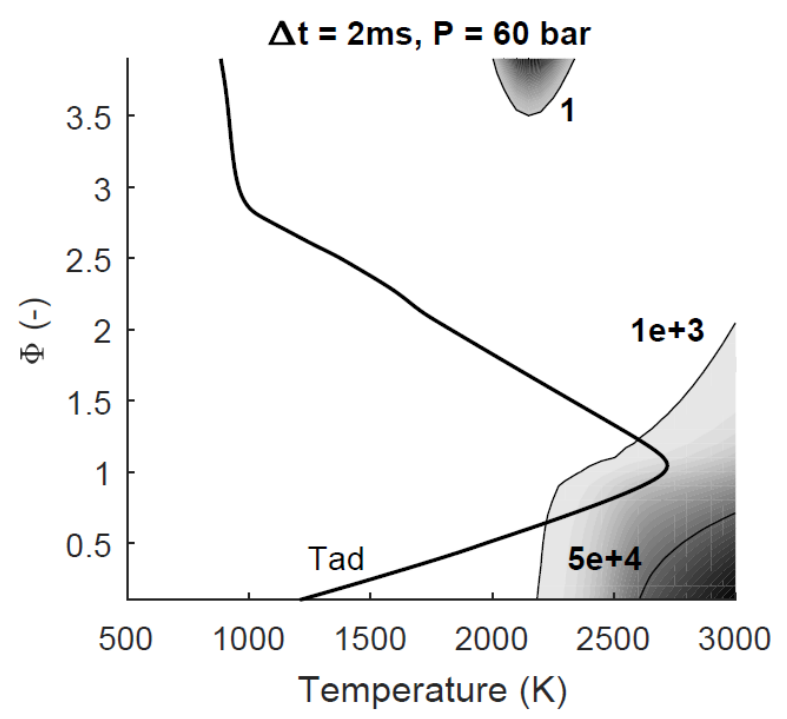

(a) Methanol

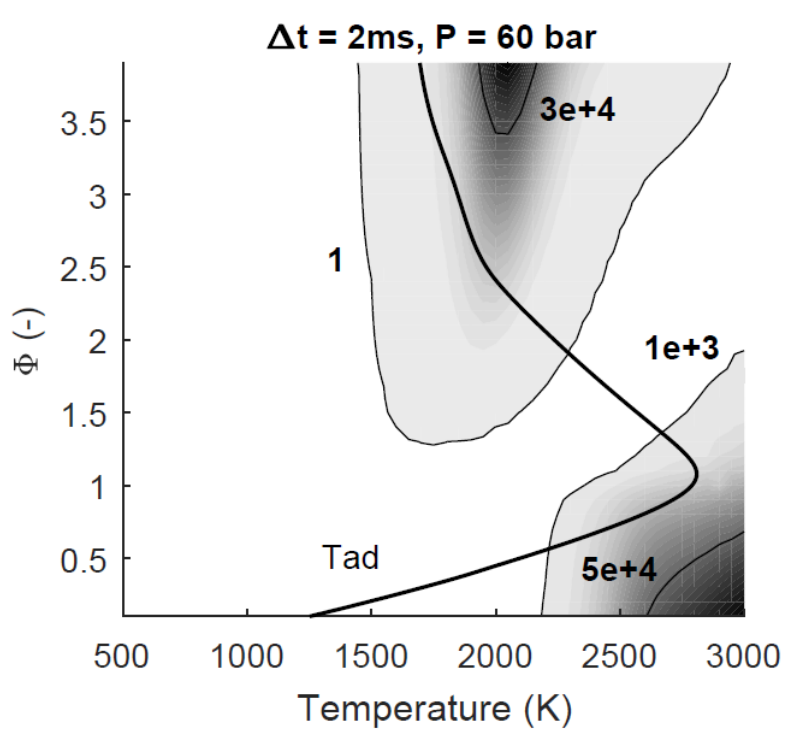

(b) Diesel

Figure 4: The formation of emissions of soot (in ppm by mass, in 'island' at top of plots, i.e. at the high equivalence ratios) and $\mathrm{NO}_{\mathrm{X}}$ (in ppm by volume, bottom right of plots, i.e. at high temperatures and lower equivalence ratios) as a function of equivalence ratio and temperature, for methanol and diesel. Adiabatic flame temperatures also shown. 


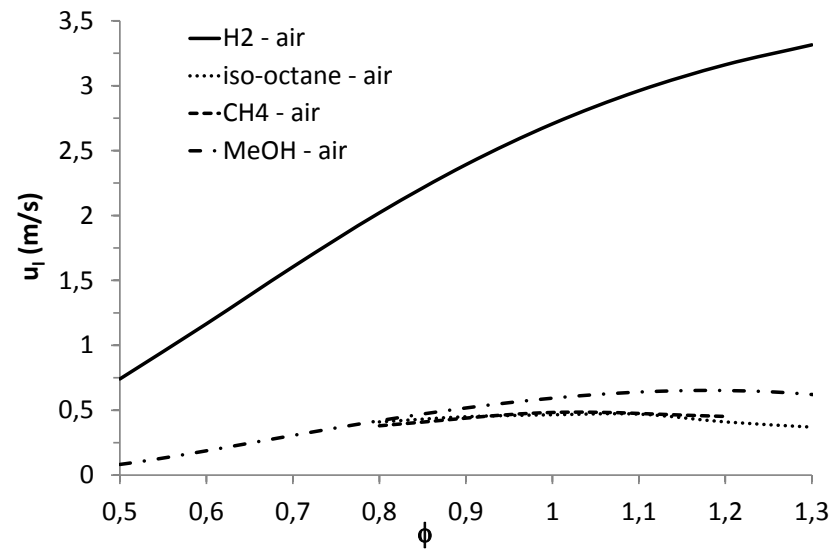

Figure 5: Laminar burning velocities of hydrogen $\left(\mathrm{H}_{2}\right)$, iso-octane, methane $\left(\mathrm{CH}_{4}\right)$ and methanol $(\mathrm{MeOH})$ at 1 bar and $360 \mathrm{~K}$. 


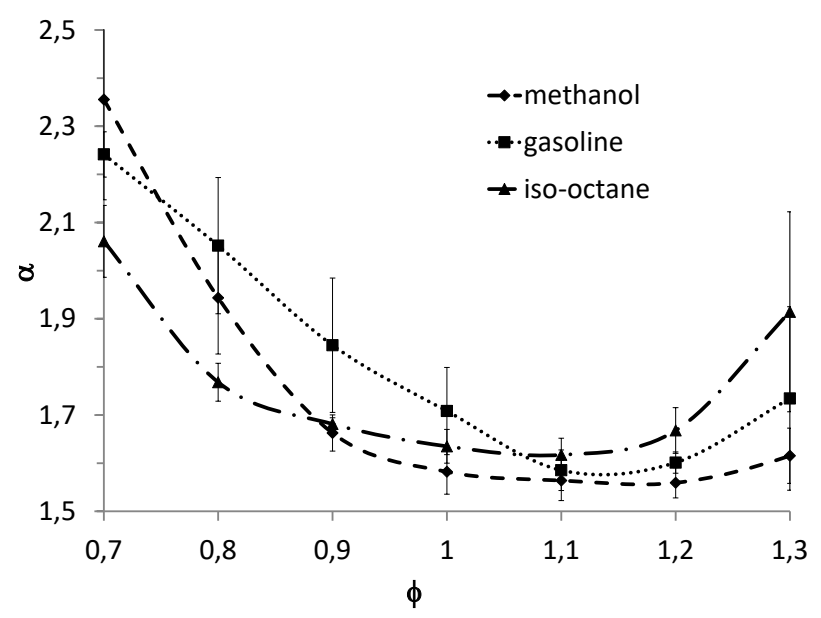

Figure 6: Temperature exponent of laminar burning velocity dependence at 1 bar 


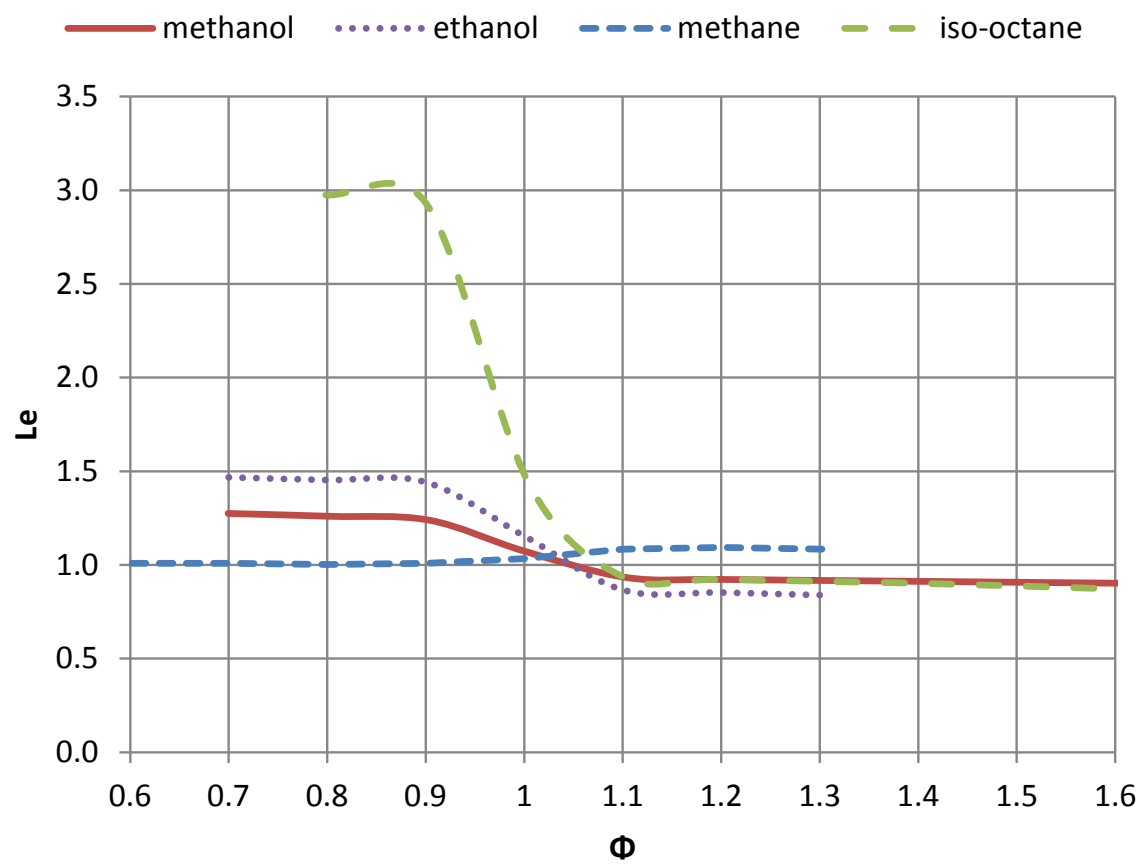

Figure 7: Calculated Lewis numbers for various fuels at $0.5 \mathrm{MPa}, 360 \mathrm{~K}$. Replotted from [277] 


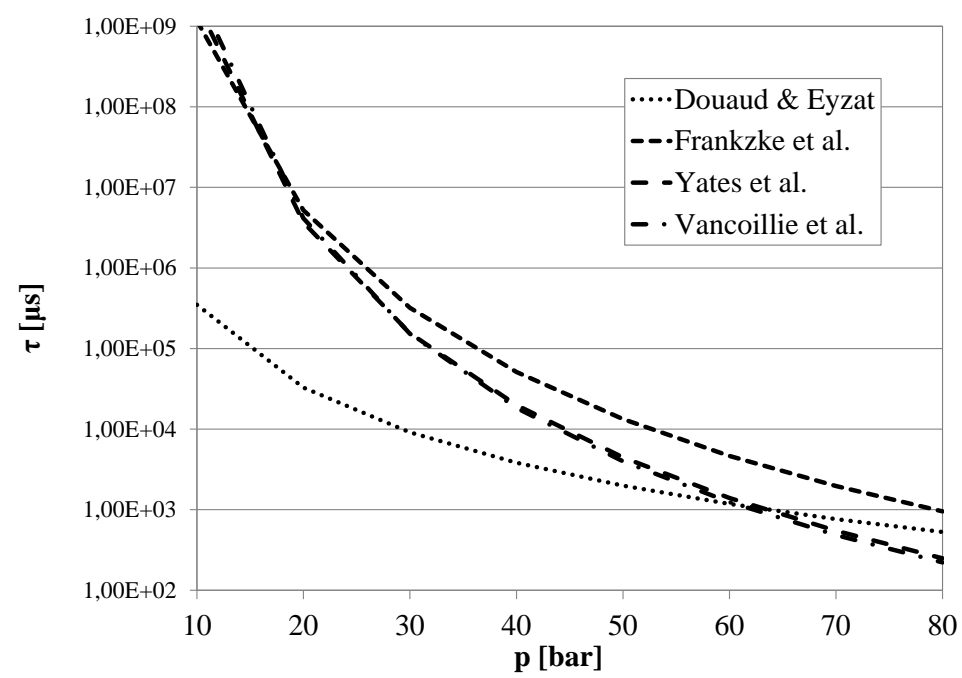

Figure 8: Comparison of different $\tau$ correlations for an adiabatic compression from $10 \mathrm{bar} / 575$ $\mathrm{K}$ to $80 \mathrm{bar} / 1042 \mathrm{~K}(\phi=1.0)$ 


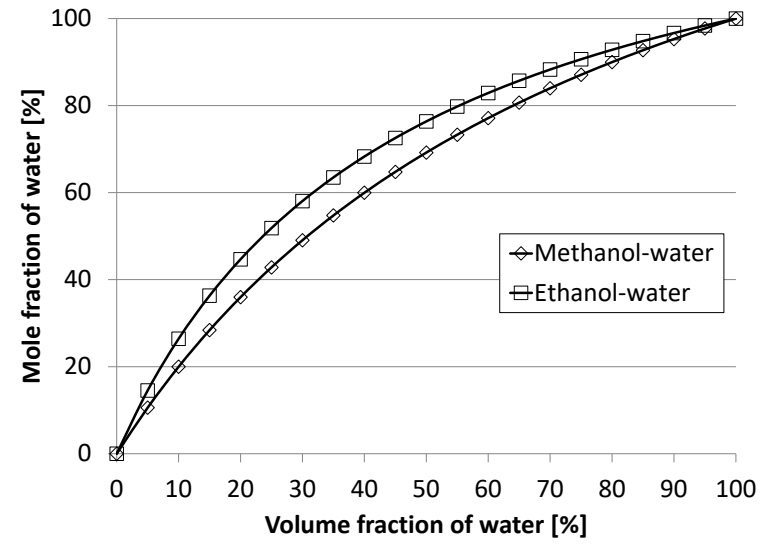

Figure 9: Mixtures of water with methanol or ethanol: mole fraction of water as a function of volume fraction. Reproduced from 32 . 


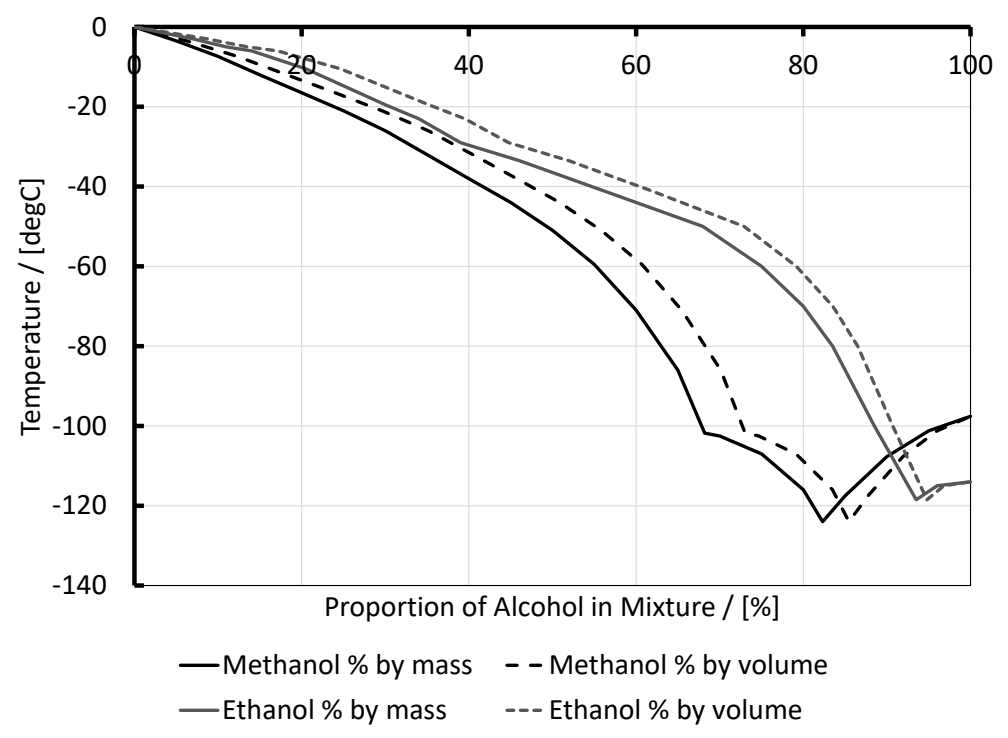

Figure 10: Freezing points of alcohol-water mixtures by mass and by volume. Data replotted and calculated from 29,278 


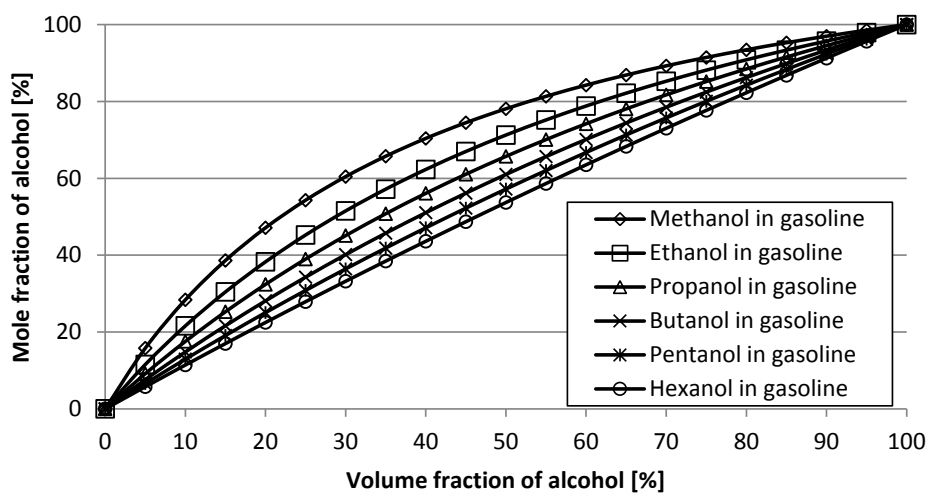

Figure 11: Mixtures of alcohols with gasoline: mole fraction of alcohol as a function of volume fraction. Reproduced from 32 . 


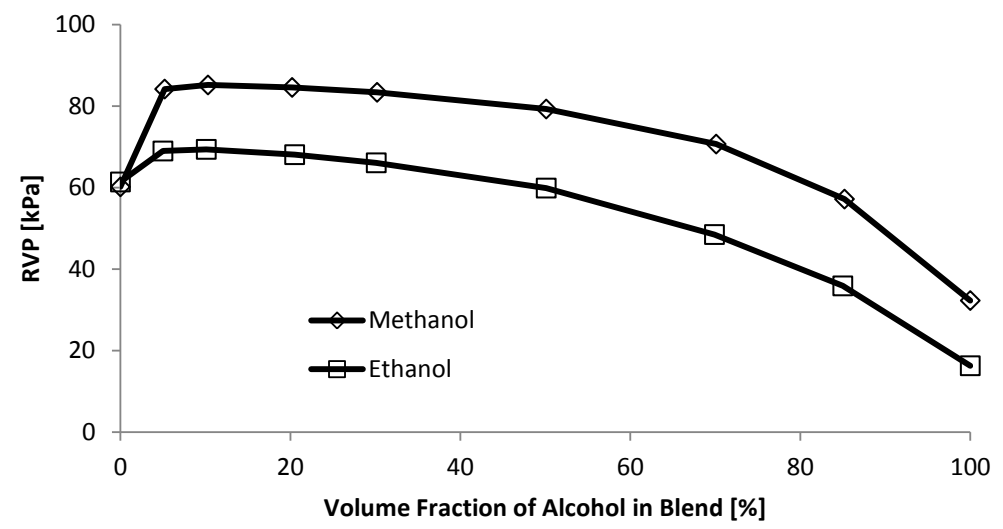

Figure 12: RVP of methanol-gasoline and ethanol-gasoline blends. Reproduced from [32. 


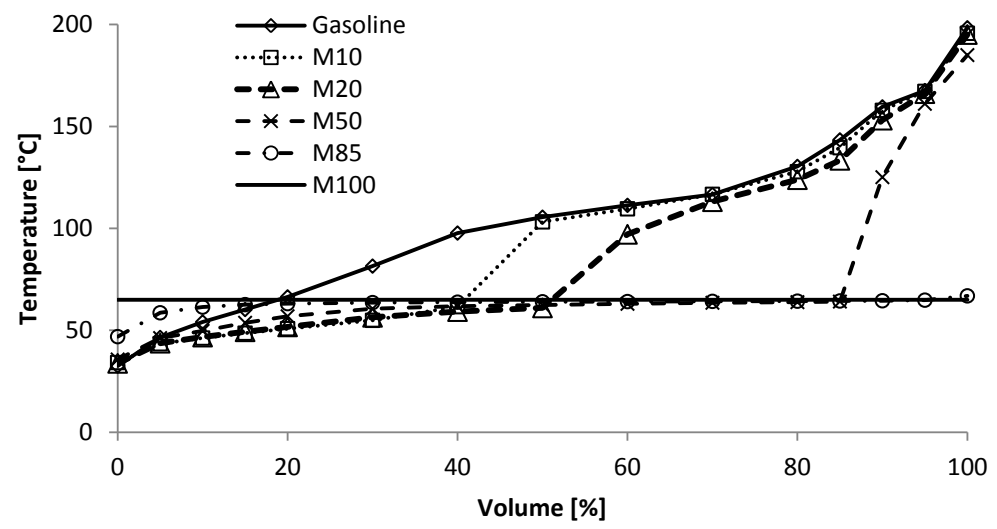

Figure 13: Distillation curve of methanol-gasoline blends. Reproduced from [32]. 

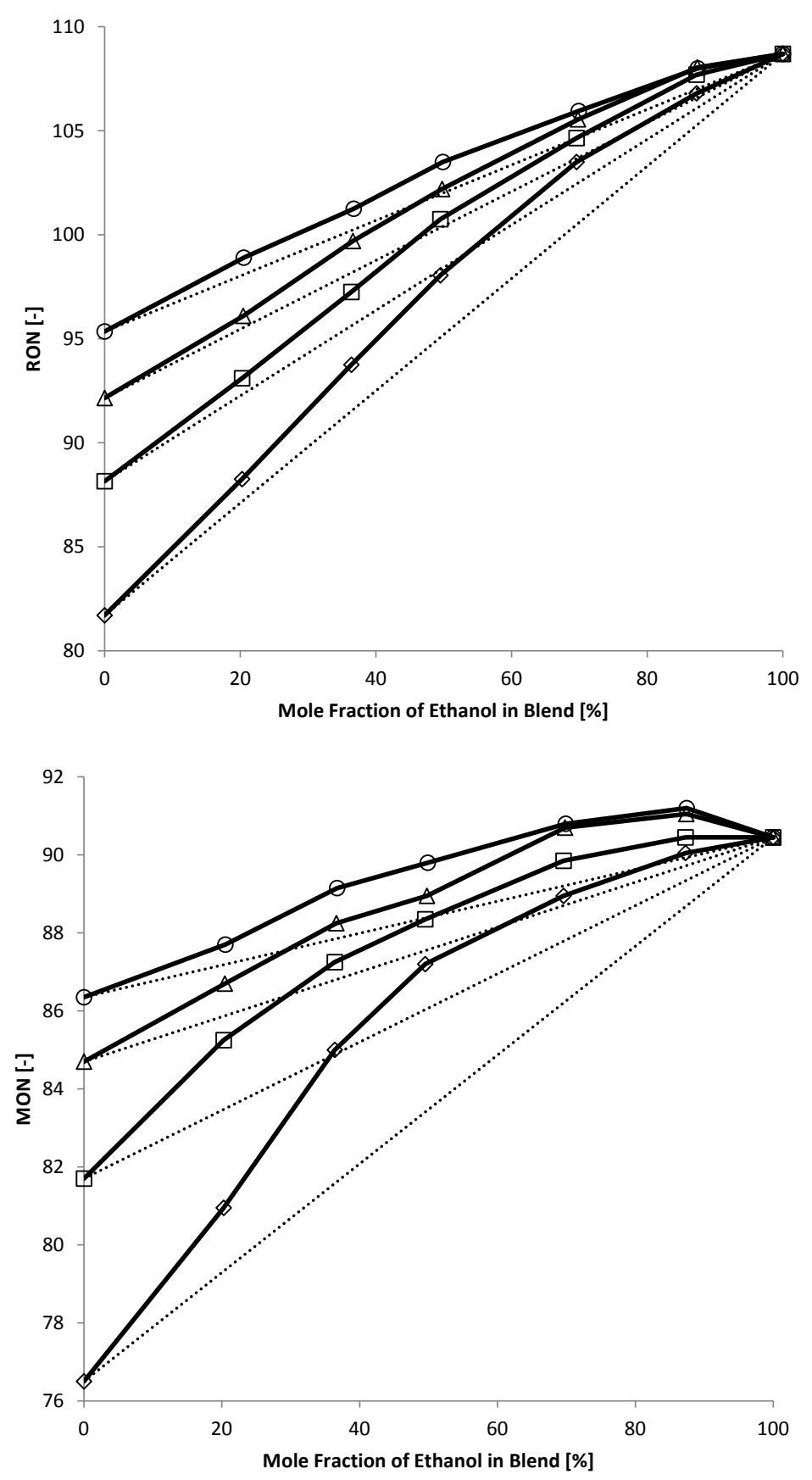

Figure 14: Non-linear behaviour of RON and MON values of ethanol blends with different gasoline blendstocks. Measurements - symbols. Replotted from [131. 


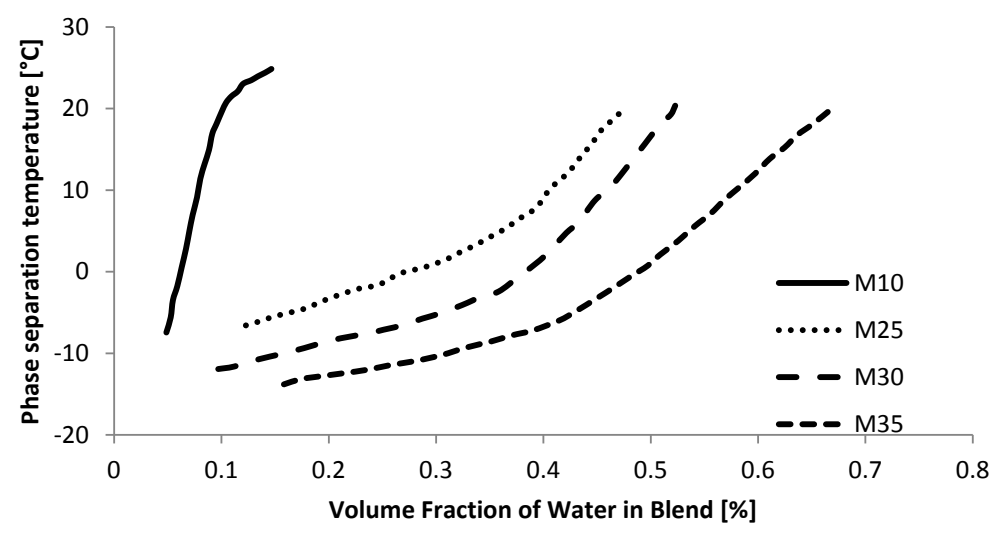

Figure 15: Effect of water on the phase separation temperature of methanol-gasoline blends. Replotted from 134. 


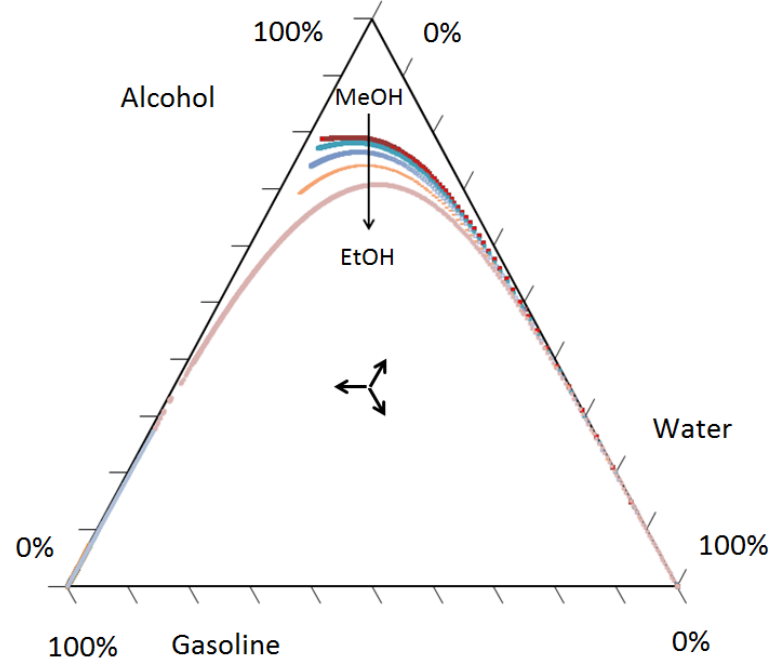

Figure 16: Phase diagram of alcohol/water/gasoline mixtures. Reproduced from 32 . 


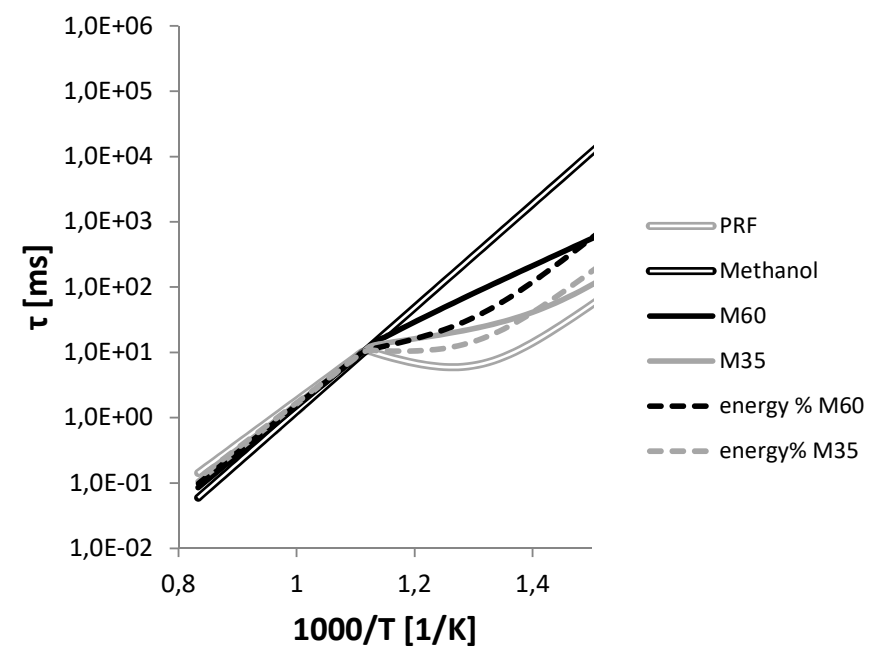

Figure 17: Ignition delays $\tau$ as a function of temperature $T$ for methanol, PRF80, and methanol/PRF80 blends (M35 and M60). Solid lines show values calculated with the model of Yates et al. 68, dashed lines show values calculated with a mixing law. Replotted from [32. 


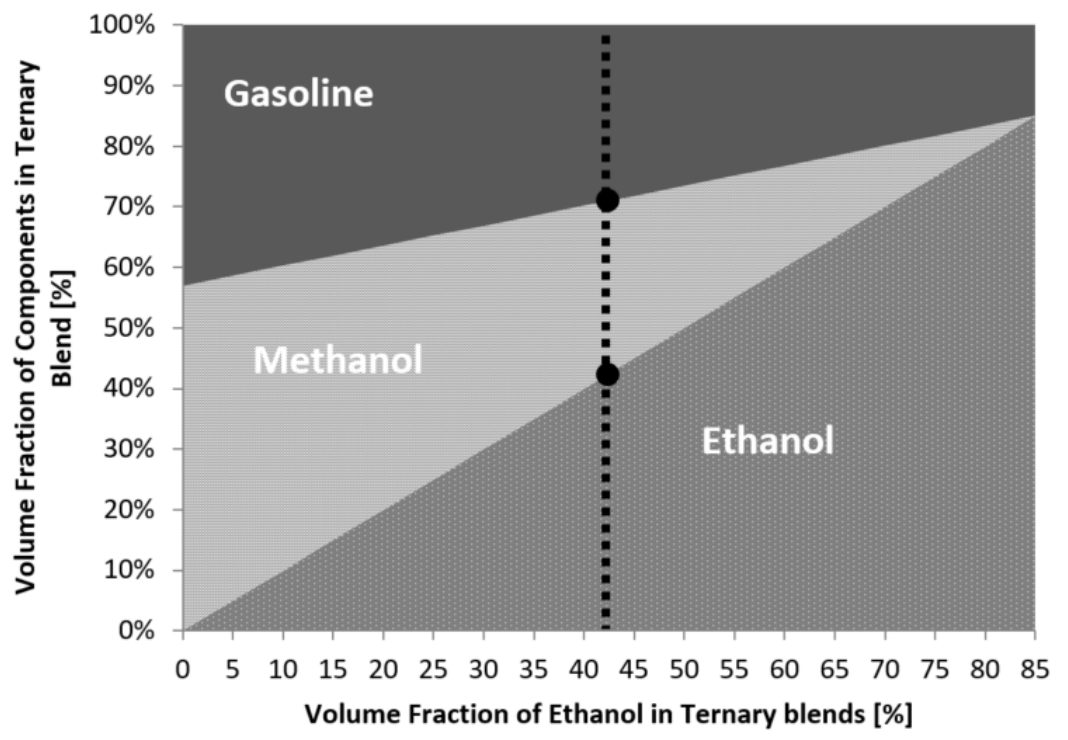

Figure 18: Iso-stoichiometric GEM blends equivalent to conventional E85. Replotted from 32 . 


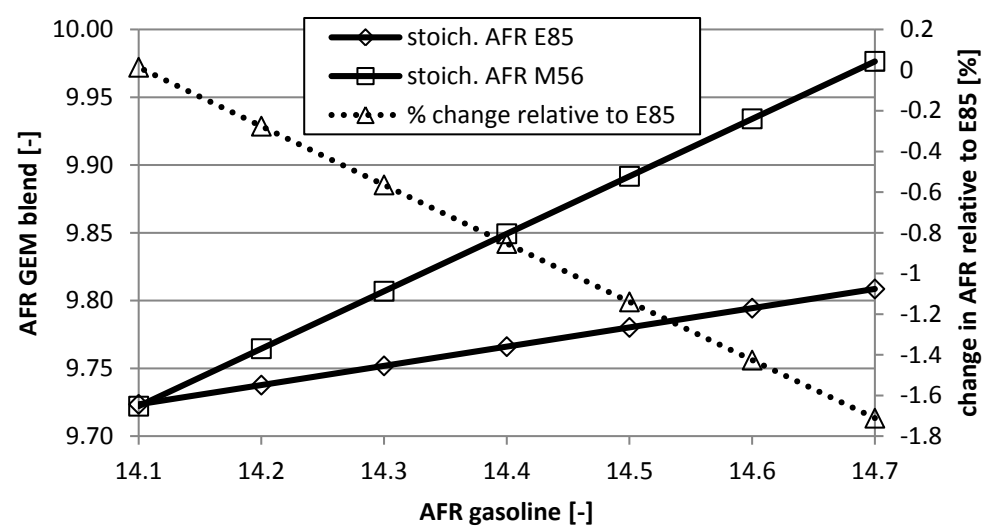

Figure 19: Variation of AFR of E85 and M56 as a function of the AFR of gasoline and the deviation of the AFR of M56 relative to E85. Reproduced from [32]. 


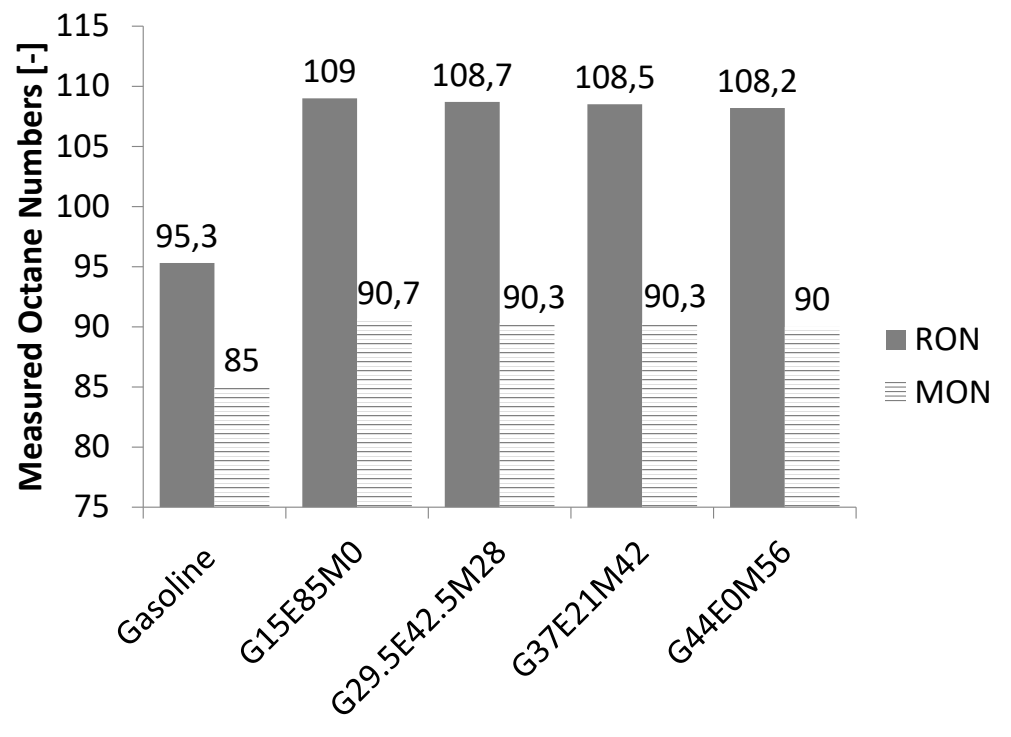

Figure 20: Measured Research (RON) and Motor (MON) octane numbers for several GEM blends. Replotted from [6]. Component volume percentages shown as numbers after letters denoting gasoline $(\mathrm{G})$, ethanol $(\mathrm{E})$ and methanol $(\mathrm{M})$. 


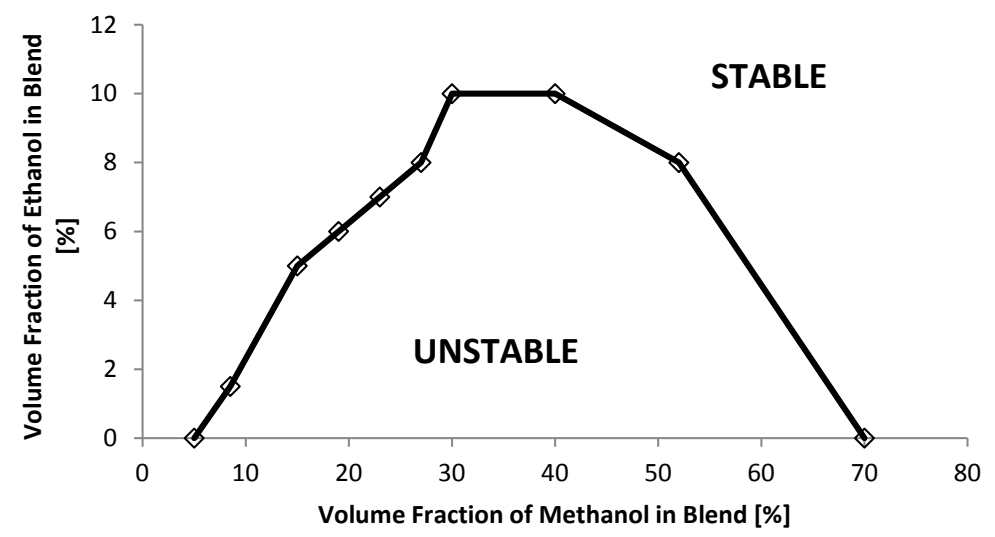

Figure 21: Boundary between stable and unstable region in which phase separation can occur at $-15^{\circ} \mathrm{C}$. Replotted from 134 


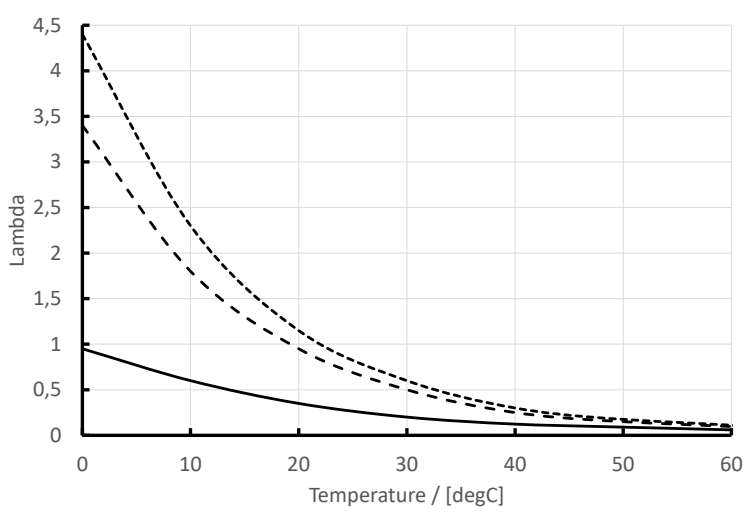

-Isooctane - -Methanol ----Ethanol

Figure 22: Effect of temperature on vapour-phase lambda for methanol, ethanol and isooctane 

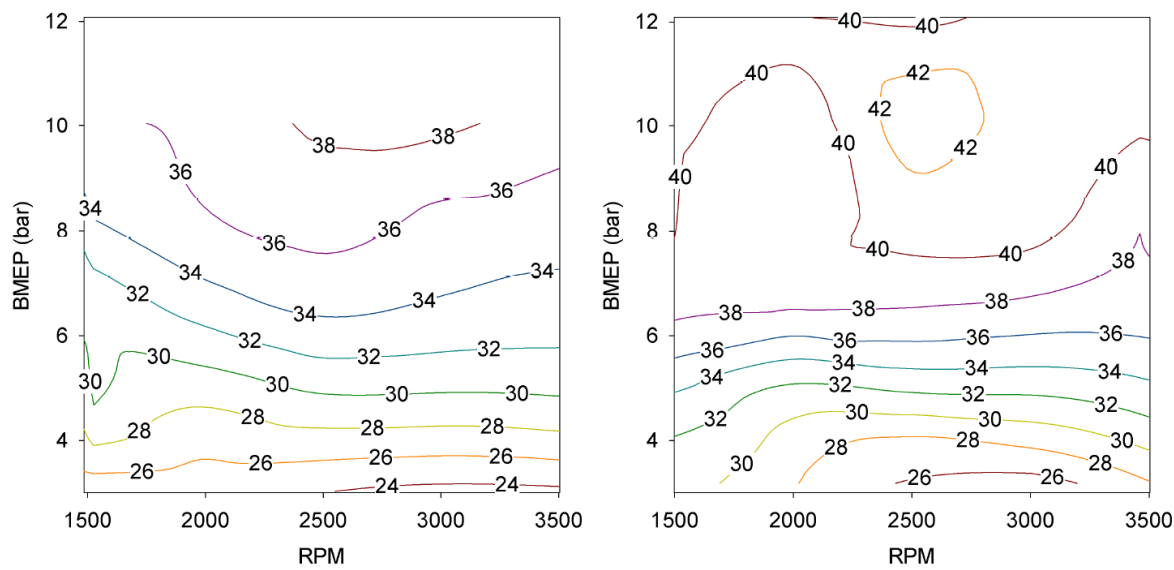

Figure 23: Brake thermal efficiency of a 19.5:1 compression ratio engine operated on pure methanol, as a function of load (BMEP) and engine speed. Left - throttled, stoichiometric operation. Right - WOT EGR operation. 


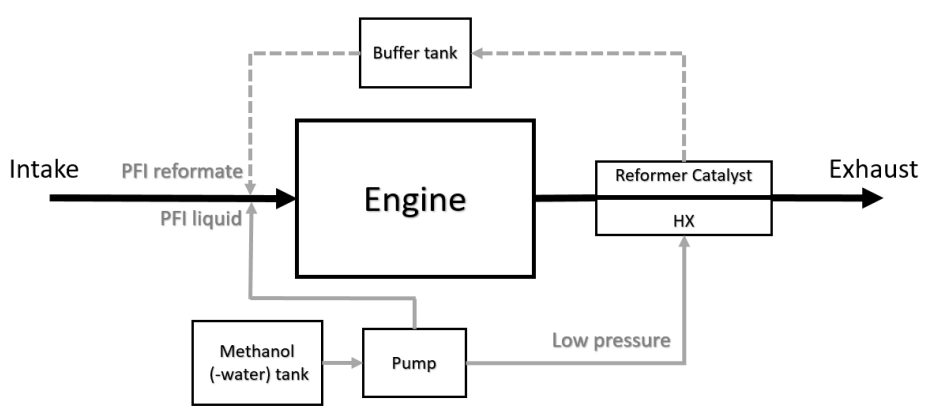

(a) Reforming concept of Kowalewicz 237]

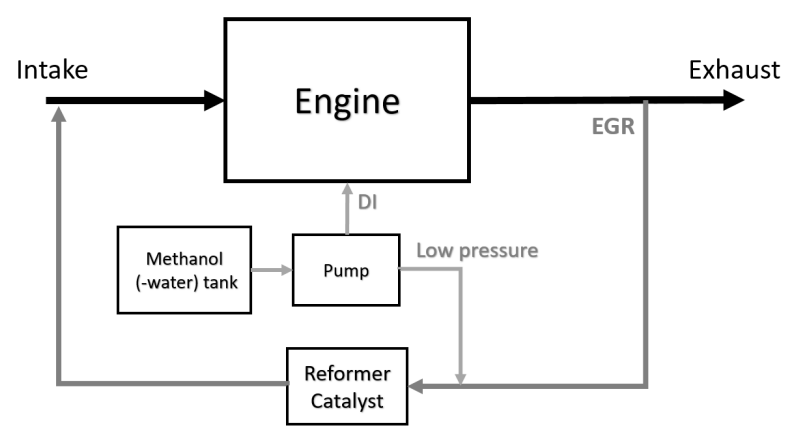

(b) Reforming concept of Turner 241]

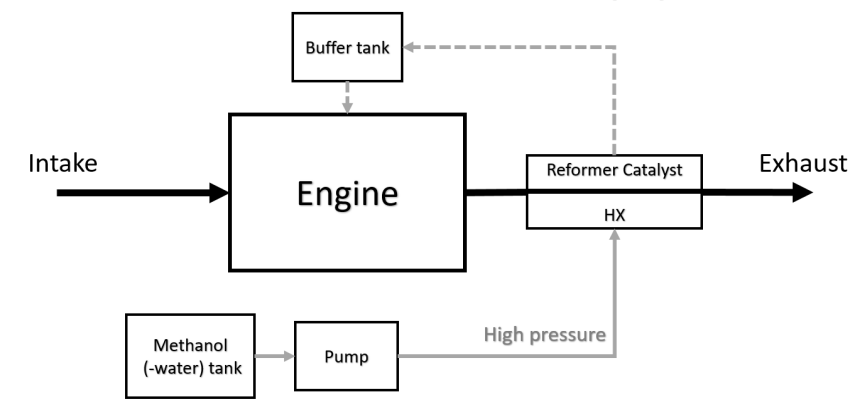

(c) Reforming concept of Poran and Tartakovsky 232

Figure 24: Reforming concepts 


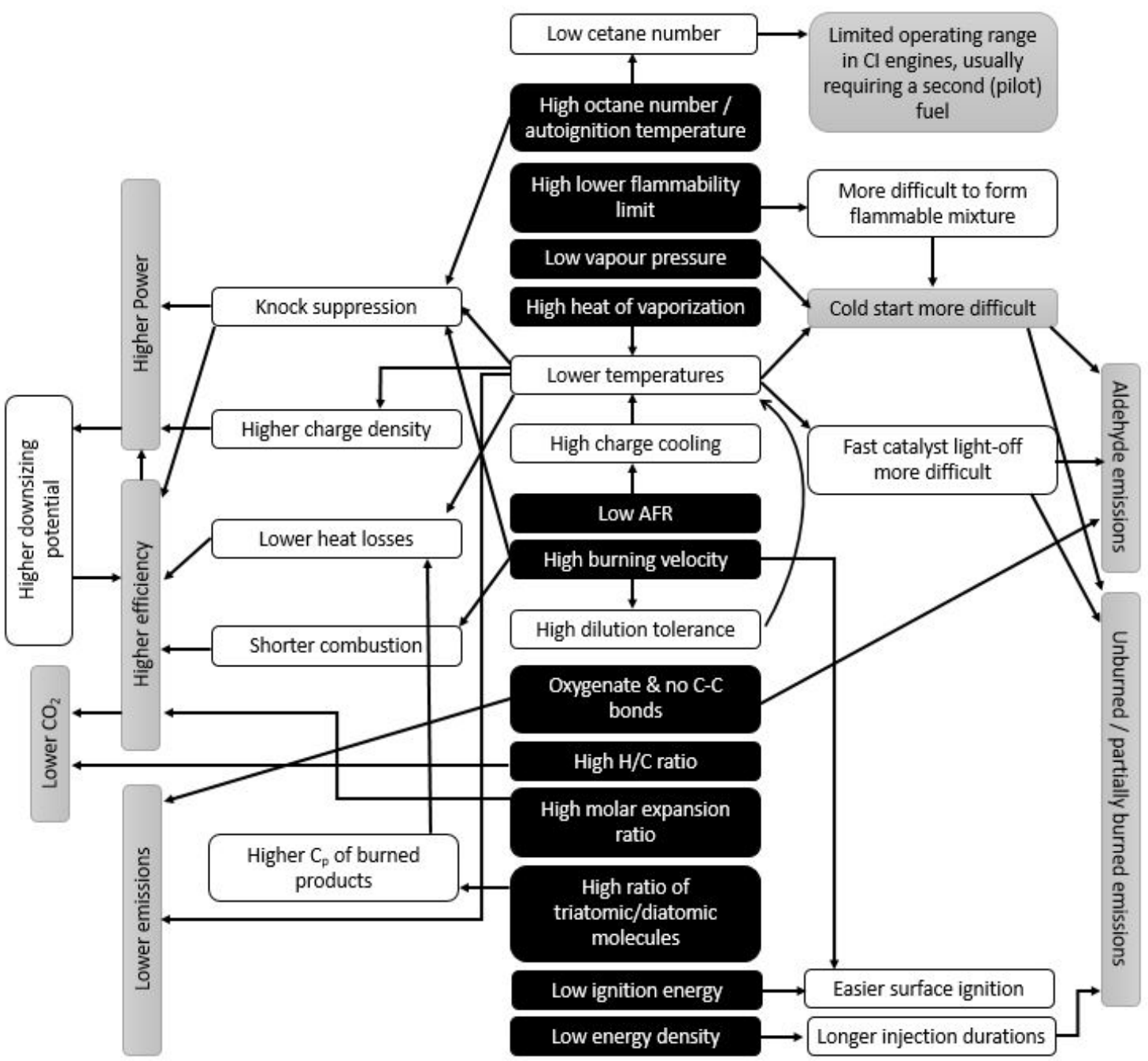

Figure 25: Effect of methanol properties on engine performance 